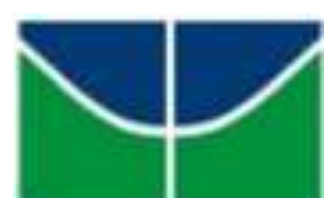

UNIVERSIDADE DE BRASÍLIA

FACULDADE DE TECNOLOGIA

DEPARTAMENTO DE ENGENHARIA FLORESTAL

\title{
VALORAÇÃO ECONÔMICA DO PARQUE NACIONAL DE BRASÍLIA
}

JUAN PABLO MUÑOZ MUÑOZ

BRASÍLIA/DF, JULHO 2015 
JUAN PABLO MUÑOZ MUÑOZ

\section{VALORAÇÃO ECONÔMICA DO PARQUE NACIONAL DE BRASÍLIA}

ORIENTADOR. Prof. Dr. HUMBERTO ANGELO

PUBLICAÇÃO PPGEFL.DM-260/2015

BRASÍLIA/DF, JULHO 2015 
FACULDADE DE TECNOLOGIA.

DEPARTAMENTO DE ENGENHARIA FLORESTAL.

VALORAÇÃO ECONÔMICA DO PARQUE NACIONAL DE BRASÍLIA.

JUAN PABLO MUÑOZ MUÑOZ.

Dissertação submetida ao Programa de Pós-Graduação em Ciências Florestais, do Departamento de Engenharia Florestal da Faculdade de Tecnologia da Universidade de Brasília, como parte dos requisitos necessários para a obtenção do grau de Mestre na área de concentração em manejo florestal.

APROVADA POR:

Prof. Dr. Humberto Angelo (Departamento de Engenharia Florestal/UnB)

(Orientador)

(Examinador interno)

(Examinador interno)

(Suplente)

Brasília/DF, JULHO DE 2015. 


\section{FICHA CATALOGRÁFICA}

\begin{tabular}{|llll|}
\hline \multirow{4}{*}{ M967v } & & \\
& MUÑOZ, JUAN PABLO & & \\
& VALORAÇÃO ECONÔMICA DO PARQUE NACIONAL DE \\
& BRASÍLIA \\
& / Juan Pablo Muñoz; orientador Humberto Angelo. -- \\
& Brasília, 2015. \\
& 81 p. \\
& Dissertação (Mestrado - Mestrado em Ciências \\
& Florestais) -- Universidade de Brasília, 2015. \\
& 1. valoração ambiental. 2. disposição a pagar. 3. \\
& gestão ambiental. I. Angelo, Humberto, orient. II. \\
& Título. \\
\hline
\end{tabular}

\section{REFERÊNCIA BIBLIOGRÁFICA}

MUNOZ, J.P (2015). Valoração econômica do Parque Nacional de Brasília. Distrito Federal, 2015. Tese de Mestrado em Ciências Florestais, Publicação PPGEFL.DM260/2015. Departamento de Engenharia Florestal, Universidade de Brasília, Brasília, DF.

\section{CESSÃO DE DIREITOS}

Autor: JUAN PABLO MUÑOZ MUÑOZ.

Titulo: VALORAÇÃO ECONÔMICA DO PARQUE NACIONAL DE BRASÍLIA.

Grau: Mestre.

Ano: 2015.

É concedida à Universidade de Brasília permissão para reproduzir cópias desta dissertação de mestrado e para emprestar ou vender tais cópias somente para propósitos acadêmicos e científicos. O autor reserva outros direitos de publicação e nenhuma parte desta dissertação de mestrado pode ser reproduzida sem a autorização por escrito do autor. 


\section{AGRADECIMENTOS}

A todos que fizeram parte deste sonho. A toda a minha família, à Coordenação de Aperfeiçoamento de Pessoal de Nível Superior (CAPES), pelo fornecimento da bolsa de mestrado, ao Programa de Pós-Graduação em Ciências Florestais da Universidade de Brasília - pelo apoio-, ao meu Orientador e a todos os professores do programa, pela amizade, ensinamentos, incentivo e convivência, à Secretaria de Pós-Graduação do Departamento de Engenharia Florestal da UnB, pelo apoio e paciência e à todas as pessoas que, diretamente ou indiretamente, contribuíram e conviveram comigo em minhas aventuras, angústias e indagações nessa fase. 


\section{RESUMO}

Objetivou-se estimar o valor econômico do Parque Nacional de Brasília (PNB), no Distrito Federal - Brasil, analisar a disposição da população em pagar pela manutenção e conservação do PNB, baseando-se em variáveis de segmentação socioeconômicas e conhecimento ecológico dos entrevistados. Para tanto, foram aplicados 385 questionários no período de fevereiro a abril de 2014. Foi analisado o perfil dos entrevistados dispostos a pagar com uma regressão logística para determinar quais das variáveis da segmentação influenciariam de maneira significativa na decisão entre estar disposto a pagar ou não pelo plano proposto para o PNB. Como resultado estimou-se uma disposição a pagar de $\mathrm{R} \$ 9,31$ por mês, o que demonstra de maneira geral, a população de interesse, revelou uma contribuição significativa ao parque visando o bem estar humano e também o reconhecendo como um patrimônio natural importante, demandando a preservação desse ativo ambiental, mesmo sendo necessário aplicar recursos financeiros próprios, o qual permite gerar subsídios para a avaliação, elaboração, melhora na execução de políticas públicas ambientais, programas de responsabilidade socioambiental em prol da melhoria do PNB.

Palavras-chaves: valoração ambiental, disposição a pagar, gestão ambiental. 


\begin{abstract}
The aim of this study was to estimate the economic value of the Brasilia's National Park, on Federal District - Brazil, and analyze the willingness to pay of the population based on socioeconomic segmentation variables, and ecological knowledge those interviewed, for the maintenance and conservation of the park. Therefore, were applied 385 questionnaires during February, March and April of 2014, with questions divided into two parts: the first, to get respondent's information about the defined segmentation characteristics; the second composed of the willingness to pay for maintenance plan and maintenance of the park. Was analyzed the profile of respondents willing to pay with a logistic regression to determine which variables segmentation influenced significantly in the decision between being willing to pay or not for the proposed plan to the Park. As a result was estimated the willingness to pay $\mathrm{R} \$ 9,31$ / month, which shows in general, the population of interest, revealed a significant contribution of the park to the human well-being and recognizes it as an important natural heritage. Most people demand the preservation of environmental asset, even if it was necessary to apply their own financial resources, which allows you to generate subsidies for the evaluation, development, improvement and implementation of environmental policies, environmental responsibility programs for the improvement of BNP.
\end{abstract}

Keywords: environmental valuation, Willingness to Pay, discount rate, environmental management. 


\section{SUMÁRIO}

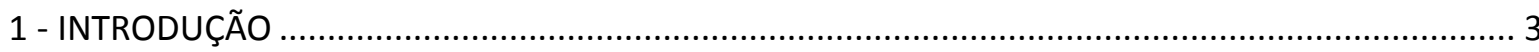

1.2 OBJETIVOS

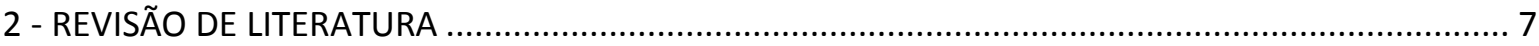

2.1 As Unidades de Conservação ............................................................................................ 7

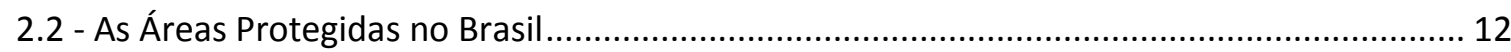

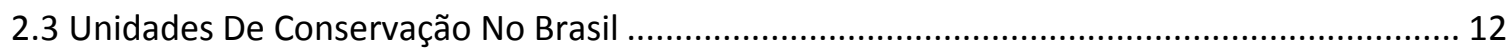

2.3.1 Número de Unidades de Conservação no Brasil ............................................................ 13

2.4 A Gestão Do Sistema Nacional De Unidades De Conservação (SNUC) ………........................ 15

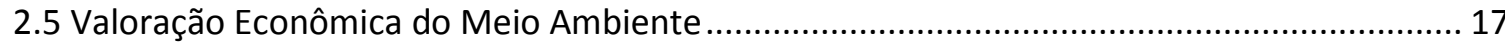

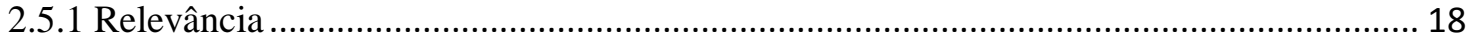

2.6 Conceito de Valor Econômico do Meio Ambiente e Seus Componentes ................................ 20

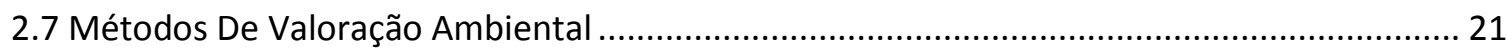

2.7.1. Métodos da Função da Demanda ............................................................................. 23

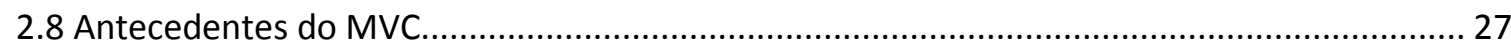

2.8.1 Os Vieses Do Método De Valoração Contingente E O Painel Noaa Blue Ribbon .......... 29

2.8.2 Medidas de bem-estar para variações de bens ambientais ............................................. 32

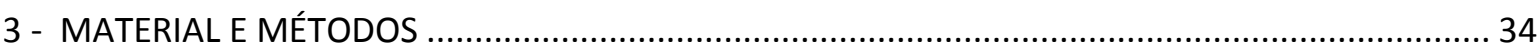

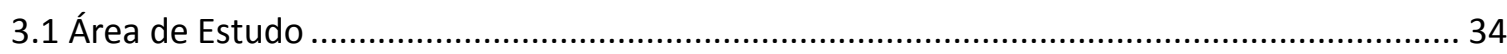

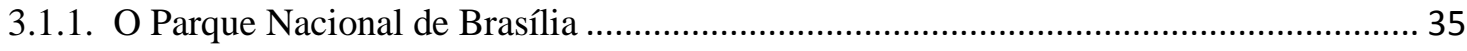

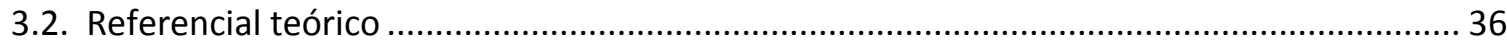

3.2.1 Modelo de referendum - abordagem de Hanemann......................................................... 36

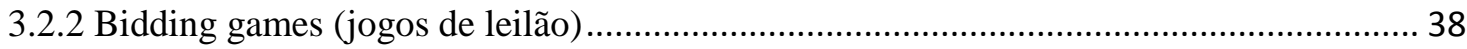

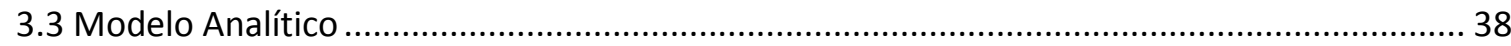

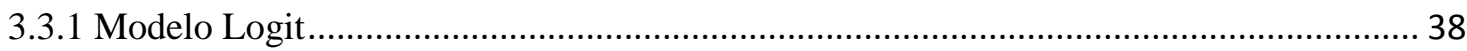

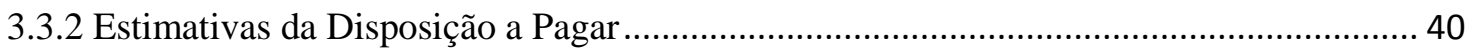

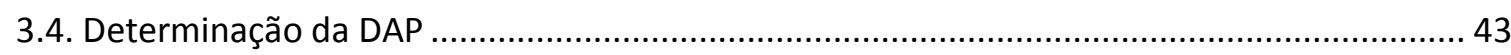

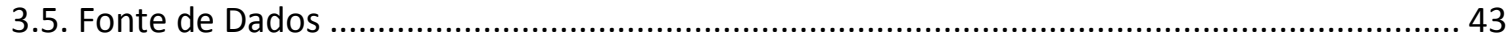

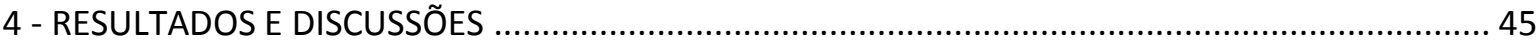

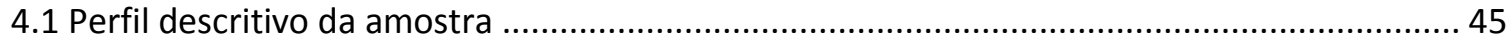

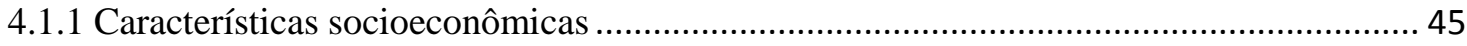

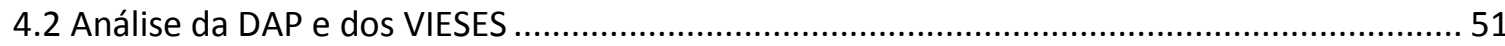




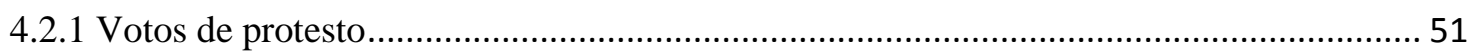

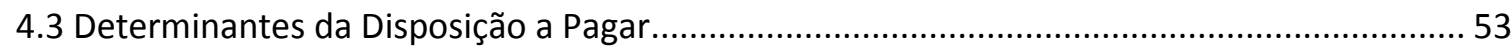

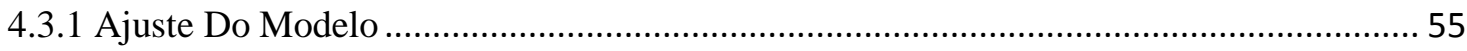

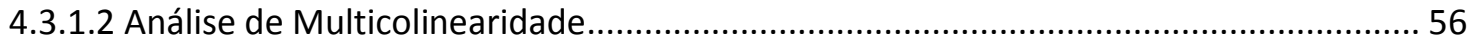

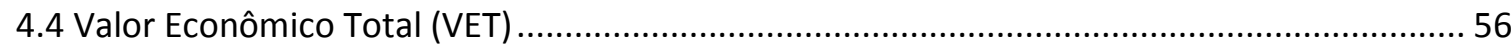

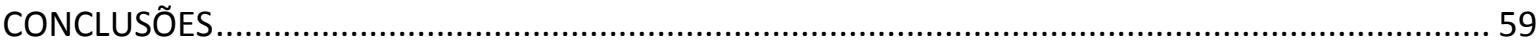

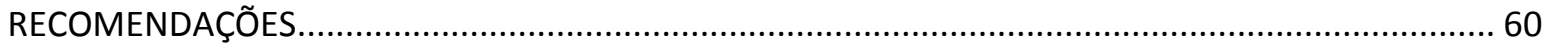

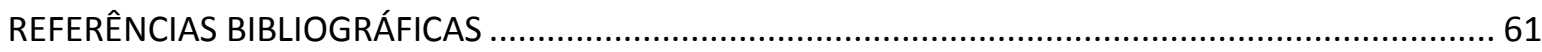

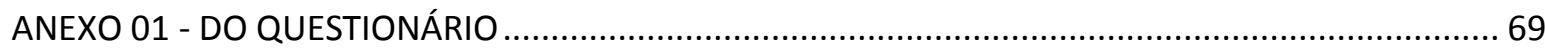

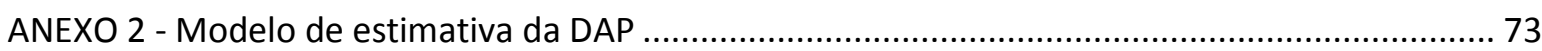

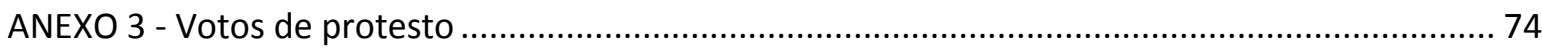

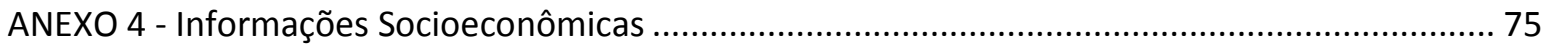

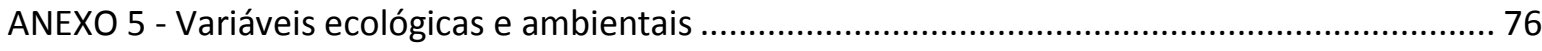

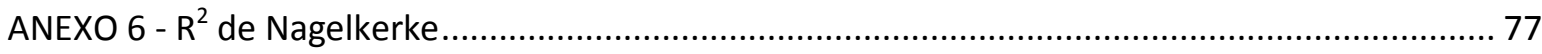

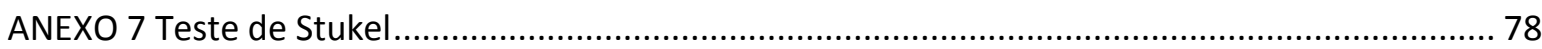

ANEXO 8 - Teste de Hosmer- Lemeshow C e H. Teste le Cessie-van Houwelingen.......................... 79

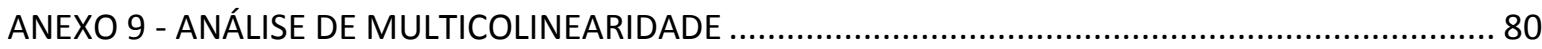




\section{LISTA DE QUADROS E TABELAS}

Quadro 2.1 Categorias de manejo do sistema de áreas protegidas defendida pela IUCN, 2015

Quadro 2.2 Velho e novo paradigma para a gestão de áreas protegidas

Quadro 2.3 Grupos de UCs com base nas características de uso

Quadro 2.4 Número de unidades e a área total $\left(\mathrm{Km}^{2}\right)$ representando cada categoria de manejo proposta pelo SNUC

Quadro 2.5: Unidades de Conservação no Bioma Cerrado

Quadro 2.6: Estudos de valoração econômica ambiental utilizando o MVC.

Quadro 2.7: Valores econômicos indicados para a determinação do VET

Quadro 2.8: Métodos de valoração e tipos de valores - ABNT

Quadro 3.1 Valores de referências leiloados para obter a DAP máxima

Quadro 4.1 Estimativa da amostra

Quadro 4.2: Distribuição da renda declarada pelas pessoas entrevistadas

Quadro 4.3 Motivos para explicar a não DAP

Quadro 4.4 Valores Econômicos dos Bens e Serviços proporcionados pelo PNB

Tabela 4.1 DAP versus regiões administrativas do Distrito Federal

Tabela 4.2 Níveis de renda dos entrevistados versus DAP manifestada - PNB

Tabela 4.3 Valores das variáveis significativas

Tabela 4.4 Estatísticas do bootstraping na DAP. 


\section{LISTA DE FIGURAS}

Figura 3.1 Localização do Parque Nacional de Brasília no Distrito Federal- Brasil

Figura 4.1 Características socioeconômicas dos entrevistados

Figura 4.2 Distribuição percentual da amostra em relação à idade

Figura 4.3 Escolaridade da população amostrada

Figura 4.4 Comportamento da DAP e nível de renda

Figura 4.5 Comportamento de frequência de visitas ao PNB. 


\section{LISTA DE SÍMBOLOS, NOMENCLATURA E ABREVIAÇÕES}

ABNT Associação Brasileira de Normas Técnicas

APA Áreas De Proteção Ambiental

ARIE Áreas De Relevante Interesse Ecológico

CERCLA Comprehensive Environmental Response Compensation, And Liability Act

CNUC Cadastro Nacional de Unidades de Conservação

DAA-DAR Disposição A Aceitar ou Receber Compensação

DAP Disposição A Pagar

DF Distrito Federal

ESEC Estações Ecológicas

FLONA Florestas Nacionais

IBAMA Instituto Brasileiro do Meio Ambiente e dos Recursos Naturais Renováveis

IUCN International Union for Conservation of Nature

$\mathrm{Km}^{2} \quad$ Quilômetros quadrados

MCV Método de Custos de Viagem

MMA Ministério do Meio Ambiente

MONAT Monumentos Naturais

MPH Método de Preços Hedônicos

MVC Método de Valoração Contingente

NEXUCS Núcleo para a Excelência de Unidades de Conservação Ambiental

NOAA National Oceanic and Atmospheric Administration

ONGs Organizações Não Governamentais

ONU Organização das Nações Unidas

PARNA Parques Nacionais

PI Proteção Integral

PNB Parque Nacional de Brasília

RDS Reservas De Desenvolvimento Sustentável

REBIO Reservas Biológicas

REF Reservas De Fauna 
RESEX Reservas Extrativistas

RPPN Reservas Particulares Do Patrimônio Natural

RVS Refúgios De Vida Silvestre

SNUC Sistema Nacional de Unidades de Conservação

SPSS Statistical Package for the Social Sciences

UC Unidade de Conservação

UNESCO Organização das Nações Unidas para a educação, a ciência e a cultura

US Uso Sustentável

VC Valoração Contingente

VDAP Valor presente da disposição a pagar

VET Valor Econômico Total 


\section{1 - INTRODUÇÃO}

O interesse em proteger determinadas áreas naturais como um benefício comum para a sociedade em geral surgiu em meados do século XIX, quando nasceu, também, o conceito de proteção da natureza a partir da criação de espaços reservados separados da convivência humana, cujo uso seria controlado pelo governo. A criação do Parque Nacional de Yellowstone, em 1872, é o primeiro parque nacional americano, considerado como orgulho e identidade nacional para os americanos, e é uma referência na base conceitual para a criação e gestão de unidades de conservação modernas no mundo inteiro. (NPS, 2015).

A ideia de parque nacional se espalhou rapidamente no mundo. Inspirados na experiência americana, diversos países criaram seus parques nacionais: Canadá- 1885, Nova Zelândia- 1894, Austrália e África do Sul em 1898, México- 1898, Argentina- 1903 e o Brasil- 1937 com a criação do primeiro Parque Nacional de Itatiaia. (NEXUCS ORG, 2012).

No caso de Brasília tem como marco a criação do PNB em 1961, com cerca de 30 mil hectares, que está relacionada com a construção da nova capital do país. Pela lei ordinária número 11285 de 2006, altera os limites redefinindo sua poligonal, acrescentando sua área para 42.389.01 hectares à área núcleo da Reserva da Biosfera do Cerrado.

O PNB surgiu como necessidade de proteger ecossistemas naturais de grande relevância ecológica e beleza cênica a flora típica do cerrado do Planalto Central, a fauna típica da região, as nascentes de águas cristalinas que fornecem água potável para a capital federal, para contribuir com o equilíbrio das condições climáticas e evitar a erosão do solo, possibilitar a realização de pesquisas científicas e o desenvolvimento de atividades de educação e interpretação ambiental, de recreação em contato com a natureza e de turismo ecológico.

O PNB é um espaço territorial delimitado, cercado, um bem público de acesso restrito às áreas preservadas de acesso proibido ao público, mas conta com a área de recreação e lazer "Parque Água Mineral", que possuí museu, biblioteca, área de piscinas e duas trilhas.

Pela sua proximidade com a metrópole de Brasília, o parque tem uma dinâmica peri-urbana o que gera conflitos e um grande impacto no entorno do Parque. 
O Parque carrega em sua história uma ocupação irregular [Chácara Santa Luzia], um aterro de lixo como vizinho, uma vez que o Parque faz divisa com o lixão a céu aberto da Cidade Estrutural, proliferação de espécies exóticas de plantas e animais, incêndios e um acelerado e desordenado crescimento urbano ao redor do Parque.

Apesar da importância dos recursos naturais, o seu uso inadequado e excessivo, gestão deficiente, falta de valoração econômica da biodiversidade e dos serviços ambientais, são causas determinantes na degradação e no impacto ao ecossistema, algumas vezes irreversíveis, reduzindo ou enfraquecendo sua capacidade e seu potencial de prestar serviços e de proporcionar bem-estar, com consequências negativas para as futuras gerações. (MALTA et al 2012).

A valoração dos ecossistemas é essencial para mostrar sua importância econômica, social e obter o compromisso da sociedade e dos políticos frente à biodiversidade. Valorar economicamente o ambiente envolve a tentativa de atribuir valores quantitativos para os bens e serviços fornecidos por recursos naturais, independentemente da existência de preços de mercado para os mesmos.

A valoração pode ajudar a orientar políticas públicas tais como: tributação; alocação de subsídios; decisão de gastar com a conservação de recursos ou com a mitigação de impactos ambientais; exige uma valoração adequada de custos e benefícios ambientais a alcançar.

Nesse sentido, a importância do trabalho é gerar informações sobre o potencial que os usuários têm de gerar recursos que permitem criar subsídios para a avaliação, elaboração, melhora e execução de políticas públicas ambientais, programas de responsabilidade socioambiental e o reconhecimento do parque como um patrimônio natural importante que contribuí significativamente para o bem estar humano, demandando assim sua preservação.

Como PNB é um bem público, mais precisamente um ativo ambiental, a disposição a pagar pela conservação e manutenção desse ativo não indica somente um valor que reflete as preferências dos indivíduos. Logo, torna-se importante verificar se o indivíduo possui a percepção de que a preservação e a conservação de bens ambientais possam se manifestar em variações no seu bem-estar.

De acordo com Gomes da Silva (2003) a relevância da valoração ambiental reside 
no fato de que essa é essencial para criar um valor de referência que indique uma sinalização de mercado dos recursos ambientais. Com isso, os agentes públicos e privados terão subsídios para avaliação econômica de tomadas de decisões políticas sobre a utilização eficiente desses ativos. A criação de um valor de referência para um bem ambiental fornece informações ao poder público, à sociedade civil organizada e às organizações não-governamentais (ONGs), o que resulta em um gerenciamento mais eficaz desses recursos.

A avaliação contingente para determinar a percepção ambiental da sociedade e a disposição a pagar pela conservação e manutenção de um bem ou serviço ambiental, tem sido empregada em vários estudos. No Brasil, pode-se citar o trabalho de Schmidt et al. (2014), que propôs a disposição a pagar média espontânea de $\mathrm{R} \$ \mathrm{R} \$ 15,12$ por mês dos usuários do Parque do Ingá em Maringá- Pr; Bentes et al. (2014) estimou a disposição a pagar pelo rio Tocantins para os pescadores artesanais da Jusante da UHE de Tucuruí encontrando um o valor médio da DAP de $\mathrm{R} \$ 31,58$; Araujo et al. (2014) ponderou os benefícios dos serviços ambientais da gruta do Salitre, Diamantina, Minas Gerais- Brasil, estabelecendo uma DAP média dos visitantes da gruta resultou em $\mathrm{R} \$ 6,48$ e dos moradores do entorno R \$7,78; Barros (2013) estimou o valor econômico do Parque Estadual Dunas de Natal em Natal-RN, contabilizou uma DAP para a manutenção do Parque de R\$8,47; Almeida et al (2014) aferiu a Disposição a Pagar aos frequentadores do parque Olhos D’água - DF, o valor médio encontrado dos dispostos a pagar foi de $\mathrm{R} \$ 15,80$ por mês.

A inovação deste trabalho é a identificação dos determinantes da disposição a pagar pelo PNB, o que significa uma ferramenta a mais para os tomadores de decisões para a manutenção e conservação do Parque.

\subsection{OBJETIVOS}

O presente estudo trata de estimar o valor econômico do Parque Nacional Brasília no Distrito Federal - Brasil.

Em especial, propõem-se:

1 - verificar se há ou não disposição a pagar pelos serviços ambientais do PNB;

2- quantificar a percepção de valor do Parque Nacional Brasília (PNB) pela população do Distrito Federal; 
3- identificar os determinantes sociais, econômicos e ambientais que afetam a DAP; e 4 - gerar subsídios para valoração do PNB. 


\section{2 - REVISÃO DE LITERATURA}

\subsection{As Unidades de Conservação}

O interesse em proteger determinadas áreas naturais como benefício comum para a sociedade em geral surgiu em meados do século XIX, quando nasceu, também, o conceito de proteção da natureza a partir da criação de espaços reservados separados da convivência humana, cujo uso seria controlado pelo governo. A criação do Parque Nacional de Yellowstone, em 1872, é o primeiro parque nacional americano e é considerado como orgulho e identidade nacional para os americanos e é referência na base conceitual para a criação e gestão de unidades de conservação modernas no mundo inteiro. (NPS, 2015)

A ideia de parque nacional se espalhou rapidamente para o mundo. Inspirados na experiência americana diversos países criaram seus parques nacionais: Canada- 1885, Nova Zelândia- 1894, Austrália e África do Sul em 1898, México- 1898, Argentina- 1903 e o Brasil em 1937 com a criação do primeiro Parque Nacional de Itatiaia. (NEXUCS ORG, 2012)

As unidades de conservação (UC's) são áreas de terra ou mar instituídas pelo Poder Público, especialmente dedicadas à proteção e manutenção da biodiversidade e dos recursos naturais (fauna, flora, microrganismos, corpos d'água, solo, clima, paisagens, e todos os processos ecológicos pertinentes aos ecossistemas naturais) e culturais associados. (IUCN, 2012)

Alguns dos benefícios que proporcionam as UC's são: o principal é a conservação da biodiversidade, habitats de espécies, processos ecológicos essenciais, manter a capacidade produtiva dos ecossistemas, sequestro de carbono, salvaguardar habitats para a sobrevivência das espécies, fornecer bens e serviços ambientais, polinização, mitigação mudança climática, mitigação de desastres, turismo e recreação, proporcionar fontes de emprego para as comunidades locais, preservar as características históricas, culturais e espirituais, inspiração humana, orgulho nacional, pesquisa científica, educação, turismo e lazer. (CEPAL, 2014; TEEB, 2010).

Paralelamente ao nascimento do conceito de áreas protegidas, começou a tornar-se prática comum a realização de encontros internacionais para discutir e trocar informações 
entre cientistas, o que favoreceu um movimento internacional para a criação de unidades de conservação.

Nas primeiras décadas do século XX, a terminologia para descrever as UC's era confusa e na Convenção para a proteção da flora/fauna e das belezas cênicas dos países da América, em Washington em 1940, padronizou-se, sendo definidas quatro categorias: Parque Nacional, Reserva Nacional, Monumento Natural e Reserva restrita de regiões virgens.

Na Convenção em Washington- 1940, o Brasil aderiu e ratificou em 1948, quando foi criada a União Internacional para a conservação da natureza e dos recursos naturais, em 1956, logo depois mudou o nome para União Internacional para a Conservação da Natureza e recursos naturais e é agora a união mundial para a Natureza (IUCN), reúne Estados, agências governamentais, e uma gama de ONG's em uma única parceria: cerca de 800 membros de 130 países no total.

No âmbito da IUCN foi criada a Comissão Mundial de Áreas Protegidas - WCPA desde 1996, com a tarefa de promover e monitorar o estabelecimento de uma rede global de reservas terrestres e marinhas.

As áreas protegidas são administradas para muitas finalidades e têm sido chamadas por muitos nomes diferentes. A IUCN desenvolveu um sistema de categorias de gestões de áreas protegidas baseadas nos objetivos de gerenciamentos principais (IUCN, 2015). Todas as categorias são destinadas para caber dentro da definição geral de área protegida. (ver quadro 2.1) 
Quadro 2.1: Categorias de manejo do sistema de áreas protegidas defendida pela IUCN, 2015.

\begin{tabular}{|c|l|l|}
\hline Categoría & \multicolumn{1}{|c|}{ Denominação } & \multicolumn{1}{c|}{ Objetivo } \\
\hline I & $\begin{array}{c}|c| \\
\text { a) Reserva Natural Restrita } \\
\text { b) Área silvestre }\end{array}$ & $\begin{array}{l}\text { a) Reserva Natural Restrita: área } \\
\text { protegida manejada principalmente } \\
\text { para a ciência. } \\
\text { b) Reserva ecológica: área protegida } \\
\text { manejada principalmente para a } \\
\text { proteção da natureza. Fins científicos } \\
\text { ou proteção da natureza. }\end{array}$ \\
\hline II & Parque Nacional & $\begin{array}{l}\text { Area protegida manejada } \\
\text { especialmente para a proteção e } \\
\text { conservação dos ecossistemas e } \\
\text { recreaçáo. }\end{array}$ \\
\hline III & Monumento Natural & $\begin{array}{l}\text { Para conservação de características } \\
\text { naturais específicas. }\end{array}$ \\
\hline IV & Santúario de vida silvestre & $\begin{array}{l}\text { Para conservação de hábitats e/ou para } \\
\text { satisfazer as necessidades de } \\
\text { determinadas espécies. }\end{array}$ \\
\hline V & Paisagem terrestre e marinha Protegida & $\begin{array}{l}\text { Conservação da paisagem terrestre e } \\
\text { marinha com fins de recreação. }\end{array}$ \\
\hline VI & Área protegida com recursos manejado. & $\begin{array}{l}\text { Para o uso sustentável dos recursos } \\
\text { naturais. }\end{array}$ \\
\hline
\end{tabular}

Fonte: IUCN, (2015).

Em 2003, no V Congresso realizado em Durban- África do Sul surgiram tendências que apontam para uma nova direção na forma como gerir as unidades de conservação. Tais tendências são definidas como o velho e o novo paradigma de gestão (ver quadro 2.2) das áreas protegidas. (PHILLIPS, 2003).

O resultado é o surgimento de um novo paradigma para as áreas protegidas, em contraste com quase todos os aspectos com que prevaleceu há 40 anos. Os elementos essenciais do paradigma a partir do início do século XXI são listados a seguir: 
Quadro 2.2: velho e novo paradigma para a gestão de áreas protegidas.

\begin{tabular}{|c|c|c|}
\hline Tema & Como foram as UC's & Como são as UC's atualmente \\
\hline Objetivos & $\begin{array}{l}\text { Designadas para a conservação. } \\
\text { Estabelecida principalmente para a } \\
\text { proteção da vida silvestre e } \\
\text { paisagens espetaculares. } \\
\text { Manejado principalmente para } \\
\text { visitantes e turistas. } \\
\text { Valorado como ambientes silvestres. } \\
\text { Relacionadas com a proteção. }\end{array}$ & $\begin{array}{l}\text { Mantidas também com objetivos sociais } \\
\text { e econômicos. } \\
\text { Estabelecidas muitas vezes por razões } \\
\text { científicas, econômicas e culturais. } \\
\text { Turismo como meio de contribuição } \\
\text { para a economia local. } \\
\text { Valorizadas pela importância cultural } \\
\text { dos ambientes selvagens. } \\
\text { Mantidas também para a restauração e } \\
\text { reabilitação. }\end{array}$ \\
\hline Administração & Administradas pelo governo central & Administradas por muitos parceiros. \\
\hline $\begin{array}{l}\text { População } \\
\text { local }\end{array}$ & $\begin{array}{l}\text { Planejada e manejada contra a } \\
\text { população local. } \\
\text { Manejadas sem levar em conta } \\
\text { opiniões locais. }\end{array}$ & $\begin{array}{l}\text { Manejados com ou para a população } \\
\text { local e, em alguns casos pela mesma } \\
\text { população local. } \\
\text { Manejadas para atender às necessidades } \\
\text { das populações locais. }\end{array}$ \\
\hline $\begin{array}{l}\text { Contexto mais } \\
\text { amplo }\end{array}$ & $\begin{array}{l}\text { Planejadas separadamente. } \\
\text { Manejadas como ilhas. }\end{array}$ & $\begin{array}{l}\text { Planejadas como parte de sistemas } \\
\text { nacionais, regionais ou internacionais. } \\
\text { Desenvolvidas como redes (núcleos } \\
\text { estritamente protegidos, com zonas de } \\
\text { amortecimento e interligados por } \\
\text { corredores verdes). }\end{array}$ \\
\hline Percepções & $\begin{array}{l}\text { Consideradas principalmente como } \\
\text { um patrimônio nacional. } \\
\text { Consideradas somente sob a ótica do } \\
\text { interesse nacional. }\end{array}$ & $\begin{array}{l}\text { Consideradas também como um } \\
\text { patrimônio da comunidade. } \\
\text { Consideradas também como de interesse } \\
\text { internacional. }\end{array}$ \\
\hline $\begin{array}{l}\text { Técnicas de } \\
\text { manejo }\end{array}$ & $\begin{array}{l}\text { Manejadas de forma relativa dentro } \\
\text { de uma escala de tempo limitada. } \\
\text { Manejadas de forma burocrática. }\end{array}$ & $\begin{array}{l}\text { Geridas de forma adaptativa } \\
\text { Geridas com sensibilidade política. }\end{array}$ \\
\hline $\begin{array}{l}\text { Capacidad de } \\
\text { manejo }\end{array}$ & $\begin{array}{l}\text { Geridas por cientistas e especialistas } \\
\text { em recursos naturais. } \\
\text { Dirigida por especialistas. }\end{array}$ & $\begin{array}{l}\text { Geridas por individuos dotados de } \\
\text { múltiplas capacidades. } \\
\text { Geridas levando em consideração os } \\
\text { saberes locais. }\end{array}$ \\
\hline Finanzas & Financiadas pelo tesouro nacional. & Financiadas por múltiplas fontes. \\
\hline
\end{tabular}
Fonte: (PHILLIPS, 2003).

Essas novas tendências podem ser identificadas no Brasil a partir da criação da principal Lei $\mathrm{n}^{\circ}$ 9.985/2000, que estabelece o Sistema Nacional de Unidades de Conservação (SNUC), cujos objetivos nacionais de conservação estabelecidos no art. 4 da Lei são os seguintes:

I. Contribuir para a manutenção da diversidade biológica e dos recursos genéticos no território nacional e nas águas jurisdicionais;

II. Proteger as espécies ameaçadas de extinção no âmbito regional e nacional; 
III. Contribuir para a preservação e a restauração da diversidade de ecossistemas naturais;

IV. Promover o desenvolvimento sustentável a partir dos recursos naturais;

V. Promover a utilização dos princípios e práticas de conservação da natureza no processo de desenvolvimento;

VI. Proteger paisagens naturais e pouco alteradas de notável beleza cênica;

VII. Proteger as características relevantes de natureza geológica, geomorfológica, espeleológica, arqueológica, paleontológica e cultural;

VIII. Proteger e recuperar recursos hídricos e edáficos;

IX. Recuperar ou restaurar ecossistemas degradados;

X. Proporcionar meios e incentivos para atividades de pesquisa científica, estudos e monitoramento ambiental;

XI. Valorizar econômica e socialmente a diversidade biológica;

XII. Favorecer condições e promover a educação e interpretação ambiental, a recreação em contato com a natureza e o turismo ecológico;

XIII. Proteger os recursos naturais necessários à subsistência de populações tradicionais, respeitando e valorizando seu conhecimento e sua cultura, e promovendo-as socialmente e economicamente.

Destaca-se o inciso XI que privilegia a valoração econômica e social da biodiversidade biológica, com o qual se cobra pelas externalidades negativas e positivas o real e justo valor.

Nesta Lei 9985/2000 no artigo 33, define-se mecanismos de Pagamentos por Serviços Ecossistêmicos (PSE) como política associada à conservação. Ao propor o PSE, internaliza-se um benefício ambiental que estaria fora do mercado (externalidade positiva), reconhecendo valor à biodiversidade e aos serviços.

Para as externalidades negativas a base legal brasileira não dispõe de critérios definidos para o uso dos resultados da valoração econômica. A fixação do valor do dano, apesar de já regulamentada, é proposta em termos de um intervalo entre um valor mínimo e um máximo. No entanto, o fato da Lei de Crimes Ambientais- Lei n. 9.605/1998-, não apresentar explicitamente um parâmetro de cálculo do dano, deixa margem para a subjetividade dos tomadores de decisões. (ARAUJO, 2011). 
Os processos que tramitam na esfera judicial envolvendo danos ambientais, necessitam de informações com base na valoração econômica para poder estimar um valor de reparação que corresponda ao custo social da variação causada.

\section{2 - As Áreas Protegidas no Brasil}

No Plano Estratégico Nacional de Áreas protegidas (PNAP) Decreto 5.758/2006, o país estabeleceu distinção entre Unidades de Conservação e outras áreas protegidas com quatro mecanismos institucionais básicos para a proteção:

a) Unidades de Conservação (UC): espaços territoriais especialmente reservados para a proteção dos recursos naturais, por iniciativa pública ou privada, incluindo proteção parcial de seu entorno, ou zona de amortecimento e corredores ecológicos;

b) Área de Preservação Permanente (APP): protege áreas naturalmente frágeis como nascentes, rios, alagados, etc.;

c) Reserva Legal (RL): corresponde a um percentual da propriedade que precisa ser mantida com a cobertura natural original.

d) Territórios Indígenas (TI): e quilombolas: destinados a proteger áreas tradicionalmente ocupadas por indígenas e quilombolas e ainda integram as áreas protegidas os jardins botânicos, os zoológicos, os hortos florestais, e qualquer outro espaço ambiental instituído pelo Poder Público (FENKER, 2013).

Devido a área a ser valorada pertencer às Unidades de Conservação (UC’s), será destacado neste trabalho esse mecanismo de proteção de áreas.

\subsection{Unidades De Conservação No Brasil}

Com base nas características da UC o SNUC criou dois grupos de unidades de proteção diferentes: unidades de proteção integral- precisam de maiores restrições pela sua fragilidade e particularidades onde o objetivo é preservar a natureza, admite-se apena o uso indireto e as unidades de uso sustentável- apresentam menos restrições e podem ser utilizadas de forma sustentável e conservadas ao mesmo tempo. Vide a descrição de cada tipo de unidade de conservação para cada grupo no Sistema Nacional de Unidades de Conservação (Lei nº 9.985/00, art. 9 ao 21), (Ver quadro 2.3):

Quadro 2.3: grupos de UC's com base nas características de uso. 


\begin{tabular}{|c|c|}
\hline $\begin{array}{c}\text { Unidades de Conservação de } \\
\text { Proteção Integral. } \\
\end{array}$ & Unidades de Conservação de Uso Sustentável. \\
\hline 1. Estações Ecológicas (ESEC) & 1. Áreas De Proteção Ambiental (APA). \\
\hline 2. Reservas Biológicas (REBIO) & $\begin{array}{l}\text { 2. Áreas De Relevante Interesse Ecológico } \\
\text { (ARIE). }\end{array}$ \\
\hline 3. Parques Nacionais (PARNA) & 3. Florestas Nacionais (FLONA). \\
\hline $\begin{array}{l}\text { 4. Monumentos Naturais } \\
\text { (MONAT) }\end{array}$ & 4. Reservas Extrativistas (RESEX). \\
\hline \multirow[t]{3}{*}{$\begin{array}{l}\text { 5. Refúgios De Vida Silvestre } \\
\text { (RVS) }\end{array}$} & 5. Reservas De Fauna (REF). \\
\hline & $\begin{array}{l}\text { 6. Reservas De Desenvolvimento Sustentável } \\
\text { (RDS). }\end{array}$ \\
\hline & $\begin{array}{l}\text { 7. Reservas Particulares Do Patrimônio Natural } \\
\text { (RPPN). }\end{array}$ \\
\hline
\end{tabular}

Os bens e serviços em geral proporcionados pelas UC's (os que variam de acordo com seus objetivos e categoria de manejo como foi explicado anteriormente) são os recursos naturais preservados sustentavelmente, a recreação, as pesquisas científicas, a manutenção de recursos ecossistêmicos como regulação do clima, proteção de recursos hídricos, ciclagem de nutrientes, polinização e controle de pragas, entre muitos outros. (NEXUCS 2012).

\subsubsection{Número de Unidades de Conservação no Brasil}

Segundo o relatório de Unidades de Conservação (2014), encontram-se cadastradas no Ministério do Meio Ambiente cerca de 1.828 áreas distribuídas nas categorias de manejo (ver quadro 2.4) destinadas à preservação e conservação da natureza. 
Quadro 2.4: Número de unidades e a área total $\left(\mathrm{Km}^{2}\right)$ representando cada categoria de manejo proposta pelo SNUC.

\begin{tabular}{|c|c|c|}
\hline Tipo / Categoría de manejo & \multicolumn{2}{|c|}{ TOTAL } \\
\hline Proteção Integral & $N^{\circ}$ de UC's. & Área total $\left(\mathrm{Km}^{2}\right)$ \\
\hline Estação Ecológica & 90 & 115.557 \\
\hline Monumento Natural & 38 & 1.390 \\
\hline Parque Nacional / Estadual / Municipal & 350 & 347.126 \\
\hline Refúgio de Vida Silvestre & 30 & 3.735 \\
\hline Reserva Biológica & 60 & 52.823 \\
\hline Total Proteção Integral & 568 & 520.632 \\
\hline Uso Sustentável & $N^{\circ}$ de UC's. & Área total $\left(\mathrm{Km}^{2}\right)$ \\
\hline Floresta Nacional / Estadual / Municipal & 104 & 300.007 \\
\hline Reserva Extrativista & 87 & 143.443 \\
\hline $\begin{array}{l}\text { Reserva de Desenvolvimento } \\
\text { Sustentável }\end{array}$ & 34 & 110.892 \\
\hline Reserva de Fauna & 0 & 0 \\
\hline Área de Proteção Ambiental & 278 & 442.771 \\
\hline Área de Relevante Interesse Ecológico & 48 & 925 \\
\hline RPPN & 709 & 5.411 \\
\hline Total Uso Sustentável & 1260 & 1.003 .448 \\
\hline $\begin{array}{l}\text { TOTAL GERAL ( Proteção } \\
\text { Integral + Uso Sustentável) }\end{array}$ & 1828 & 1.524.080 \\
\hline
\end{tabular}

Fonte: CNUC/MMA - (www.mma.gov.br/cadastro_uc) Atualizada em: 11/02/2014

Poucas são as unidades de conservação com áreas bem significativas. O Bioma Cerrado apresenta 8,4 \% do seu território, legalmente protegido (ver quadro 2.5) por unidades de conservação. Pode-se mencionar o Parque Nacional das Emas, o Parque Nacional Grande Sertão Veredas, o Parque Nacional da Chapada dos Guimarães, o Parque Nacional da Serra da Canastra, o Parque Nacional da Chapada dos Veadeiros, o Parque Nacional das Nascentes do Rio Parnaíba e o Parque Nacional de Brasília. (CNUC/MMA, 2014). 
Quadro 2.5: Unidades de Conservação no Bioma Cerrado.

\begin{tabular}{|c|c|c|c|}
\hline Área total do bioma $\mathrm{Km}^{2}$ & \multicolumn{3}{|l|}{2.036 .448} \\
\hline Tipo / Categoria & \multicolumn{3}{|c|}{ CERRADO } \\
\hline Proteção Integral (PI) & $\mathbf{N}^{\circ}$ & Área $\left(\mathrm{Km}^{2}\right)$ & $\%$ \\
\hline Estação Ecológica & 28 & 11.370 & $0,6 \%$ \\
\hline Monumento Natural & 11 & 313 & $0,0 \%$ \\
\hline Parque & 66 & 48.409 & $2,4 \%$ \\
\hline Refúgio de Vida Silvestre & 4 & 2.488 & $0,1 \%$ \\
\hline Reserva Biológica & 6 & 156 & $0,0 \%$ \\
\hline TOTAL PI & 115 & 62.736 & \\
\hline Uso Sustentável (US) & $\mathbf{N}^{\circ}$ & Área $\left(K^{2}{ }^{2}\right)$ & $\%$ \\
\hline Floresta Nacional & 11 & 562 & 0,0 \\
\hline Reserva Extrativista & 6 & 883 & 0,0 \\
\hline $\begin{array}{l}\text { Reserva de Desenvolvimento } \\
\text { Sustentável }\end{array}$ & 1 & 588 & 0,0 \\
\hline Reserva de Fauna & 0 & 0 & 0,0 \\
\hline Área de Proteção Ambiental & 65 & 108.622 & 5,3 \\
\hline Área de Relevante Interesse Ecológico & 16 & 80 & 0,0 \\
\hline RPPN & 148 & 976 & 0,0 \\
\hline TOTAL US & 247 & 111.710 & \\
\hline TOTAL PI e US & 362 & 174.446 & $8,4 \%$ \\
\hline
\end{tabular}

Fonte: CNUC/MMA - (www.mma.gov.br/cadastro_uc) Atualizada em: 11/02/2014

\subsection{A Gestão Do Sistema Nacional De Unidades De Conservação (SNUC)}

O SNUC é gerido pelos seguintes órgãos, com as respectivas atribuições (art.6):

Órgão consultivo e deliberativo: representado pelo Conselho Nacional do Meio Ambiente (CONAMA), tem a função de acompanhar a implementação do SNUC;

Órgão central: representado pelo Ministério do Meio Ambiente, tem a finalidade de coordenar o SNUC;

Órgãos executores: representados na esfera federal, pelo Instituto Chico Mendes de Conservação da Biodiversidade (ICMBio) criado em 2007, pela Lei 11.516; e IBAMA, em caráter supletivo, e nas esferas estadual e municipal, pelos órgãos estaduais e municipais de meio ambiente. Os órgãos executores do SNUC têm a função de programar, subsidiar as propostas de criação e administrar as unidades de conservação federais, estaduais e municipais, mas nas respectivas esferas de atuação.

Segundo o Instituto Chico Mendes de Conservação da Biodiversidade (ICMBio), a criação de Unidades de Conservação encontra respaldo em diversos instrumentos legais para a conservação da biodiversidade no Brasil como: 
- Constituição Federal (1988) - Art. 225

- Conferência das Nações Unidas para o Meio Ambiente e o Desenvolvimento (RIO 92)

- Convenção sobre Diversidade Biológica (CDB)

- Sistema Nacional de Unidades de Conservação da Natureza (SNUC) Lei 9.985 de $18 / 07 / 2000$

- Regulamentação da Lei do SNUC Decreto 4.340, de 22 de agosto de 2002

- Política Nacional de Biodiversidade Decreto 4.339, de 22 de Agosto de 2002

- Programa Nacional da Diversidade Biológica - PRONABIO Decreto 4.703, de 21 de maio de 2003

- Projeto de Conservação e Utilização Sustentável da Diversidade Biológica Brasileira - PROBIO Decreto 5.092 de 21 de maio de 2004

- Plano Nacional de Áreas Protegidas - PNAP Decreto 5758/2006

- CONABIO - Comissão Nacional de Biodiversidade - Resolução 03 de 21/12/2006 - Decisão VIII/15

- Política Nacional de Desenvolvimento Sustentável dos Povos e Comunidades Tradicionais (PNPCT) - Decreto 6.040, de 7 de fevereiro de 2007

- Áreas Prioritárias para Conservação, Uso Sustentável e Repartição de Benefícios da Biodiversidade Brasileira - Portaria MMA 09/2007.

As UC's constituem peças-chaves para promover a conservação e a provisão de serviços ambientais que contribuem para o crescimento de uma série de cadeias econômicas e não admitem uso econômico direto insustentável.

Para serem viáveis, as UC's devem promover bens e serviços com valor social e econômico que justifiquem sua criação e manutenção, o que por sua vez, também demanda a valoração econômica dos recursos naturais e dos seus serviços, a qual pode servir como base para um modelo de gestão que contribua para que elas alcancem os objetivos do plano de manejo para os quais foram estabelecidas. (NEXUCS, 2012).

Muito esforço tem sido despendido por organismos multilaterais e pelas nações visando tornar efetiva a valoração e preservação da biodiversidade e a sua incorporação nos preços, adotando mecanismos econômicos, destacando-se: o Protocolo de KYOTO, atribuindo valor e responsabilidade de pagamento pelo sequestro de carbono, como os Mecanismos de Desenvolvimento Limpo (MDL), visando uma produção mais limpa; os 
Mecanismos de Redução das Emissões (REED e REED+), que conferem valor e responsabilidade de pagamento pelas reduções de emissões ou emissões evitadas; o mecanismo TEEB- 2013, concedendo valor e responsabilidade de pagamento pelos serviços ambientais (PSA). (FENKER, 2013).

\subsection{Valoração Econômica do Meio Ambiente}

O meio ambiente reúne um conjunto de itens e funções apreciadas, consumidas ou utilizadas que afetam positivamente gerando bem-estar a sociedade, portanto, é conveniente questionar o valor econômico de cada um deles. (TURNER et al, 2010). A valoração econômica ambiental utiliza um referencial teórico neoclássico (a teoria do bemestar). O bem-estar que a sociedade deriva da qualidade ambiental, faz sentido. Sem esquecer que a qualidade do ambiente no qual se está decidindo é o resultado da atividade da mesma sociedade.

A sociedade valora quatro funções que se encontram no meio ambiente: a) forma parte da função de produção; b) que funciona como um receptor de resíduos; c) fornece bens naturais e d) fornece os meios para sustentar a vida. (PEARCE, 1976).

Um problema básico o qual se deve abordar para a sociedade é a alocação de recursos, deixado no "mercado", em que operam uma série de agentes econômicos que atuam como forma "racional" gerado preços, o que determina a solução para o problema de alocação de recursos escassos. Os consumidores mostram assim suas preferências por bens e serviços, demostrando sua disposição de pagar por eles. (AZQUETA 1999).

Há um conjunto de ativos que carecem de um mercado, onde troca-se a inexistência de sinalização de "preços" para seus serviços, induzindo aos mercados as falhas na sua alocação eficiente, o que traz o problema de uso excessivo dos recursos. Através disso surge a necessidade de conceituar o valor econômico e de desenvolver métodos para estimá-lo.

De forma geral, os métodos de valoração econômica ambiental são utilizados para estimar os valores que as pessoas atribuem aos recursos ambientais, com base em suas preferências individuais. Logo, taxar economicamente é usar um indicador que geralmente é o dinheiro para contabilizar a importância do meio ambiente no bem-estar da sociedade. (PEARCE, 1993; BATEMAN E TURNER, 1992) 


\subsubsection{Relevância}

Os relatórios de "The Economics of Ecosystems and Biodiversity" (McVITTIE, 2013) oferecem estimativas dos custos dos ecossistemas e da biodiversidade em escala global, explicando como usar instrumentos econômicos para capturar esses valores.

Em 50 anos a aplicação mais visível usando o método de valoração contingente para avaliar os danos de recursos naturais foi o vazamento de petróleo do Exxon Valdez; embora, para uma indicação da importância da Valoração Contingente, pode-se observar nas bases de dados com informações de estudos de valoração, tais como: Ecosystem Services Database (ESD), Environmental Valuation Reference Inventory (EVRI), International Institute for Environment Development (IIED).

Alguns exemplos de estudos realizados utilizando o Método de Valoração Contingente são apresentados no quadro 2.6. 
Quadro 2.6: estudos de valoração econômica ambiental utilizando o MVC.

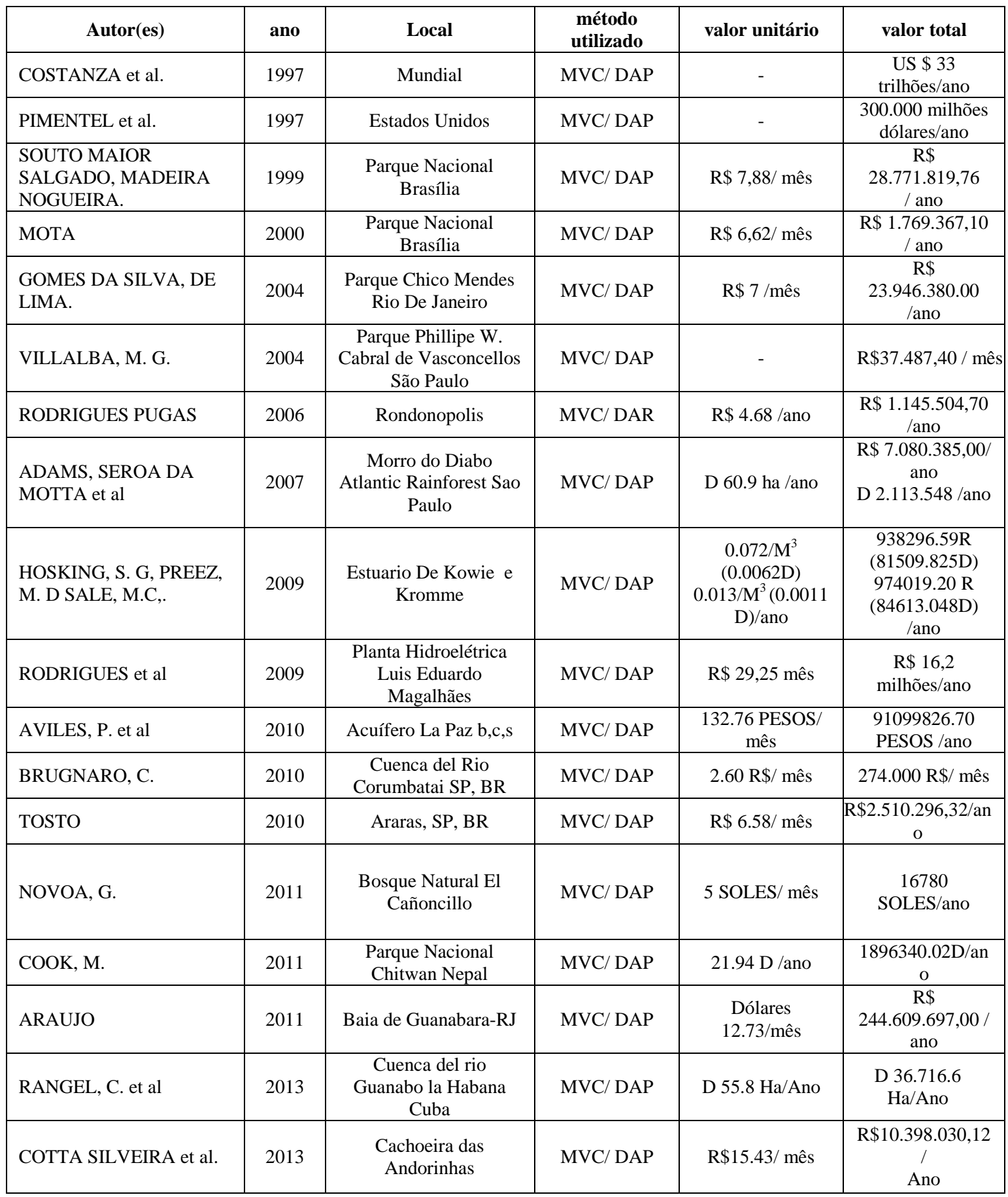

No Brasil, algumas pesquisas que abordam valoração econômica em ativos naturais foram realizadas com distintas formulações do problema de valoração econômica do meio ambiente, é difícil proceder a uma comparação dos resultados, devido as distintas unidades de medição utilizadas.

A contribuição das unidades de conservação para a economia do Brasil, em um estudo realizado por Medeiros et al (2011), mostra resultados sobre o potencial de cinco 
dos diversos bens ou serviços provisionados pelas unidades de conservação para a sociedade Brasileira; a visitação nos 67 parques nacionais existentes no Brasil tem potencial para gerar entre $\mathrm{R} \$ 1,6$ Bilhão e $\mathrm{R} \$ 1,8$ bilhão por ano, considerando as estimativas de fluxo de turistas projetadas para o país até 2016, ano que em ocorrerá as olimpíadas.

A criação e manutenção das unidades de conservação no Brasil impediram a emissão de pelo menos $\mathrm{R} \$ 2,8$ bilhões de toneladas de carbono, com um valor monetário conservadoramente estimado em $\mathrm{R} \$ 96$ bilhões. Cerca de $80 \%$ da hidroeletricidade do país vem de fontes geradoras de água que têm pelo menos uma tributação a jusante de unidade de conservação; 9\% da água para consumo humano é diretamente captada em unidades de conservação e $26 \%$ é captada em fontes a jusante de unidades de conservação, além disso, $4 \%$ da água utilizada na agricultura e na irrigação é captada de fontes dentro ou posterior de unidades de conservação. (MEDEIROS et al, 2011)

Em cada um dos casos descritos percebe-se que o investimento em áreas protegidas pode fornecer um benefício para a economia nacional e locais em torno da área protegida.

\subsection{Conceito de Valor Econômico do Meio Ambiente e Seus Componentes}

Segundo Nogueira (et al. 2000); Maia (2002); Hackett (2006); Muller (2007; ABNT (2008); Samdin (2008) e Kolstad (2009), em princípio e dentro da análise econômica, deve-se considerar o valor econômico total (Ver quadro 2.8) ou Valor Econômico do Recurso Ambiental (VERA), conceito cujo há atribuição de valor a algo e é dado em termos do seu valor de uso e não uso dos serviços e bens ambientais.

O valor de uso refere-se ao uso efetivo, direto ou potencial que o recurso pode prover, e por tanto incorpora o uso direto e indireto dos bens e serviços ambientais.

Devido à incerteza associada ao potencial de uso futuro (benefícios futuros), o valor derivado da proteção dos recursos da biodiversidade associado a estas tem sido chamado de "valores de opção" e "quase-opção". O valor de opção refere-se ao valor da disponibilidade do recurso ambiental para um possível uso futuro e o valor de quase-opção, tem origem que com o tempo, sejam reduzidas as incertezas sobre a utilidade e disponibilidade dos recursos, representando o valor de reter as opções de uso futuro do recurso, dado uma hipótese de crescente conhecimento científico, técnico, econômico ou 
social sobre as possibilidades futuras do recurso ambiental sob investigação (ganho associado ao segurar na presença de incerteza para o futuro. (NOGUEIRA el al, 2000)

A compreensão do valor de quase-opção é importante na definição do VET, pois demonstra que as estimativas de valoração podem variar ao logo do tempo, sobretudo, quando as metodologias de valoração incorporam alternativas tecnológicas de prevenção e reparação dos danos causados, bem como se aprimoram as técnicas de quantificar os impactos dos danos ao meio ambiente. (NOGUEIRA et al, 2000; MAIA, 2002; HACKETT, 2009)

O valor de não-uso (também chamado de valor intrínseco ou valor de existência) reflete um valor que reside nos recursos ambientais por si só, independentemente de uma relação com os seres humanos de uso efetivo no presente ou de possibilidades de uso futuro. $\mathrm{O}$ indivíduo considera que o recurso tem direito de existir e está disposto a abrir mão para garantir que o recurso exista.

Quadro 2.7: valores econômicos indicados para a determinação do VET.

\begin{tabular}{|c|c|c|c|}
\hline \multicolumn{4}{|c|}{ VET $=$ Valor de uso + valor de não uso } \\
\hline \multicolumn{3}{|c|}{ Valor De Uso } & Valor de Não-Uso \\
\hline Valor de Uso Direto & Valor de Uso Indireto & Valor de Opção & Valor de Existência \\
\hline \multicolumn{4}{|c|}{ Definição } \\
\hline $\begin{array}{lr}\text { Bens e } & \text { serviços } \\
\text { ambientais } & \\
\text { apropriados } & \\
\text { diretamente } & \text { da } \\
\text { exploração do recurso } \\
\text { e consumidos hoje. }\end{array}$ & \begin{tabular}{lrr} 
Bens e & \multicolumn{2}{r}{ serviços } \\
ambientais & que & são \\
gerados de & funções \\
ecossistêmicas & e \\
apropriados & e \\
consumidos & & \\
indiretamente & hoje.
\end{tabular} & $\begin{array}{l}\text { Bens } \text { e rerviços } \\
\text { ambientais de usos } \\
\text { diretos e indiretos a } \\
\text { serem apropriados e } \\
\text { consumidos no futuro. }\end{array}$ & $\begin{array}{l}\text { Valor não associado ao } \\
\text { uso atual ou futuro e que } \\
\text { reflete questões morais, } \\
\text { culturais, éticas ou } \\
\text { altruísticas. }\end{array}$ \\
\hline
\end{tabular}

Fonte: Seroa da Motta (1998).

\subsection{Métodos De Valoração Ambiental}

Como referencial da literatura utilizaram-se os lineamentos feitos pelo Grupo Nacional de Administração Oceânica e Atmosférica no Método de Avaliação Contingente (NOAA 1993), a Norma oficial NBR 14653-6 da Associação Brasileira de Normas Técnicas (ABNT, 2008) que fixa as diretrizes para avaliação dos recursos naturais que se baseia na literatura mais atualizada compreendendo os valores de uso direto; uso indireto; de opção e existência, sendo o Valor Econômico do Recurso Ambiental o somatório geral de todos os valores (ver quadro 2.9). 
Quadro 2.8: Métodos de valoração e tipos de valores - ABNT.

\begin{tabular}{|c|c|c|c|c|}
\hline \multirow{2}{*}{ MÉTODOS DE VALORAÇÃO } & \multicolumn{3}{|c|}{ Valor de Uso } & \multirow{2}{*}{ Valor de Existência } \\
\cline { 2 - 4 } & $\begin{array}{c}\text { Valor Uso } \\
\text { Direto }\end{array}$ & $\begin{array}{c}\text { Valor Uso } \\
\text { Indireto }\end{array}$ & Valor Opção & Não aplicável \\
\hline Custo de reposição & $\checkmark$ & $\checkmark$ & Não aplicável & Não aplicável \\
\hline Custos evitados & $\checkmark$ & $\checkmark$ & Não aplicável & Não aplicável \\
\hline Custos de controle & $\checkmark$ & $\checkmark$ & Não aplicável & Não aplicável \\
\hline Mercado de bens substitutos & $\checkmark$ & $\checkmark$ & Não aplicável & Não aplicável \\
\hline Custo de viagem & $\checkmark$ & $\checkmark$ & Não aplicável & Não aplicável \\
\hline Preços hedônicos & $\checkmark$ & $\checkmark$ & $\checkmark$ & $\checkmark$ \\
\hline Valoração contingente & $\checkmark$ & $\checkmark$ & $\checkmark$ & $\checkmark$ \\
\hline
\end{tabular}

Fonte: Elaboração Própria baseado em ABNT NBR14653-6.

Os economistas desenvolveram técnicas para avaliar bens e serviços ambientais que não sejam transacionados no mercado, não existe uma classificação universalmente aceita sobre os métodos de valoração econômica ambiental (SEROA DA MOTTA, 1998; BATEMAN E TURNER 1992), classificam-se estas técnicas de acordo com a função de produção e a função de demanda:

Métodos da Função de Produção: produtividade marginal e de mercados de bens substitutos (reposição, gastos defensivos ou custos evitados e custos de controle).

Métodos da Função de Demanda: métodos de mercado de bens complementares (custo de viagem e preços hedônicos) e método da valoração contingente, os quais são classificados por sua vez de acordo com a disponibilidade de informações em dois grupos, as preferências reveladas (ou métodos indiretos) e as preferências declaradas (métodos diretos):

a- OS MÉTODOS INDIRETOS analisam e tentam inferir o comportamento da pessoa, a valorização implícita que é dada ao bem em estudo por meio de mercados substitutos. Fazem parte desse grupo: o método do custo de viagem e método de preços hedônicos.

b- OS MÉTODOS DIRETOS ou hipotéticos demandam que as pessoas revelem suas preferências por meio de pesquisas, questionários e de mercados hipotéticos, a última abordagem é muitas vezes referida como o método de valoração contingente (CVM), que tem se mostrado como uma ferramenta útil para determinar o valor que as pessoas dão ao meio ambiente, especialmente quando é usado no contexto de serviços ambientais.

A seguir há uma breve descrição de cada um dos métodos de função de demanda, apresentando aspectos básicos e relevantes ao avaliar bens e serviços ambientais. 


\subsubsection{Métodos da Função da Demanda}

\subsubsection{Método Custo Viagem (MCV)}

É baseado no comportamento observado, consiste por sua vez na soma dos gastos efetuados pelas pessoas para se deslocarem a um lugar onde podem usufruir dos benefícios advindos de serviços e bens ambientais - geralmente recreação-, o qual pode ser utilizado como aproximação dos benefícios (TEEB, 2010). O método estima a demanda pelo ativo ambiental, criando a curva de demanda com base nos custos de viagem, o que inclui transporte, tempo de viagem, taxa de entrada, hospedagem, alimentação, entre outros gastos complementares e outras variáveis socioeconômicas (renda per capita, distribuição etária, perfil de escolaridade, etc.). Além disso, o custo do tempo gasto no deslocamento tem que ser considerado. Esta informação é principalmente reunida através de inquéritos no local. (HANLEY et al. 2013)

Parte da premissa de que o preço de entrada ao ativo ambiental seja zero, o custo de acesso é geralmente maior do que zero, uma vez que é geralmente vai se incorrer em despesas. (ARAÚJO, 2007)

Tendo encontrado a função de demanda é derivado o excedente do consumidor, que representa o grau de benefício que supõe o gozo do bem.

De maneira geral, a demanda por visitas (DV), será uma função do custo de viagem $(C V)$, controlando as características socioeconômicas dos visitantes $(C S)$, e a existência de substitutos $(E S)$, ao patrimônio natural. Tem-se a seguinte representação para a função demanda pelo patrimônio natural:

$$
\mathrm{DV}=f(\mathrm{CV}, \mathrm{CS}, \mathrm{ES})
$$

Com a taxa de visitação estimada, pode-se multiplicá-la pela população zonal e conhecer o número esperado de visitantes por zona.

O método apresenta alguns esforços econométricos com significativos problemas de especificação, já se deve tentar isolar outros efeitos. As hipóteses assumidas para determinar os custos de viagem, que devem incluir tempo e excluir o consumo de outros serviços não associados ao local, certamente afetam as magnitudes das medidas de variação de bem-estar. (SEROA DA MOTTA 1998). 


\subsubsection{Método dos Preços Hedônicos (MPH)}

A base do método dos Preços Hedônicos (MPH) é identificar os atributos ou em um bem composto privado e que estes sejam complementares a bens ou serviços ambientais. Com a complementaridade, é possível mensurar o preço implícito do atributo ambiental no preço de mercado quando outros atributos são isolados (PEARCE et al, 2006; TEEB, 2010). Quando uma pessoa em um mercado imobiliário quer comprar um imóvel, as características do imóvel (locacional e os diferentes níveis de atributos ambientais como qualidade do ar, proximidade a um sítio natural, etc) guiam sua escolha, está aí a forma correta, "valorando" essas particularidades do imóvel.

Portanto, como esses atributos são valorados pelos indivíduos, as diferenças de preços dos imóveis, devidos à diferença de nível dos atributos ambientais, devem refletir a disposição a pagar por variações nesses atributos (SEROA DA MOTTA, 1998). Alguns estudos demonstraram que as propriedades próximas a um espaço verde ou corpo d'água são mais caras do que aquelas que não são. (MAYOR et al 2009; CHO et al, 2009)

O método permite avaliar o preço implícito de um atributo ambiental na formação de um preço observável de um bem composto.

Se Pi é o preço de uma propriedade, pode-se expressar:

$$
\mathrm{Pi}=f\left(\mathrm{ai}_{1}, \mathrm{ai}_{2}, \ldots, \mathrm{Ei}\right)
$$

Onde:

'ai' representa os vários atributos da propriedade i e 'Ei' representa o nível do bem ou serviço ambiental "E" associado a esta propriedade $i$.

\subsubsection{Método de Valoração Contingente (MVC)}

Algo importante para este estudo é o instrumento de Valoração contingente. É um método usado para estabelecer valores econômicos sobre bens e serviços ambientais que não sejam transacionados no mercado. O valor é medido pela disposição máxima a pagar (DAP) ou disposição a aceitar uma compensação (DAR) de uma pessoa por uma troca para variações hipotéticas na prestação de serviços ecossistêmicos. (TEEB 2010).

Uma pesquisa de avaliação contingente constrói cenários que oferecem várias ações públicas possíveis para desenvolver no futuro. A base teórica do método está nas 
preferências do consumidor, via função de utilidade individual. Os entrevistados são questionados sobre suas preferências em relação as alternativas de ações ou projetos. Em seguida, essas escolhas feitas pelos entrevistados são analisadas de forma semelhante às escolhas feitas pelos consumidores nos mercados reais. Em ambos os casos, o valor econômico é derivado das escolhas observadas, seja no mundo real ou em um mercado hipotético criado em uma enquete. (OSORIO et. al., 2009).

O MVC é usado para avaliar os benefícios da melhoria no ambiente para evitar a sua deterioração de acordo com a quantidade de dinheiro que os potenciais beneficiários desta melhoria estariam dispostos a pagar (DAP), é solicitado o máximo que eles pagariam para obter um montante adicional ou uma melhoria na qualidade de serviço ou grupo de serviços; ou a avaliação dos custos gerados pelos danos ambientais, por meio da quantidade de dinheiro que estariam dispostos a aceitar como compensação por alterações especificadas na quantidade, ou qualidade de tais bens, ou serviços solicitados ao entrevistado - um montante mínimo como compensação - ou de Disposição a aceitar ou Receber (DAA-DAR) para aceitar a menor quantidade ou qualidade degradada de qualquer serviço ambiental. (CARSON et. al, 1992, TEEB, 2010).

O MVC é um modelo probabilístico, a partir dele calcula-se a probabilidade de obter uma resposta positiva ou negativa a uma pergunta sobre a disponibilidade de pagamento para uma melhoria do ambiente (ou disposição de aceitar uma compensação de uma perda ambiental), que depende dos atributos socioeconômicos da pessoa entrevistada, e dos atributos de qualidade e quantidade do bem ambiental que está sendo oferecido. (OSORIO et. Al., 2009).

A informação é utilizada nas equações de regressão para estimar a função de Valoração. Uma estimativa de sucesso utiliza variáveis identificadas como teoria, capaz de prever a disposição das pessoas a pagar, isso é a prova parcial de confiabilidade e validade (MITCHELL e CARSON, 1989).

\subsubsection{Modelo Teórico Do Método De Valoração Contingente}

Baseia-se na formulação desenvolvida por Hanemann (1984). O modelo assume que os indivíduos derivam utilidade (bem-estar) da disponibilidade e/ou qualidade de um bem ambiental (h) e de sua renda (Y). A parte observável da função utilidade é explicada pelas características socioeconômicas do indivíduo (S) e os atributos do bem ambiental (h); a parte observável é a renda do indivíduo (Y). 
Assim, para o investigador $\mathrm{U}_{0}$ e $\mathrm{U}_{1}$ são variáveis aleatórias com alguma distribuição de probabilidade.

$\mathrm{U}_{0}=\mathrm{u}\left(\mathrm{h}_{0}, \mathrm{Y} ; \mathrm{S}\right)$

$\mathrm{U}_{1}=\mathrm{u}\left(\mathrm{h}_{1}, \mathrm{Y} ; \mathrm{S}\right)$

Onde $\mathrm{U}_{0}$ é a função de utilidade no âmbito do estado inicial da qualidade do bem ambiental, com características $h_{0}$. Enquanto isso, $\mathrm{U}_{1}$ é a função de utilidade com a melhoria na qualidade ambiental gerada pelo projeto a avaliar com características $\mathrm{h}_{1}$.Agora, as funções de utilidade podem ser escritas como:

$\mathrm{U}(\mathrm{h}, \mathrm{Y} ; \mathrm{S})=\mathrm{V}(\mathrm{h}, \mathrm{Y} ; \mathrm{S})+\varepsilon$

Onde V (h, Y; S) representa a função de utilidade indireta, ou seja, a função que representa a máxima utilidade que pode ser alcançada dada a renda e outras variáveis. $\mathrm{O}$ termo $\varepsilon$ representa a parte da utilidade que não pode ser explicada pelas variáveis incluídas no modelo.

Para analisar se o indivíduo aceito ou não a mudança na utilidade, de $\mathrm{U}_{0}$ para $\mathrm{U}_{1}$, no modelo hipotético, pode-se ter em conta a máxima disponibilidade de pagar (DAP), para uma melhoria da qualidade ou quantidade dos recursos.

\subsubsection{Modelo da Disposição de Pagar (DAP)}

Segundo as equações (3.1), (3.2) e (3.3) o indivíduo aceitará o projeto que envolva melhorias na qualidade ou quantidade do recurso somente se a utilidade gerada realizando o pagamento para acessar o projeto e à melhoria ambiental (DAP) é maior ou igual a utilidade que se percebe atualmente sem nenhuma melhoria ambiental.

$\mathrm{V}_{1}\left(\mathrm{~h}_{1}, \mathrm{Y}-\mathrm{DAP} ; \mathrm{S}\right)+\varepsilon_{1} \geq \mathrm{V}_{0}\left(\mathrm{~h}_{0}, \mathrm{Y} ; \mathrm{S}\right)+\varepsilon_{0}$

Agora, a resposta à proposição de pagar para acessar a melhoria ambiental é uma variável aleatória com uma distribuição de probabilidade dada por:

$\mathrm{P}_{0}=\operatorname{Pr}$ (Disponibilidade individual a pagar pela mudança) 
Onde a disponibilidade a pagar pelo indivíduo depende do resultado da equação

Desta forma, pode-se expressar:

$$
\begin{aligned}
& \mathrm{P}_{0}=\operatorname{Pr}\left(\mathrm{V}_{1}\left(\mathrm{~h}_{1}, \mathrm{Y}-\mathrm{DAP} ; \mathrm{S}\right)+\varepsilon 1 \geq \mathrm{V}_{0}\left(\mathrm{~h}_{0}, \mathrm{Y} ; \mathrm{S}\right)+\varepsilon_{0}\right) \\
& \mathrm{P}_{0}=\operatorname{Pr}\left(\mathrm{V}_{1}\left(\mathrm{~h}_{1}, \mathrm{Y}-\mathrm{DAP} ; \mathrm{S}\right)-\mathrm{V}_{0}\left(\mathrm{~h}_{0}, \mathrm{Y} ; \mathrm{S}\right) \geq \varepsilon_{0}-\varepsilon_{1}\right)
\end{aligned}
$$

Dado que a resposta à pergunta Sim/Não é uma variável aleatória, a probabilidade de uma resposta positiva será dada por:

$\operatorname{Pr}(\mathrm{SIM})=\operatorname{Fn}(\Delta \mathrm{V})$

Se Fn $(\Delta V)$ representa a função de distribuição de probabilidade cumulativa de $\eta$, e é assumida uma função logística para tal distribuição, tem-se:

$\mathrm{P}_{0}=\mathrm{Fn}(\Delta \mathrm{V})$

$\mathrm{P}_{0}=\mathrm{Fn}(\Delta \mathrm{V})=\left(1+\mathrm{e}^{-\Delta \mathrm{V}}\right)$

\subsection{Antecedentes do MVC}

A valoração contingente teve início em 1947, quando Ciriacy-Wantrup escreveu sobre os benefícios da prevenção da erosão que tinha um caráter público, usou entrevistas pessoais para identificar as demandas das pessoas perguntando sobre sua disposição a pagar para se beneficiar de quantidades adicionais de um bem.

Na década de 1960 o MVC começou a ser aplicado em pesquisas acadêmicas. O primeiro estudo de avaliação contingente foi realizado por Davis (1963), que por sua vez estudou o planejamento da recreação como um problema econômico. Davis determinou o valor dos bosques do Maine nos Estados Unidos da América para caçadores e amantes da natureza, mostraram que o método é útil para perguntar sobre as preferências dos indivíduos por bens públicos, pelo qual tem grande aceitação para a política pública.

A economia ambiental teve uma grande contribuição com a publicação de "Conservação reconsiderada", de John Krutilla em 1967, este identifica a natureza irreversível do desenvolvimento de ambientes naturais, e sugere a existência de diferenças entre as medidas de bem-estar para o que ele chama de "grandes maravilhas cênicas", além de introduzir o "valor de existência" de bens e serviços ambientais, definido como o valor 
que os indivíduos atribuem a um bem ambiental, que por sua vez não está relacionada a qualquer uso no presente ou futuro.

O conceito de valor de quase opção foi introduzido na publicação "Environmental Preservation, Uncertainty, and Irreversibility” de Arrow e Fisher, (1974).

O MVC tem sido um método reconhecido pelo Conselho de Recursos Hídricos americanos (Water Resources Council) desde 1979. Na década de 80 se incorporou a VC na tomada de decisões institucionais, e estes estudos são considerados grandes fornecedores de evidências na hora de avaliar e tomar decisões jurídicas, em grande parte estimulada pela aceitação do método pela Comprehensive Environmental Response Compensation, and Liability Act - CERCLA, em 1980- nos Estados Unidos da Américacomo uma técnica para medir o grau de danos aos recursos naturais, cujo requer avaliação de mudanças no bem-estar social, impactos ambientais negativos devido à descarga de substâncias perigosas. (BATEMAN et al 2001).

Pode-se considerar que o exemplo mais destacado no MVC é a avaliação do dano - Recursos Naturais após o vazamento do petróleo do Exxon Valdez. Em 24 de Março de 1989, quando o petroleiro Exxon Valdez transportando mais de 50 milhões de litros de petróleo encalhou em Prince William Sound (PWS), causando o vazamento de 41 milhões de litros (11 milhões de galões) de petróleo na água, resultando em 1.300 milhas de costa oleada, morte de 250.000 aves, 2.800 lontras, mais de 250 focas marinhas e a destruição dos ovos de salmão e arenque quase incontáveis. Este evento e suas consequências provocaram um debate entre os economistas sobre a adequação dos métodos de avaliação dos bens públicos. (KLING, et.al 2012).

Os Estados Unidos da América, o Estado do Alasca e a Exxon contrataram dois dos pesquisadores mais eminentes no campo para realizar uma avaliação extensa e completa, utilizando o MVC a fim de medir o valor dos danos de não uso causados pelo desastre. A Exxon preocupada com o tamanho da avaliação dos danos que resultariam de tal estudo encomendou a uma série de economistas igualmente para investigar a validade da técnica.

Kahneman e Knetsch, (1990) escreveram um artigo "Valuing Public Goods: The Purchase of Moral Satisfaction", numerando as críticas sobre a validade do MVC decorrente de problemas associados a vieses de informação, comportamento estratégico, formato de pergunta, o efeito incrustação etc, e concluíram que as respostas de VC 
refletem a disposição a pagar pela satisfação moral de contribuir com o bem público, e não o valor econômico desses bens.

No relatório de estudo de VC desenhado para medir a perda de valores de uso passivos derivadas de lesões de recursos naturais causados pelo derramamento de petróleo realizado pelo Estado do Alasca contra Exxon, avaliou os danos em US \$2,8 bilhões de dólares (com base nos valores de DAP médio de US \$ 31 por família. (CARSON et al, 1992).

Em resposta às críticas dos inquéritos de avaliação contingente, um grupo de economistas de alto perfil (presidido por ganhadores do prêmio Nobel Kenneth Arrow e Robert Solow) convocaram sob os auspícios da Oceanic and Atmospheric Administration Nacional (NOAA) em 1993.

\subsubsection{Os Vieses Do Método De Valoração Contingente E O Painel Noaa Blue Ribbon}

A polêmica sobre a validade prática da valoração contingente e a complexidade deste método envolve diferentes tipos de vieses em que se pode incorrer. Durante boa parte dos anos setenta e oitenta, muitos dos estudos de valoração contingente dedicaram especial atenção para detecta-los e corrigi-los.

Podem ser identificados, pelo menos, nove importantes tipos de vieses:

- Viés estratégico: refere-se aos erros decorrentes de estratégias utilizadas pelo entrevistado que acredita que podem influenciar as tomadas de decisões acerca da questão ambiental envolvida, não revelando sua verdadeira preferência, de modo a maximizar seu bem-estar esperado. (CARSON e GROVES, 2007).

- Viés hipotético: surge em resposta a uma pergunta hipotética onde o entrevistado não tem nenhuma experiência no mercado. Em suma, o que as pessoas dizem é diferente do que elas fazem. Os entrevistados não acreditam no cenário e não fazem suas escolhas em um contexto seguindo as hipóteses propostas. Quando as perguntas hipotéticas sobre a disposição a pagar são feitas, os resultados tendem a ser hipotéticos, já que isso não acarretara custos.

- Viés da informação: forma como o entrevistado apresenta a informação pode influir na DAP, seja pelo grau de veracidade, seja pelo grau de detalhamento. A forma como a informação foi elaborada pode induzir a determinado resultado. 
- Viés do entrevistador: acontece quando o entrevistado responde positivamente a questão da DAP, mas é diferente daquela que seria verdadeira com a finalidade de agradar ao entrevistador e não causar má impressão, ou para desencargo de consciência.

- Viés do instrumento ou veículo de pagamento: o instrumento ou veículo de pagamento pode influenciar na DAP do indivíduo, a alternativa é escolher a forma de pagamento o mais próxima de uma situação real. (CARSON E GROVES, 2007).

- Viés do ponto inicial: o ponto inicial dos lances iniciais pode desestimular o entrevistado a pensar seriamente sobre a sua verdadeira DAP, a alternativa é utilizar cartões de pagamento, mas muitas vezes o entrevistado opta pelo primeiro valor oferecido por considerá-lo o valor correto. No método de referendum os valores subsequentes são rejeitados pelas pessoas, porque se consideram os valores iniciais corretos.

- Viés da obediência: as pessoas geralmente ficam constrangidas de manifestar uma posição negativa em relação às questões ambientais. Isso pode superestimar a DAP, principalmente nos métodos referendum e jogos de leilão. Para contornar esse viés, sugere-se que sejam utilizadas técnicas que façam o entrevistado crer na efetividade da cobrança.

- Viés de protesto: apregoa uma forma de comportamento político em que os indivíduos usam a resposta para expressar seu protesto com algo relacionado à pesquisa. Para contornar esse problema, devem ser incluídas questões que seja possível verificar a razão de uma posição negativa em relação à DAP.

Apos identificados os votos de protesto, o estado da arte e excluir os votos de protesto da amostra. (MORRISON ET AL., 2000).

- Viés Parte-Todo: o entrevistado tende a interpretar a oferta hipotética de um bem específico ou serviço ambiental, apresentada na pesquisa, como algo mais abrangente. Trata-se da dificuldade de distinguir o bem específico ("parte") de um conjunto mais amplo de bens ("todo").

Outros problemas que se manifestam na literatura:

(1) problemas de cognição: dificuldades de observação, compreensão de um sistema ambiental particular, e o peso dos atributos do bem; 
(2) inconsistência: indivíduos não podem aceitar que o preço pode capturar todas as informações relevantes sobre um bem e seu valor;

(3) a composição: a incapacidade dos indivíduos para aceitar que um bem ambiental ou serviço pode ser "mercantilizado", a fim de ser fixado o preço. (BATEMAN et al 2001).

Como esclarecimento referente aos vieses do MVC, o Painel do National Oceanic and Atmospheric Administration (NOAA), consultou a opinião da maioria dos especialistas, apoiantes e opositores para definir critérios e procedimentos para mensuração dos danos ambientais causados por derramamento de óleo. O relatório da Comissão NOAA publicou em 1993, o reconhecimento a validade do método da valoração contingente para calcular o valor da perda de bem-estar por mudanças ambientais, como único método capaz de captar valores de existência, mas incluiu diversas recomendações para sua elaboração e execução para assegurar que no leve a estimar valores exageradamente viesados. (ARROW et al, 1993).

As recomendações mais importantes estão abaixo relacionadas:

1. O MVC deve ser aplicado como entrevistas pessoais, ao invés de telefone. Se não for possível aplicação pessoal é preferível a realização de entrevistas por telefone antes que via e-mail. Entrevistas telefônicas têm algumas vantagens em termos de custo e supervisão.

2. Uma pesquisa piloto é um elemento essencial em qualquer estudo de VC.

3. A enquete deve incluir perguntas sobre as variáveis socioeconômicas que permitem uma melhor análise dos resultados.

4. Nos estudos de valoração contingente, deve-se tentar determinar o DAP para um futuro acidente, ao invés de tentar determinar a remuneração DAA mínima por um incidente que já ocorreu.

5. Na aplicação destes estudos deve-se aplicar um formato de pergunta de tipo Referendo.

6. Os estudos de valoração contingente devem começar mostrando um cenário que permita a compreensão dos efeitos do programa em questão.

7. Deve-se lembrar aos entrevistados de que a DAP para uma melhoria no bem ambiental no estúdio reduzirá sua renda futura. 
8. O veículo de pagamento deve ser realista e apropriado às condições culturais e econômicas.

9. Devem-se incluir questões de validação da pesquisa para ver se houve compreensão e aceitação do cenário proposto pelo entrevistado.

10. Lembrete de produtos substitutos - os entrevistados devem ser lembrados de produtos substitutos. Este lembrete deve ser introduzido com força e imediatamente antes da avaliação principal para garantir que os entrevistados tenham as alternativas claramente em mente.

11. Recomenda-se adotar um modelo de questionário que priorize perguntas fechadas, claras e sem intimidação, para que seja compreensível para os indivíduos com diferentes experiências e níveis de educação e para que consigam entender a natureza e o contexto do bem a valorar. (MITCHELL e CARSON, 1989; CARSON et al, 2001).

\subsubsection{Medidas de bem-estar para variações de bens ambientais}

A economia do bem-estar tenta atribuir um valor monetário aos ganhos e perdas dos indivíduos quando estes são afetados por uma mudança na provisão de um bem público, no caso, um bem ambiental. No MVC o que é valorado é uma proposta de variação de cenário, dado um contexto de pressão para substituição bem especificada. Um dos cenários representa a alternativa em questão (mercado hipotético), enquanto o outro representaria o cenário padrão, ou status quo. A definição do status quo e do cenário hipotético proposto é eficaz para a percepção e formação do valor. (VASCONCELLOS, 2012).

Hicks propôs em 1941 quatro medidas de bem-estar: excedente compensatório, variação compensatória, excedente equivalente e variação equivalente - podem significar que o consumidor tenha que fazer um pagamento (DAP) ou receber (DAR) uma compensação para manter seu nível de utilidade em um nível específico. As medidas de excedente são as adequadas para a maioria dos ativos ambientais pela forma como eles podem ser adquiridos. (Hanley e Spash, 1993; Azqueta, 1999).

No presente estudo, de acordo com os objetivos da pesquisa, será escolhido o conceito de excedente de compensação (EC) uma vez que se buscou o valor que o indivíduo está disposto a pagar pelo PNB. A medida de excedente de compensação pode ser entendida como o máximo valor monetário que os consumidores estão DAP para obter 
o incremento na qualidade e quantidade de bens e serviços ambientais fornecidos pelo PNB, e ainda manter seus níveis atuais de utilidade. No caso de uma diminuição na qualidade e quantidade de bens e serviços, o excedente de compensação é definido como a quantia mínima que o consumidor está DAR para ser compensado pela diminuição na qualidade e quantidade. 


\section{3 - MATERIAL E MÉTODOS}

\section{1 Área de Estudo}

O bem ambiental valorado neste estudo abrange o PNB, conforme é apresentado na figura 3.1. Está localizado nas coordenadas $15^{\circ} 38^{\prime} 28^{\prime \prime} \mathrm{S}, 48^{\circ} 1^{\prime} 15^{\prime \prime} \mathrm{W}$. Abrange as regiões administrativas de Brasília (DF), sobradinho (DF), Brasilândia (DF) e Padre Bernardo em Goiás.

O PNB está situado na porção noroeste do Distrito Federal (DF). Por ser uma unidade de conservação de proteção integral administrada pelo Instituto Chico Mendes de Conservação da Biodiversidade, situa-se na categoria de parque nacional com manejo de uso indireto. Tem menos de $1 \%$ de sua área aberta aos visitantes. (ICMBio-MMA)

O acesso principal ao PNB se dá pela Estrada Parque Indústria e Abastecimento Via EPIA, onde se situam as entradas para a Zona de Uso Intensivo (Portão 1, de uso de visitantes) e para a Zona de Uso Especial (Portão 2, de uso administrativo), as outras entradas do Parque são de serviço, com acesso controlado.

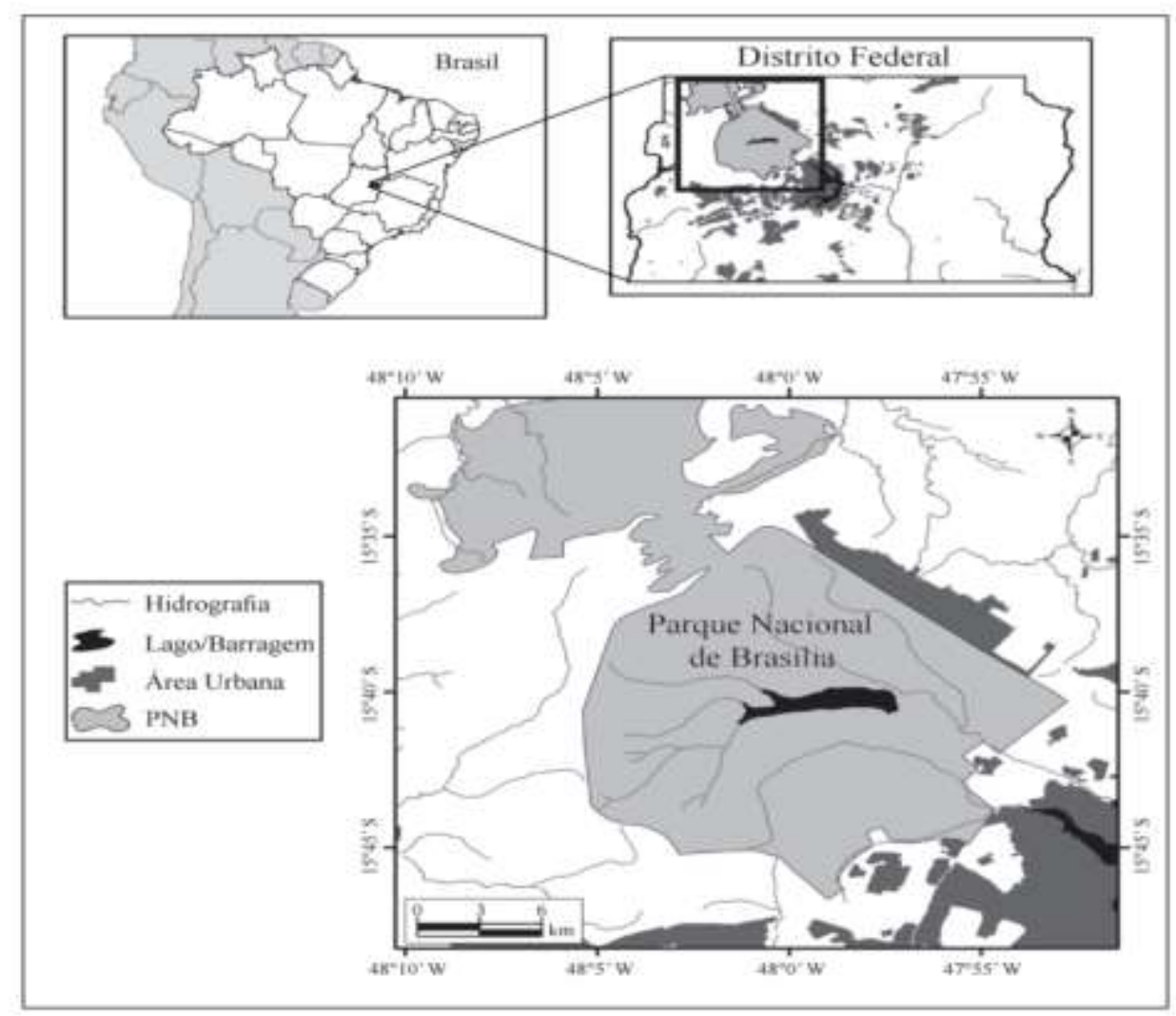

Figura 3.1: Localização do Parque Nacional Brasília no Distrito federal, Brasil. Fonte: Martins, C. R. et al 2011 


\subsubsection{O Parque Nacional de Brasília}

Criado pelo Decreto n.0 241 datado de 29 de novembro de 1961 com uma área de 30.000 hectares. A criação do Parque Nacional de Brasília está intimamente relacionada com a construção da nova Capital Federal. Pela lei ordinária número 11285 de 09.03.2006 redefiniu sua poligonal, acrescentando sua área para 42.389.01 hectares, A nova poligonal incluiu a região do vale do rio da Palma e dos ribeirões Dois Irmãos e Cupim, a área total do parque correspondente a 7,31\% do Distrito Federal.

O objetivo do Parque é preservar amostras típicas do ecossistema do cerrado do Planalto Central, de grande relevância ecológica e beleza cênica, possibilitando a realização de pesquisas científicas e o desenvolvimento de atividades de educação e interpretação ambiental, de recreação em contato com a natureza e de turismo, evitar a predação da fauna, garantir a preservação dos mananciais abrigando as bacias dos córregos (sistema Torto/Santa Maria) localizadas no Parque, que fornecem 27\% da água potável que abastecem os moradores do Plano Piloto, Lago Sul, Lago Norte, Paranoá e Cruzeiro, sendo fundamental para o microclima e promoção da recreação e do lazer dentro das dependências do Parque para a sociedade brasiliense, tanto quanto para as cidades circunvizinhas e turistas. Nas suas principais atrações, as piscinas que se formaram a partir dos poços de água, que surgiram às margens do Córrego Acampamento, pela extração de pedras e areia feita antes da implantação de Brasília, banheiros, lanchonetes, gramados e as duas trilhas (Capivara e Cristal Água).

Porém, a proximidade com a cidade gera pressões de diferentes ordens sobre o Parque. Tanta riqueza está ameaçada pelo depósito de lixo na Cidade Estrutural a céu aberto, que recebe os rejeitos produzidos na capital (SAMPAIO, 2006), a proliferação de espécies exóticas de plantas (HOROWITZ, 2013) e de animais, como urubus, ratos, baratas e cães, dentro da unidade de conservação do cerrado. Os bichos urbanos caçam as espécies endêmicas e espalham doenças, causando desequilíbrio à fauna silvestre. (Correio Braziliense, 2014)

De acordo com um estudo feito por Cavalcanti (2013), comprovou uma influência direta em nascentes e cursos de água, com presença de chorume, contaminado a água do córrego do Acampamento que nasce na unidade de conservação, o que pode comprometer a captação para o abastecimento de água, no caso da ampliação dos sistemas de abastecimento no Distrito Federal utilizando como manancial o lago Paranoá. Segundo o referido autor, até mesmo as árvores próximas ao aterro apresentam metais pesados na 
folhagem. Segundo Da Silva (2006) outros problemas futuros do parque, considerando as características atuais do crescimento urbano do Distrito Federal, em ritmo acelerado e desordenado, as bordas do parque sofrem a pressão de invasões e grandes loteamentos de terras públicas e privadas e construção de rodovias.

O Parque Nacional de Brasília tende com o tempo tornar-se uma "ilha", ou seja, um ambiente natural rodeado de ambientes alterados. Essa pressão em seu entorno provoca incêndios florestais, isolamento da fauna e da flora, comprometendo o trânsito gênico e a sobrevivência de várias espécies. Neste caso, o resultado que pode ser esperado é uma alta dominância de poucas espécies que possuam boa capacidade de dispersão, aliada a extinções locais e perda de biodiversidade. (FUNATURA/IBAMA, 2014).

\subsection{Referencial teórico}

A operacionalização do MVC acontece via a aplicação de questionários cuidadosamente elaborados de maneira a obter das pessoas os seus valores de DAP (Pearce, 1993), existem várias formas de fazer isso: jogos de leilão, referendum-escolha dicotômica (sim/não), jogos de trade-off, entre outros. (Hufschmidt et al, 1983).

Para o presente estudo utilizou-se como técnica de elicitação final o modelo referendum com jogos de leilão, adaptado da metodologia proposta por SILVA (2003), e seguindo a abordagem de HANEMANN et.al. (1991). Dessa forma, foram apresentados vários valores aos entrevistados para verificar se aceitavam ou não. $\mathrm{O}$ valor inicial não variou ao longo da amostra.

\subsubsection{Modelo de referendum - abordagem de Hanemann}

A abordagem parte do pressuposto de que o indivíduo é maximizador da utilidade. É feita a pergunta - Você estaria disposto a pagar uma quantidade X em Reais por mês para garantir melhora ambiental de $q 0$ para $q 1$, ou para manter a qualidade ambiental $q 1$ ? (HANEMANN et al 1991, 1994; SILVA , 2003; OSORIO et al 2009) a qual reflete a preferência desse indivíduo.

O indivíduo pode responder "sim" ou "não", dada uma função de utilidade indireta, representada por $v(M, q, C)$ em que $M$ é a renda; $q$ parâmetro ambiental; e $C$, vetor de características socioeconômicas individuais. Assim, tem-se as seguintes escolhas do consumidor:

$\mathrm{v}\left(\mathrm{M}-\mathrm{X}, \mathrm{q}_{1}, \mathrm{C}\right)+\mathrm{e}_{1}-\mathrm{v}\left(\mathrm{M}, \mathrm{q}_{0}, \mathrm{C}\right)+\mathrm{e}_{0} \geq 0$ para uma resposta "sim" $\mathrm{e}$ 
$\mathrm{v}\left(\mathrm{M}-\mathrm{X}, \mathrm{q}_{1}, \mathrm{C}\right)+\mathrm{e}_{1}-\mathrm{v}\left(\mathrm{M}, \mathrm{q}_{0}, \mathrm{C}\right)+\mathrm{e}_{0}<0$ para uma resposta "não"

Em que $e_{1}$ e $e_{0}$ são os erros aleatórios.

O consumidor só estará disposto a pagar a quantia $\mathrm{R} \$ \mathrm{X}$ proposta se o ganho de utilidade decorrente da melhora ambiental for maior ou pelo menos igual à perda de utilidade em função da aquisição de um menor número de outros bens de mercado, visto que tem agora uma renda menor $(\mathrm{M}-\mathrm{X})$.

Em relação às probabilidades, as equações podem ser representadas da seguinte forma:

$\mathrm{P}$ (responder "sim") $=\mathrm{P}(\mathrm{EC} \geq \mathrm{X})$

$\mathrm{P}$ (responder "não") $=\mathrm{P}(\mathrm{EC}<\mathrm{X})$

A DAP pela mudança ambiental corresponde ao excedente do consumidor (EC). O EC corresponde ao valor máximo que ele estaria disposto a pagar. Assim, para um valor proposto superior ao EC, o indivíduo opta por permanecer no nível ambiental atual $\left(\mathrm{q}_{0}\right)$. Já para um valor menor que o EC, o indivíduo se mostra disposto à pagar um pouco mais pelo acréscimo de q0 para $\mathrm{q}_{1}$. Caso o valor proposto e o EC sejam iguais, o indivíduo é indiferente entre optar ou não pela melhoria ambiental, já que qualquer uma das escolhas não muda seu nível de utilidade.

Portanto, a medida que se aumenta o valor proposto $X$, maior é a probabilidade do indivíduo responder "não"; e, na medida em que se diminui o valor X, maior é a probabilidade dele responder "sim".

A resposta do indivíduo é uma variável aleatória e sua distribuição de probabilidade é dada por:

$\mathrm{P}_{1}=\operatorname{Pr}\{\mathrm{o}$ indivíduo aceita pagar $\}$

$\mathrm{P}_{1}=\operatorname{Pr}\left\{\mathrm{v}\left(\mathrm{M}-\mathrm{X}, \mathrm{q}_{1}, \mathrm{C}\right)+\mathrm{e}_{1} \geq \mathrm{v}\left(\mathrm{M}-\mathrm{X}, \mathrm{q}_{0}, \mathrm{C}\right)+\mathrm{e}_{0}\right\}$,

$\mathrm{P}_{1}=\operatorname{Pr}\{\Delta \mathrm{v} \geq \delta\}$

Em que: $\quad v=v\left(M-X, q_{1}, C\right)-v\left(M, q_{0}, C\right)$

$=\mathrm{e}_{0}-\mathrm{e}_{1}$ 
Portanto,

$\mathrm{P}_{0}=\operatorname{Pr}\{\mathrm{o}$ indivíduo não aceita pagar $\}$

$\mathrm{P}_{0}=1-\mathrm{P}_{1}$

\subsubsection{Bidding games (jogos de leilão)}

A ideia consiste em criar uma série de valores monetários e negociá-los com o entrevistado para obter a DAP máxima para a mudança no bem ambiental.

O que caracteriza um método desse grupo e a forma direta de se obter a DAP nos procedimentos da pesquisa de campo.

Os entrevistados são questionados iterativamente para indicar sua máxima DAP: inicialmente apresenta-se um valor médio ao indivíduo e pergunta se ele "estaria disposto a pagar um valor X para manter ou melhorar os parâmetros ambientais existentes?" É oferecido um lance superior até obter um lance com resposta negativa, sendo a sua DAP máxima o último lance aceito no processo; caso contrário, se ele responder "não" ao primeiro lance, os lances sucessores seriam inferiores ao primeiro, o jogo de leilão termina quando o entrevistado faz as mudanças correspondentes de "sim" para "não" ou "não" para "sim", a DAP máxima é o último lance aceito no processo. (HOYOS, 2010).

\subsection{Modelo Analítico}

\subsubsection{Modelo Logit}

Por ser adequado para estimar a probabilidade da ocorrência do evento, optou-se pela utilização do modelo Logit para analisar o perfil dos usuários dispostos a pagar. A decisão de uma pessoa para participar pela proposta no estudo é sim ou não (variável dicotômica). Será sim, se a pessoa decide participar, e não em qualquer outro caso. A decisão de participar depende de vários fatores, tais como salário, escolaridade, etc. (GUJARATI et al 2010).

O modelo Logit estima a probabilidade de um indivíduo se dispor a pagar e, posteriormente, o preço em que a probabilidade de uma resposta sim seja de $50 \%$, sendo este o valor máximo que o indivíduo está disposto a pagar.

O modelo baseia-se na função de probabilidade logística acumulada e é apresentado da seguinte forma: 
$P i=f(\beta x)$

Em que, $P_{i}$ é a probabilidade do indivíduo $i$ responder sim à pergunta se está disposto a pagar pela melhoria ou manutenção da qualidade ambiental de um bem; $f$ é a função densidade; $X$ é um vetor de variáveis explicativas; e $\beta$ parâmetros desconhecidos a serem estimados. Assim:

$\mathrm{Pi}=\frac{1}{1+\mathrm{e}^{-\beta \mathrm{X}}}$

Tem-se: em que $\mathrm{X}$ é um vetor de variáveis explicativas; e $\beta$, parâmetros desconhecidos a serem estimados; e Pi probabilidade de o indivíduo i responder SIM à indagação se está disposto a pagar para usufruir dos benefícios resultantes da conservação e manutenção de uma área ambiental.

A variável Pi não é observada. Observa-se $\mathrm{Yi}=1$, quando o indivíduo responder SIM e Yi=0, quando o indivíduo responda NÃO. Dessa forma, a estimação dos parâmetros $(\beta)$, deve ser feita por Máxima Verossimilhança.

Dividindo a probabilidade de ocorrência $\left(P_{i}\right)$ pela de não-ocorrência $\left(1-P_{i}\right)$,

$\mathrm{e}^{\beta \mathrm{X}}=\frac{\mathrm{Pi}}{1-\mathrm{Pi}}$

Tomando (2.8) linear nos parâmetros, tem-se

$\beta X=\log \left(\frac{\mathrm{Pi}}{1-\mathrm{Pi}}\right)$

Reordenando

$\log \left(\frac{\mathrm{Pi}}{1-\mathrm{Pi}}\right)=\beta X$

A variável dependente, nessa regressão, é o logaritmo das chances de uma escolha. O lado esquerdo da equação (3.10) é denominado Logito e é uma função linear dos parâmetros e das variáveis explicativas. 


\subsubsection{Estimativas da Disposição a Pagar}

Para estimar a DAP considerou-se inicialmente a forma funcional linear de Hanemann (1984) e suas respectivas medidas de bem-estar, expressada pela seguinte forma funcional:

$(\Delta \mathrm{V})=\alpha_{j}+\beta \mathrm{X}, \quad \beta>0$ e $j=0,1$

Onde, os termos $\alpha_{0}, \alpha_{1}, \beta$ são funções de $S$.

Considerando a definição de diferença de utilidade tem-se:

$(\Delta \mathrm{V})=\left(\alpha_{1}-\alpha_{0}\right)-\beta \mathrm{X}$

$(\Delta \mathrm{V})=\left(\alpha_{1}+\beta(\mathrm{X}-\mathrm{DAP})-\left(\alpha_{0}+\beta \mathrm{X}\right)\right.$

$(\Delta \mathrm{V}))=\left(\alpha_{1}-\alpha_{0}+\beta \mathrm{X}-\beta \mathrm{DAP}-\beta \mathrm{X}\right)=\alpha_{1}-\alpha_{0}+\beta \mathrm{DAP}$

A função de distribuição de probabilidade é descrita por:

$\mathrm{P}_{0}=\mathrm{Fn}(\Delta \mathrm{V})=\left(1+\mathrm{e}^{-(\alpha 1-\alpha 0-\beta \mathrm{DAP})}\right)^{-1}$

$\operatorname{Pr}(\operatorname{Sim})=\left(1+\mathrm{e}^{-(\alpha 1-\alpha 0-\beta \mathrm{DAP})}\right)^{-1}$

onde $\alpha=\alpha 1-\alpha 0$ é o seguinte:

$\operatorname{Pr}(\operatorname{Sim})=\left[1+\mathrm{e}^{-(\alpha+\beta \mathrm{X})}\right]^{-1}$

$\operatorname{Pr}(\mathrm{Não})=1-\operatorname{Pr}(\operatorname{Sim})$

Para estimar a DAP, empregou-se a função logística, que pode ser expressa pela seguinte forma funcional:

$\ln \left[\frac{\operatorname{Pr} i(\operatorname{Sim})}{1-\operatorname{Pri}(\operatorname{Sim})}\right]=\beta_{1}+\beta_{2} \mathrm{DAPp}_{\mathrm{i}}+\beta_{3} \mathrm{RM}_{\mathrm{i}}+\beta_{4} \mathrm{SEX}_{\mathrm{i}}+\beta_{5} \mathrm{ID}_{\mathrm{i}}+\beta_{6} \mathrm{VP}_{\mathrm{i}}+\beta_{7} \mathrm{GR}_{\mathrm{i}}+\beta_{8} \mathrm{GESC}_{\mathrm{i}}+$ $\beta_{9} \mathrm{OCUP}_{\mathrm{i}}+\beta_{10} \mathrm{DOM}_{\mathrm{i}}+\beta_{11} \mathrm{CONPi}+\varepsilon$

Em que:

$\ln \left[\frac{\operatorname{Pr} i(\text { Sim })}{1-\operatorname{Pri}(\text { Sim })}\right]$ : é o logaritmo natural da relação entre a probabilidade de resposta afirmativa (Sim) e a probabilidade de resposta negativa $[1-\operatorname{Pr}(\operatorname{Sim})]$ à pergunta de DAP da 
i-ésima observação, assume o valor de 1 se o indivíduo entrevistado responde de forma afirmativa à questão, e caso contrário assume o valor 0 .

DAPp: representa a taxa proposta em reais como pagamento na questão de disponibilidade de pagar.

$\boldsymbol{R M i}$ : representa a renda mensal do entrevistado medido em Reais por mês.

SEXi: sexo, assume o valor de 1 se o entrevistado é masculino e 0 se é feminino.

IDi: representa a idade em anos do entrevistado.

VPi: frequência de visita ao PNB, foram tratados como uma variável dummy, sendo categorizados como usuários frequente (diariamente), médio (semanalmente), eventual (mensalmente) e raro (anualmente). foi representada por quatro variáveis dummy, $\mathrm{X}_{1}, \mathrm{X}_{2}$, $\mathrm{X}_{3}$ e $\mathrm{X}_{4}$. Sendo 1 para usuários de cada categoria e 0 para os outros.

GRi: grau de responsabilidade Ambiental de 0 a 5 .

GESCi: nível de educação mais alto alcançado pelo entrevistado. Sendo dividido em sem instrução, com ensino fundamental (primeiro grau), com ensino secundário (segunda grau), com ensino superior e pós-graduação (terceiro grau).

OCUPi: adotou-se uma escala dicotômica para ser avaliada: Empregado=1, outros. $=0$

DOMi: distância em quilômetros do local de residência até a entrada do parque.

CONPi: conhecimento do parque, assume o valor 1 se o entrevistado conhece o PNB e 0 se não conhece o PNB.

$\boldsymbol{\beta}_{\boldsymbol{i}}$ (de $i=1,2,3$ ate 11 ) são os coeficientes a serem estimados;

$\varepsilon=$ erro aleatório.

Desse modo, estimam-se os coeficientes de melhor ajuste entre os dados, assumindo o modelo teórico representado pela equação $3.17 \mathrm{ccc}$. Os coeficientes obtidos a partir da estimativa são fundamentais, uma vez que fornecem informações sobre o quanto uma mudança em cada variável explicativa afeta a máxima DAP.

As hipóteses a serem testadas são de que: é esperado um sinal negativo para o coeficiente $\beta_{2}$, indicando que a probabilidade de o indivíduo aceitar entre o valor do pagamento proposto diminui se aumentar o montante sugerido.

Para os coeficientes $\beta_{3}, \beta_{5}, \beta_{6}, \beta_{7}, \beta_{8}, \beta_{9}$ e $\beta_{11}$ espera-se que sejam positivos, o qual indica que a probabilidade de aceitar a Disposição a Pagar cresce com o aumento de tais variáveis; com maior renda o entrevistado conhece o Parque, o visita, tem um alto grau de responsabilidade ambiental, com o passar dos anos tem um maior grau de educação e 
acesso a um melhor trabalho, o valor esperado da probabilidade de responder afirmativamente à questão da disponibilidade para pagar aumenta.

Para $\beta_{4}$ e $\beta_{10}$ não definiu-se uma expectativa previa dos efeitos, pode ou não ser positivos, sendo testados em uma maneira exploratória para verificar se há, ou não, a influência na DAP do produto estudado.

É notório que a escolha de tais variáveis foi feita com base em estudos de valoração ambiental que utilizaram o MVC em contexto similar ao deste trabalho, como os de Poe et al (2002), Silva (2003), Horton et al (2003), Cirino e Lima (2008), Brugnaro (2010), Bhandari e Heshmati (2010).

\subsubsection{Método de estimação}

Utilizou-se o método de máxima verossimilhança (MV) para estimar o modelo logit. Este método estima os parâmetros do modelo por meio da maximização da função de verossimilhança em relação aos parâmetros do modelo, encontrando valores que maximizam a probabilidade de encontrar as respostas obtidas na pesquisa. Para tanto, recorreu-se ao software de estatística IBM-SPSS Statistics 20.0 para Windows.

Um modelo terá um ajuste positivo para os dados se os valores previstos por ele refletirem adequadamente os valores observados, no caso de regressão logística não há uniformidade nos testes a utilizar. (Iglesias, 2013)

Para avaliar o modelo ajustado empregou-se o teste de Wald a $5 \%$, o $\mathrm{R}^{2}$ Nagelkerke, do teste estatístico baseado em probabilidades estimadas de Hosmer e Lemeshow (estatísticas $C_{g}$ e $H_{g}$ ) para medir a qualidade de ajuste fundamentado no agrupamento de observações segundo as probabilidades estimadas pelo modelo, onde a diferença entre estes testes é a forma como as chances são agrupadas do teste Estatístico Score de Stukel $\left(\hat{S}_{S T}\right)$, propostos com o fim de determinar a bondade de um modelo de regressão logística, e o teste alicerçado em resíduos suavizados de Le Cessie e Van Houwelingen $(\widehat{T} l c)$, o qual compara o valor suavizado da variável resposta para cada indivíduo com a estimativa suavizada das probabilidades sob o modelo de regressão logística. 


\subsection{Determinação da DAP}

A disposição a pagar foi estimada a partir da média aritmética dos valores atribuídos pelos entrevistados que demostraram intenção de contribuir com algum valor pelo Parque, desconsiderando a parte da amostra não disposta a pagar, uma DAP estimada a partir da media aritmética incluindo somente os entrevistados dispostos a pagar (217); e uma DAP estimada a partir do modelo de regressão logística, estimada somente com as variáveis significativas.

Aplicou-se a técnica de estatística de bootstrapping, para determinar os intervalos de confiança da DAP estimada com a média aritmética. O bootstrapping foi efetuado no software de estatística IBM-SPSS Statistics 20.0 para Windows, com um número de 5000 interações para determinação do desvio-padrão associado à DAP com um nível de 95\% para a análise.

\subsection{Fonte de Dados}

O tamanho da amostra (n). Estimou-se com base na equação de Rabolini (2009), utilizada quando a população está delimitada e é conhecido o total que a integra.

$n=\frac{Z^{2} \alpha / 2 \cdot p \cdot q \cdot N}{e^{2}(N-1)+Z^{2} \cdot p \cdot q}$

Em que $n$ é o tamanho da amostra; $Z^{2}$ estimativa do nível de confiança escolhido, expresso em número de desvios-padrão; $p$, probabilidade de o fenômeno ocorrer; $q$, probabilidade complementar; $N$, o tamanho da população; $e^{2}$, erro máximo permitido.

Para determinação da amostra da pesquisa, fora adotado dois desvios-padrão como nível de confiança. Para a probabilidade de ocorrência do evento " $p$ ", adotou-se o valor máximo 0,5 , já que essa estimativa não foi estabelecida previamente; consequentemente, “ $q$ " é igual a 0,5 .

A fronteira no espaço deste estudo compreendera a população objetivo da fronteira política ou legal das 31 Regiões Administrativas do Distrito Federal, que somam 2.570.160 habitantes de acordo com o IBGE - 2014. A escolha foi feita devido à sua proximidade geográfica e ligação com o Parque Nacional, é uma escolha conservadora porque os potenciais usuários do Parque não se limitam apenas aos limites geográficos estabelecidos. Nomeiam-se usuários os beneficiados pelos bens e serviços fornecidos pelas 
UCs: o governo, o órgão gestor, pesquisadores, visitantes, a comunidade em geral e as partes interessadas na conservação.

Os dados para este trabalho foram procedentes de fonte primária, coletados por meio de entrevistas pessoais. Empregou-se um questionário estruturado, que foi aplicado durante os meses de fevereiro, março e abril do ano 2014. Detalhes da elaboração e da aplicação do questionário são encontrados no ANEXO 01. 


\section{4 - RESULTADOS E DISCUSSÕES}

\subsection{Perfil descritivo da amostra}

Inicialmente a amostra calculada foi de 385 entrevistas, no entanto, ao serem adicionados os $10 \%$ de margem de segurança, obtiveram-se uma amostra de 425 pessoas visando perdas de questionários aplicados, para determinar a sua disposição a pagar pelo PNB. No quadro 4.1 são apresentados os valores utilizados na equação 3.18.

$$
n=\frac{\frac{Z^{2} \alpha}{2} \cdot p \cdot q \cdot N}{e^{2}(N-1)+Z^{2} \cdot p \cdot q}
$$

Quadro 4.1: estimativa da amostra

\begin{tabular}{|l|c|}
\hline Descrição & Valores \\
\hline Probabilidade da característica pesquisada(p) & 95 \\
\hline $\mathrm{P}=$ Probabilidade de ocorrência & 0,5 \\
\hline $\mathrm{Q}=$ Probabilidade de não ocorrência & 0,5 \\
\hline $\mathrm{Z}=$ Nível de confiança 95\% & 1,96 \\
\hline $\mathrm{N}=$ Tamanho da população & 2.570 .160 \\
\hline e = Erro padrão 5\% & 0,05 \\
\hline $\mathrm{n}=$ Tamanho da amostra & $\mathbf{3 8 5}$ \\
\hline
\end{tabular}

\subsubsection{Características socioeconômicas}

Do total de entrevistados, 42,9\% tinham como local de residência o Plano Piloto (a distância do Parque é de $10 \mathrm{Km}$ ), enquanto que 57,1 \% de outros locais do Distrito Federal (22 regiões administrativas). Pelos locais onde foram coletados os dados, o Plano Piloto, como esperado, apresentou maior número de residentes. As demais regiões apresentaram comportamento esperado e podem ser visualizadas na Tabela 4.1, que especifica a DAP por regiões administrativas. 
Tabela 4.1: DAP versus regiões administrativas do Distrito Federal.

\begin{tabular}{lccc|c|c|c|c|c|c|c|c|}
\hline \multirow{2}{*}{ DOMICÍLIO } & \multicolumn{10}{|c|}{ DAP_final (R\$) } & Total \\
\cline { 2 - 13 } & 0,00 & 1,00 & 3,00 & 5,00 & 10,00 & 12,00 & 15,00 & 20,00 & 25,00 & 30,00 & \\
\hline Plano piloto & 47 & 4 & 12 & 4 & 34 & 10 & 11 & 20 & 17 & 6 & $\mathbf{1 6 5}$ \\
\hline Brazlândia & 3 & 1 & 0 & 0 & 0 & 0 & 0 & 1 & 0 & 0 & $\mathbf{5}$ \\
\hline Candangolândia & 3 & 2 & 0 & 0 & 0 & 0 & 0 & 0 & 0 & 0 & $\mathbf{5}$ \\
\hline Ceilândia & 12 & 1 & 1 & 0 & 0 & 0 & 0 & 0 & 0 & 0 & $\mathbf{1 4}$ \\
\hline Cruzeiro & 16 & 0 & 3 & 0 & 4 & 0 & 2 & 4 & 0 & 0 & $\mathbf{2 9}$ \\
\hline Gama & 16 & 2 & 6 & 0 & 4 & 1 & 0 & 1 & 1 & 0 & $\mathbf{3 1}$ \\
\hline Guará & 8 & 0 & 3 & 1 & 5 & 0 & 0 & 0 & 0 & 0 & $\mathbf{1 7}$ \\
\hline Lago Norte & 5 & 0 & 1 & 1 & 1 & 0 & 2 & 1 & 9 & 2 & $\mathbf{2 2}$ \\
\hline Núcleo Bandeirante & 4 & 0 & 3 & 1 & 1 & 0 & 0 & 0 & 0 & 0 & $\mathbf{9}$ \\
\hline Paranoá & 4 & 0 & 0 & 1 & 0 & 0 & 0 & 0 & 0 & 0 & $\mathbf{5}$ \\
\hline Planaltina & 16 & 0 & 0 & 0 & 1 & 0 & 0 & 0 & 0 & 0 & $\mathbf{1 7}$ \\
\hline Recanto das Emas & 6 & 0 & 0 & 0 & 0 & 1 & 0 & 0 & 0 & 0 & $\mathbf{7}$ \\
\hline Riacho Fundo & 2 & 1 & 2 & 0 & 1 & 0 & 0 & 0 & 1 & 0 & $\mathbf{7}$ \\
\hline Samambaia & 4 & 0 & 0 & 0 & 0 & 0 & 0 & 0 & 0 & 0 & $\mathbf{4}$ \\
\hline Santa Maria & 2 & 1 & 0 & 0 & 0 & 0 & 0 & 0 & 0 & 0 & $\mathbf{3}$ \\
\hline São Sebastião & 7 & 1 & 1 & 0 & 0 & 0 & 0 & 0 & 0 & 0 & $\mathbf{9}$ \\
\hline Sobradinho & 3 & 0 & 3 & 1 & 2 & 2 & 0 & 1 & 1 & 0 & $\mathbf{1 3}$ \\
\hline Taguatinga & 4 & 1 & 2 & 0 & 1 & 1 & 1 & 0 & 0 & 0 & $\mathbf{1 0}$ \\
\hline Aguas Claras & 1 & 0 & 0 & 0 & 0 & 0 & 1 & 0 & 0 & 0 & $\mathbf{2}$ \\
\hline Varjão & 3 & 0 & 0 & 0 & 0 & 0 & 0 & 0 & 0 & 0 & $\mathbf{3}$ \\
\hline Lago Sul & 0 & 0 & 0 & 0 & 1 & 0 & 0 & 1 & 0 & 1 & $\mathbf{3}$ \\
\hline Itapoã & 1 & 0 & 0 & 0 & 0 & 0 & 0 & 1 & 0 & 0 & $\mathbf{2}$ \\
\hline Vicente Pires & 1 & 0 & 0 & 0 & 1 & 0 & 1 & 0 & 0 & 0 & $\mathbf{3}$ \\
\hline Total & $\mathbf{1 6 8}$ & $\mathbf{1 4}$ & $\mathbf{3 7}$ & $\mathbf{9}$ & $\mathbf{5 6}$ & $\mathbf{1 5}$ & $\mathbf{1 8}$ & $\mathbf{3 0}$ & $\mathbf{2 9}$ & $\mathbf{9}$ & $\mathbf{3 8 5}$ \\
\hline
\end{tabular}

Constatou-se que $48,1 \%$ das pessoas entrevistadas eram do sexo feminino e $51,9 \%$ masculino (figura 4.1). A faixa etária dominante foi de um público com idade variando entre 24 a 44 anos (40,9\% da amostra). (figura 4.2) 

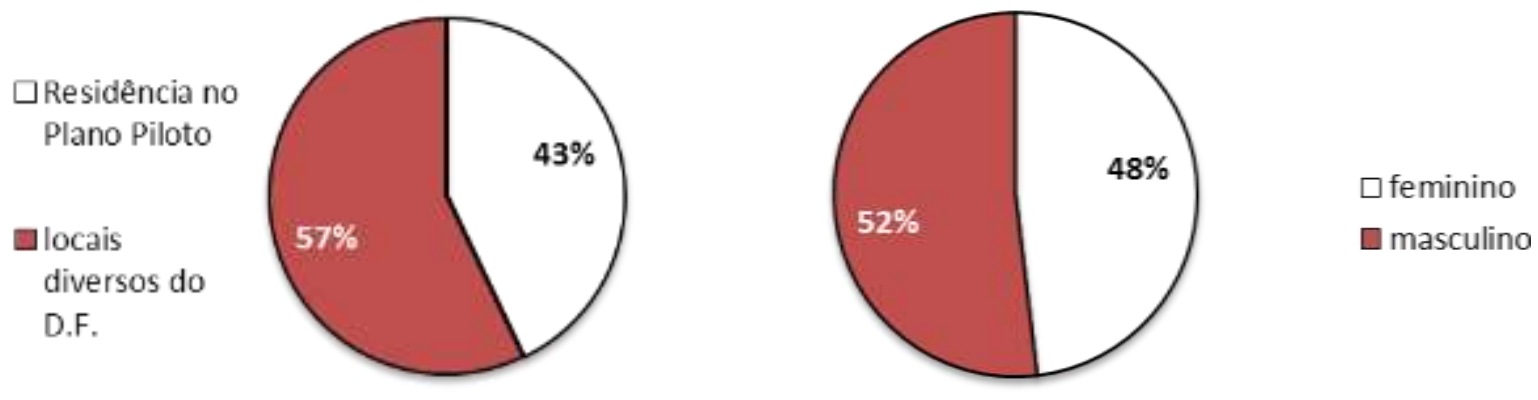

Figura 4.1: características socioeconômicas dos entrevistados.

Distribuição percentual da amostra em relação a idade

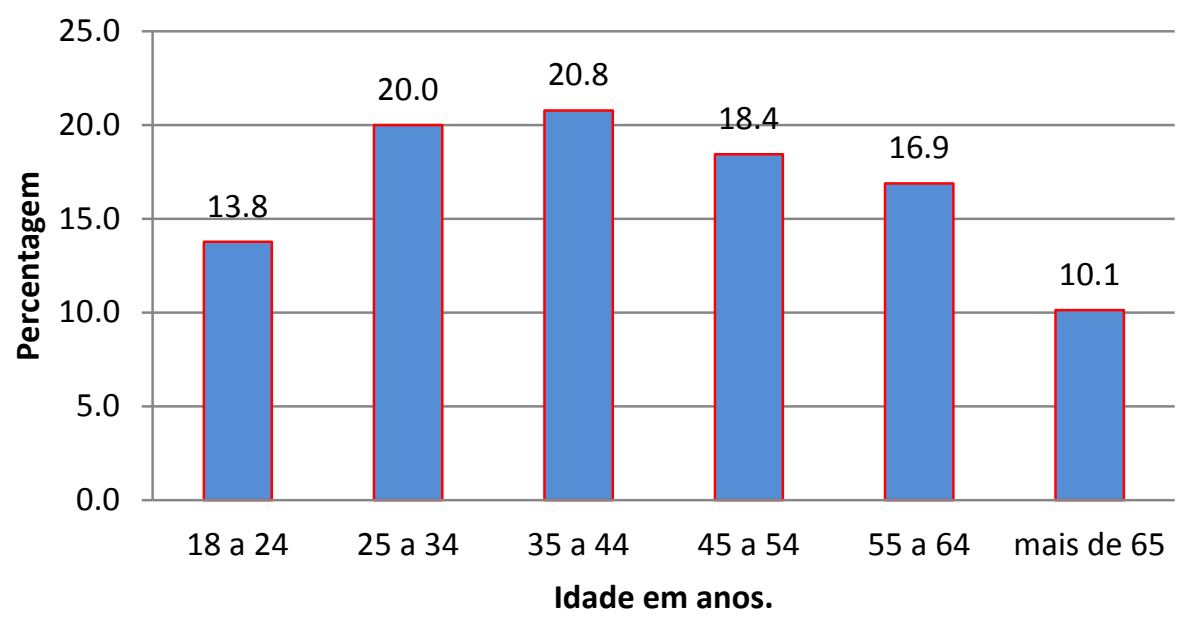

Figura 4.2 - Distribuição percentual da amostra em relação a idade.

A Tabela 4.2 possibilita maiores inferências acerca da relação existente entre educação e DAP, indica que a maioria possuía nível educacional superior, possibilitando maiores inferências acerca da relação existente entre educação e DAP. A disposição a pagar versus o nível de escolaridade informa que os entrevistados com Pós-graduação possuíam a maior propensão a contribuir para a manutenção e conservação do Parque Nacional de Brasília, pois $81.13 \%$ dos entrevistados se dispuseram a contribuir. Quando observados os entrevistados com nível superior, verifica-se que $64,7 \%$ se dispuseram a 
fazê-lo. A priori, fica claro que não é possível afirmar que quanto mais instruído, maior é a conscientização ambiental.

Tabela 4.2: DAP versus o nível de escolaridade.

\begin{tabular}{|c|c|c|c|c|c|c|c|c|c|c|c|}
\hline \multirow{2}{*}{ ESCOLARIDADE } & \multicolumn{10}{|c|}{ DAP_final } & \multirow{2}{*}{ Total } \\
\hline & 00 & 1,00 & 3,00 & 5,00 & 10,00 & 12,00 & 15,00 & 20,00 & 25,00 & 30,00 & \\
\hline Primeiro grau completo & 1 & 0 & 0 & 0 & 0 & 0 & 0 & 0 & 0 & 0 & 1 \\
\hline Primeiro grau incompleto & 1 & 0 & 0 & 0 & 0 & 0 & 0 & 0 & 0 & 0 & 1 \\
\hline Segundo grau completo & 42 & 5 & 10 & 1 & 8 & 4 & 1 & 3 & 0 & 0 & 74 \\
\hline Segundo grau incompleto & 20 & 2 & 1 & 2 & 2 & 0 & 0 & 0 & 1 & 0 & 28 \\
\hline Nivel superior completo & 62 & 1 & 18 & 4 & 27 & 8 & 12 & 20 & 18 & 4 & 174 \\
\hline Nivel superior incompleto & 19 & 3 & 2 & 0 & 7 & 1 & 0 & 1 & 1 & 1 & 35 \\
\hline Pós-graduação & 10 & 1 & 6 & 1 & 10 & 2 & 5 & 6 & 8 & 4 & 53 \\
\hline Técnico & 11 & 1 & 0 & 1 & 1 & 0 & 0 & 0 & 1 & 0 & 15 \\
\hline Sem instrução & 2 & 1 & 0 & 0 & 1 & 0 & 0 & 0 & 0 & 0 & 4 \\
\hline Total & 168 & 14 & 37 & 9 & 56 & 15 & 18 & 30 & 29 & 9 & 385 \\
\hline
\end{tabular}

O grau de instrução dos entrevistados contabilizou que 45,2\% dos entrevistados possuem nível superior completo, 9,1\% nível superior incompleto, 7,3\% segundo grau incompleto, 19,2 \% segundo grau completo e 13,8\% são pós-graduados, 3,9\% nível técnico. (Figura 4.3).

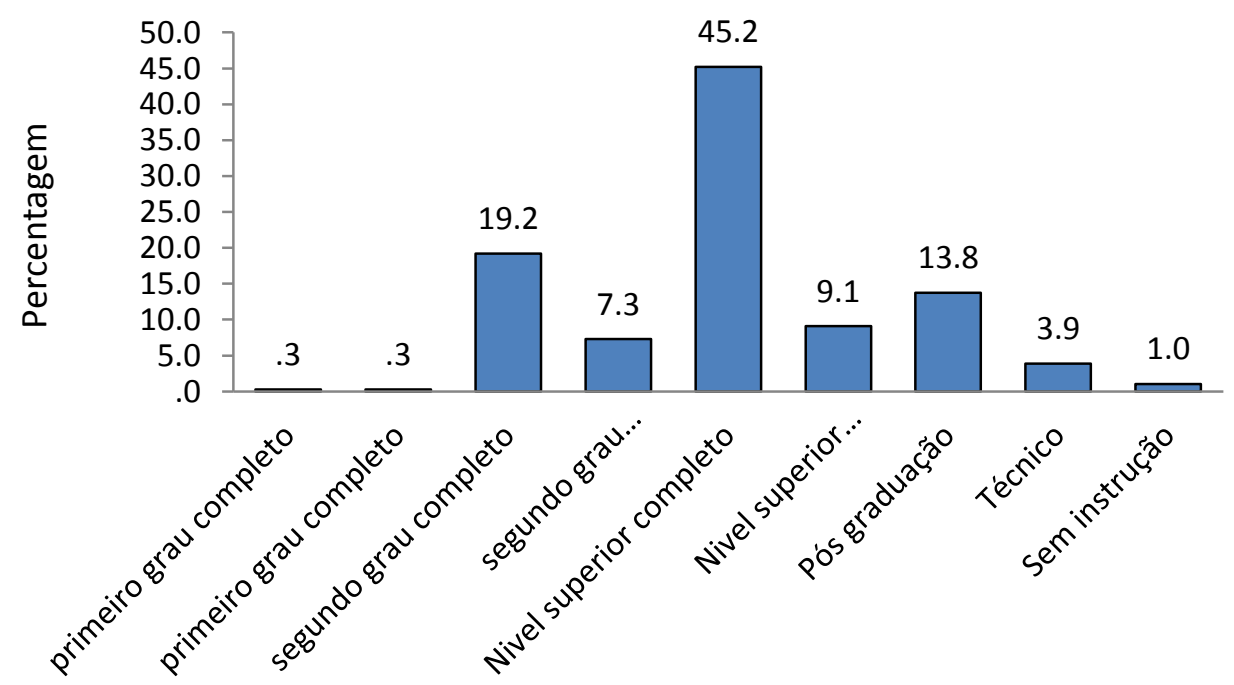

Figura 4.3: escolaridade da população amostrada.

Dos 126 empregados 69\% tem nível superior completo; dos 18 empresários, 50\% tem nível superior completo; dos 69 estudantes o 56,6\% tem nível superior completo e $30,4 \%$ tem pôs graduação; dos 82 independentes o $43,9 \%$ tem segundo grau incompleto e 
23.2\% tem nível superior completo; dos 14 professionais independentes o 92,9\% tem nível superior completo; dos 37 desempregados $54,1 \%$ tem nível superior completo e dos 22 entrevistados com outras atividades, o $50 \%$ tem segundo grau completo.

A faixa de renda amostrada retratou uma renda média dos entrevistados de $\mathrm{R} \$$ 4.912,54, o resultado é similar a Renda domiciliar média mensal no DF: R\$ 5.015,04. Conforme o Codeplan-PDAD-DF, (2014). No quadro 4.2 apresenta-se a distribuição da renda dos entrevistados.

Quadro 4.2: distribuição da renda declarada pelas pessoas entrevistadas:

\begin{tabular}{|ccc|}
\hline Faixa em R\$/ mês & Frequência & Porcentagem \\
\hline $0-900$ & 20 & 5,2 \\
\hline $901-1800$ & 49 & 12,7 \\
\hline $1801-2700$ & 65 & 16,9 \\
\hline $2.701-3.600$ & 46 & 11,9 \\
\hline $3.601-4.500$ & 54 & 14,0 \\
\hline $4.501-5.400$ & 49 & 12,7 \\
\hline $5.401-6.300$ & 29 & 7,5 \\
\hline $6.301-7.200$ & 34 & 8,8 \\
\hline$>$ A 7.201 & 39 & 10,1 \\
\hline Total & $\mathbf{3 8 5}$ & $\mathbf{1 0 0 , 0}$ \\
\hline
\end{tabular}

Quando analisada a relação existente entre a DAP e o nível de renda, verifica-se que o comportamento de pagar uma DAP alta é diretamente proporcional ao nível de renda, verifica-se que no nível de > a $\mathrm{R} \$ 7.201,00$ estava concentrada a maior proporção de contribuintes, visto que $76.92 \%$ dos entrevistados contribuiriam para o PNB. Esse comportamento é seguido com os maiores níveis de renda e vai decrescendo até os limites inferiores.

De acordo com o resultado pode-se inferir acerca da presença de viés do ponto inicial no qual o entrevistado opta pelo primeiro valor oferecido por considerá-lo o valor correto. 
A figura 4.4 possibilitaram maiores inferências acerca dessa situação

\section{Comportamento da DAP vs Renda}

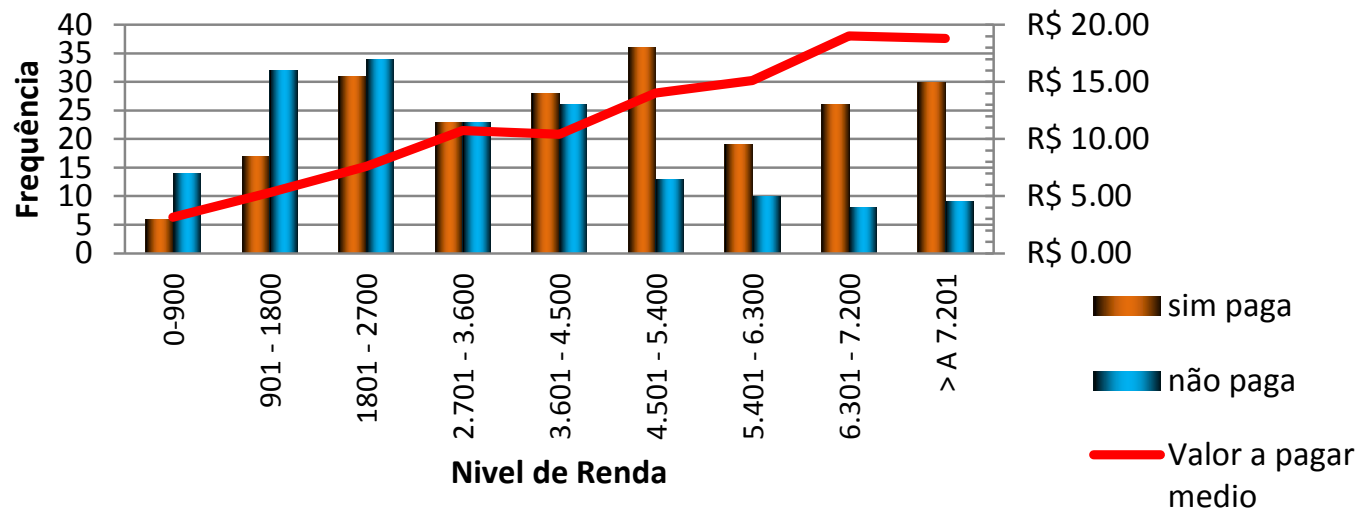

Figura 4.4: Comportamento da DAP e nível de renda.

Em relação ao comportamento de visitas ao PNB para as pessoas que conheciam o PNB (299 indivíduos que representa o 77,6\% do total da amostra) apresenta 1\% diariamente; 3,7\% semanalmente; 35,5\% mensalmente e 59,9\% quase nunca (Figura 4.5).

\section{Comportamento de Visitas ao PNB}

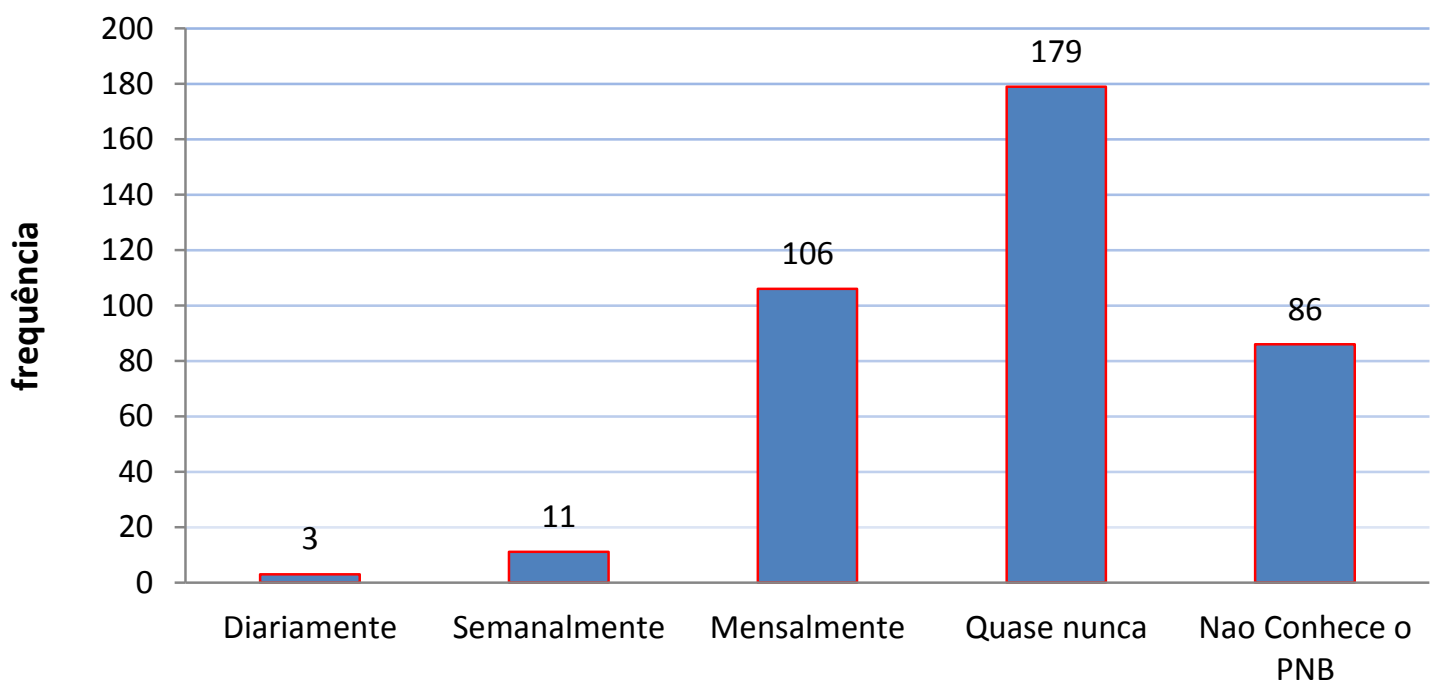

Figura 4.5: comportamento de frequência de visitas ao PNB. 


\subsection{Análise da DAP e dos VIESES}

\subsubsection{Votos de protesto}

Quanto à disposição a pagar, quantificou-se que 56,4\% dos entrevistados pagariam alguma quantia pelo bem público. A taxa geral de rejeição é alta, observa-se que 43,6\% dos entrevistados não se dispuseram a contribuir com nenhum valor para manutenção e conservação do PNB.

Segundo o Painel NOAA (1993), o entrevistado pode não querer apoiar pela incredulidade na capacidade que pode ter um indivíduo para influir em um resultado social, político ou econômico; também pela desconfiança na capacidade do governo para aplicar a ação proposta, prover bens públicos de maneira eficaz; considerar que outros deveriam ser os responsáveis pela questão proposta, como os poluidores ou o governo com seus impostos já pagos e recolhidos, desestimula as pessoas para revelar seus verdadeiros valores.

A relação entre viés e nível de instrução mostrou um resultado extraordinário, visto que os entrevistados pelo qual não se dispuseram a pagar apresentavam nível superior $36,90 \%$ e secundário $25,59 \%$. Juntos, esses dois níveis representam $62,49 \%$ do total de viés presentes na pesquisa. O resultado para o nível de instrução vs Protestos que estiveram de acordo com Da Silva (2003).

Alguns dos questionados expressavam denúncias de corrupção no governo do país e má gerência dos recursos públicos. Nessa pergunta a pessoa poderia citar mais de uma razão. Diversos motivos explicam o não pagamento da contribuição, no estudo, as respostas a esta pergunta foram colocadas em oito categorias (ver quadro 4.3).

Quadro 4.3: Motivos para explicar a não DAP.

\begin{tabular}{|l|c|c|}
\hline \multirow{2}{*}{ Motivos } & \multicolumn{2}{c|}{ Respostas } \\
\cline { 2 - 3 } & Frequência & Porcentagem \\
\hline 1 Eu não posso permitir isso & 54 & 10,7 \\
\hline 2 Eu não me importo com a melhoria da qualidade ambiental & 32 & 6,3 \\
\hline 3 Em proteger o parque não merece gastar dinheiro & 45 & 8,9 \\
\hline 4 É de responsabilidade da indústria & 17 & 3,4 \\
\hline 5 Já paga impostos suficientes & 99 & 19,6 \\
\hline 6 Estou satisfeito coma situação existente & 80 & 15,9 \\
\hline 7 Isso não ajudaria a proteger mais & 41 & 8,1 \\
\hline 8 É responsabilidade do governo & 136 & 27 \\
\hline
\end{tabular}


Os motivos 1, 2, 3, 6 apresentados no quadro 4.3, são motivos legítimos para recusarem-se a pagar, As quatro declarações restantes 4, 5, 7, 8 são crenças de protesto. Os motivos 4 e 8 argumentam que o investimento financeiro na proteção do meio ambiente deve ser da responsabilidade de outra pessoa. A declaração 4, em que a responsabilidade é limitada a apenas poluidores. A declaração 5 é uma objeção clássica ao pagamento veículo selecionado (percepção de mais impostos), um motivo comum para o protesto. A declaração 7 expressa ceticismo sobre a eficácia da política proposta, o qual se manifesta em desacordo.

Das razões citadas pelo total dos entrevistados que não contribuem para o plano proposto, $27 \%$ disseram que não estavam dispostos a pagar, porque é a responsabilidade do estado, e do total de respostas múltiplas (3 opções: 504 respostas) das pessoas que responderam que não contribuem, o $81 \%$ assinalaram a opção que é responsabilidade do governo, seguida por já paga suficientes impostos (19.6\%), o 15,9\% disseram que estavam satisfeitos com a situação existente, 10,7\%, porque eles não podem permitir serem cobrado por esse programa e conservação e manutenção do Parque.

Em relação aos motivos associados pelos entrevistados que não apresentaram disposição a pagar observou-se que a maioria das respostas alegou que isso é responsabilidade do Governo e que já pagam muitos impostos, semelhante aos resultados de Adans, (2007), também no Brasil, teve um número elevado de votos de protesto $(38,5 \%)$, onde se acredita que os indivíduos agiram em protesto contra a atitude do governo em relação à preservação do meio ambiente ou simplesmente se opor a qualquer aumento de impostos para qualquer finalidade. $\mathrm{O}$ governo deveria direcionar os impostos para a melhoria e manutenção do bem.

Os resultados de Dziegielewska e Mendelsohn (2007) acreditam que o alto número de protestos no estudo em um país com uma história comunista foi associada a grandes expectativas de ter um grande conjunto de bens providos pelo governo a custo zero. Finalmente, isso criou uma falta de confiança na capacidade de um governo de prover públicos de uma maneira efetiva e isso desencorajou as pessoas a revelarem seus valores verdadeiros. 


\subsection{Determinantes da Disposição a Pagar}

Foram validados a partir do ponto de vista teórico os resultados de retorno com a aplicação de um modelo logit com todas as variáveis acima descritas no modelo geral, as variáveis que não foram significativas não são apresentados na tabela e, por conseguinte, as únicas variáveis significativas são aquelas apresentadas.

As variáveis consideradas, e os seus valores médios são mostrados na tabela 4.3.

Tabela 4.3: Valores das variáveis significativas*
\begin{tabular}{|lc|}
\hline Resposta Sim & $56,10 \%$ \\
\hline Resposta Não & $43,90 \%$ \\
\hline Renda Mensal & 4,89 de 9 \\
\hline Idade & 3,35 de 6 \\
\hline Conhece o Parque & $76,90 \%$ \\
\hline Ocupação & $32,70 \%$ \\
\hline
\end{tabular}

*Elaborado com base nas variáveis significativas utilizadas no modelo.

Foi considerado como variável dependente a DAP em função das outras variáveis, os parâmetros estimados com o modelo Logit para a probabilidade da disposição a pagar pela Manutenção e Conservação do PNB, As influências dessas variáveis ocorreram no sentido esperado e ao nível de significância de 5\%. são apresentados somente os resultados da regressão os coeficientes estatisticamente significativos.

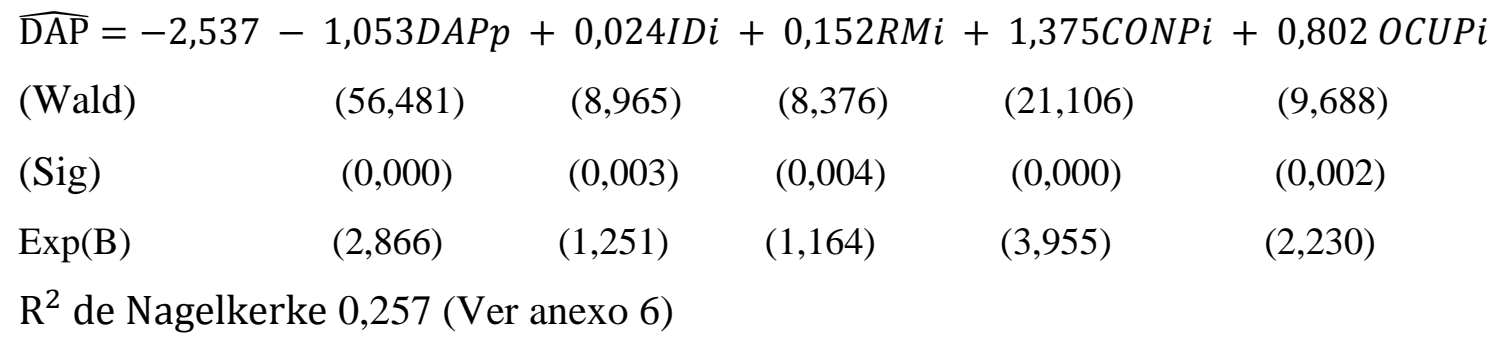

No resultado anterior, o $\mathrm{R}^{2}$ de Nagelkerke é uma transformação de $\mathrm{R}^{2}$ Cox e Snell, que permite analisar a variabilidade dos dados explicada pelo modelo. Neste caso, o modelo explica $25,7 \%$ da variabilidade. $\mathrm{O}$ valor pode ser considerado baixo, indicando uma dificuldade de explicar a DAP com as variáveis consideradas. A qualidade do ajuste é de avaliação secundária, pois o objetivo do modelo não foi prever a variável dependente, se 
não avaliar o efeito de cada variável explicativa significativa estatisticamente. (GUJARATI, 2010).

Como pode ser visto na tabela, as variáveis explicativas significativas estatisticamente são consistentes com a teoria econômica. Em primeiro lugar, a variável DAP proposta tem um coeficiente negativo, ou seja, há uma relação inversa entre o DAP e o preço sugerido, porque quanto maior é a quantidade proposta paga, há menor probabilidade de responder afirmativamente à questão de disposição a pagar dos entrevistados pelo cenário de mercado hipotético.

Em segundo lugar, a decisão do indivíduo depende de sua restrição orçamentária determinada pela renda, em que quanto maior a renda, maior a vontade de pagar, é teoricamente correto, pois quanto maior a renda do consumidor, maior em termos absolutos, será o seu excedente. Se o sinal é oposto à validade teórica do exercício da VC seria questionada. (BISHOP et al 1995, HOYOS, 2010).

A ocupação é outro fator que influencia positivamente a decisão da DAP, vai pagar mais para apoiar os recursos naturais se a pessoa tem uma renda segura, sendo empregado.

O modelo sugere que o conhecimento do bem ambiental está positivamente relacionado com a disposição a pagar dos indivíduos.

Por outro lado, mesmo sendo testada de maneira exploratória, a idade também está relacionada positivamente a disposição a pagar. A idade serve de experiência de aprendizagem, o que pode influir nas decisões, o que faz sentido com o valor de herança ou valor de opção que está relacionado com a disposição do indivíduo em garantir a preservação do ambiente para benefício de seus descendentes nas futuras gerações, o que confirmaria a teoria do altruísmo intergeracional, (Pessoas que se importam com sua descendência) que pode ser pelo prazer de dar ou pelo altruísmo paternalista, a maior idade há maior interesse em deixar um legado em termos de qualidade ambiental para as gerações mais jovens. (PADILLA et al,2002; COTTRELL, 2003)

Os valores calculados das DAP podem ser somados pelos valores médios ou com o modelo logit. A regressão foi utilizada na estimação da Disposição a pagar, referente à manutenção e conservação do PNB, pela substituição das médias (medianas) constantes, e multiplicando-as por seus respectivos parâmetros estimados pelo modelo estatístico de escolha binária, somente com as variáveis significativas. Na regressão com somente os valores significativos e a eliminação dos não dispostos a pagar, que o valor de Disposição a 
Pagar pela manutenção e conservação do PBN indica que o valor médio calculado em função dos coeficientes do modelo estatístico é um valor aproximado de $\mathrm{R} \$ 9,31$ mensal indicando uma proxy do preço que o indivíduo está disposto a pagar pela conservação e manutenção do PNB.

Conforme a tabela 4.4 determinou-se a média aritmética utilizando o bootstraping para criar o desvio-padrão e um intervalo de confiança para a DAP, importante para uma avaliação de sua precisão estatística e possibilita uma avaliação mais criteriosa por parte dos tomadores de decisão. Determinou-se um valor calculado da DAP média R $\$ 12,78$ mensal e um intervalo de confiança que permita efetuar inferências sobre a DAP.

Tabela 4.4 - Estatísticas do bootstrapping na DAP do PNB.

\begin{tabular}{|l|c|}
\hline Especificações & *Valores em R\$ \\
\hline $\mathrm{N}$ & 217 \\
\hline Média & $12,7880^{*}$ \\
\hline Inferior & $11,7018^{*}$ \\
\hline Superior & $13,9263^{*}$ \\
\hline Desv. típ. & 0,29051 \\
\hline
\end{tabular}

Sendo assim, os resultados obtidos por esta pesquisa indicam uma concordância com a literatura revisada, pois estas não ultrapassaram os valores vistos nos trabalhos anteriores, $\mathrm{O}$ valor médio encontrado dos dispostos a pagar foi de $\mathrm{R} \$ 9.31$ (nove reais e trinta e um centavos) por mês. Em dois estudos similares no parque Nacional de Brasília, aplicando o MVC encontraram resultados DAP média mensal de $\mathrm{R} \$ 7,88$ e o VET do Parque foi de $\mathrm{R} \$ 28.771 .819,76$ anuais. (CENARGEM/EMBRAPA, 1999). Em outro estudo foi encontrado uma disposição a Pagar de $\mathrm{R} \$ 6,62$ por usuário/mês representando por ano R\$1.769.367,10. (MOTA, 2000)

Estes resultados mostram que a população do Distrito Federal está propensa a pagar, independente da amostra considerada.

\subsubsection{Ajuste Do Modelo}

Os resultados para o estatístico de bondade de ajuste de Hosmer-Lemeshow foram: $\mathrm{Cg}=\mathrm{p}$-valor $=0,2358 ;$ Chi-quadrado $=10,4344$.

$\mathrm{Hg}=\mathrm{p}$-valor $=0,7143 ;$ Chi-quadrado $=5,3983$ 
Os resultados para o contraste de Stukel: $\mathrm{p}$-valor $=0,1139$ e para o estatístico de Le Cessie e Van Houwelingen: $\mathrm{p}$ - valor = 0,07414.

Contudo, alinhado com Iglesias (2013), um Chi-quadrado não significativo indica que os dados se encaixam bem com o modelo, se deseja que o p-valor seja maior que o ponto de corte estabelecido $(\alpha=0,05)$ para indicar bom ajuste. Com um p-valor $<0.05$ rejeita-se o modelo e um > 0.05 indicam que o ajuste do modelo é bom.

\subsubsection{Análise de Multicolinearidade}

De acordo com os resultados (Vide os resultados no ANEXO 9 ) existem relações entre pares de variáveis p-valor do teste do qui-quadrado de Pearson $<0,05$ ), indicando que pode haver problemas de multicolinealidade, no entanto, em alguns casos, nenhuma prova é suficientemente confiável, pois há frequências esperadas muito pequenas e algumas variáveis possuem muitas categorias, o que pode influenciar o resultado do teste e levar à rejeição da hipótese nula quando ela realmente não está certa. Além disso, segundo o tratamento dado às variáveis dentro do modelo não seria muito decisivo assumir esse resultado, no entanto, é deixada a título de informação.

\subsection{Valor Econômico Total (VET)}

Os resultados obtidos com a questão relativa às categorias de importância dos benefícios proporcionados pelo PNB à sociedade (ver anexo 5), foi possível sintetizar no Quadro 4.4 o valor qualitativo dos benefícios associados ao uso direto, indireto, de opção e de existencia do PNB. 
Quadro 4.4 -Valores Econômicos dos Bens e Serviços proporcionados pelo PNB.

\begin{tabular}{|c|c|c|c|}
\hline \multicolumn{3}{|c|}{ Valor De Uso } & Valor de Não-Uso \\
\hline Valor de Uso Direto & Valor de Uso Indireto & Valor de Opção & Valor de Existência \\
\hline \multicolumn{4}{|c|}{ Categorias ou Serviços Relacionados com o PNB. } \\
\hline $\begin{array}{l}\text {-Lazer, Recreação, } \\
\text { Turismo. } \\
\text {-Agua (quantidade e } \\
\text { qualidade), Proteção da } \\
\text { bacia e prevenção da } \\
\text { erosão do solo. } \\
\text {-Contato com a } \\
\text { Natureza, zonas } \\
\text { verdes. } \\
\text {-Insumos para a } \\
\text { produção. }\end{array}$ & $\begin{array}{l}\text {-Ambiental, } \\
\text { Ecológico, Recursos } \\
\text { Genéticos e } \\
\text { Biodiversidade. } \\
\text {-Regulação do Clima- } \\
\text { assimilação de } \\
\text { Poluentes. } \\
\text {-Reservatórios de } \\
\text { carbono. Ciclo de } \\
\text { Nutrientes. }\end{array}$ & $\begin{array}{l}\text {-Educação Cientifica e } \\
\text { Institucional } \\
\text {-Valor futuro da } \\
\text { informação. }\end{array}$ & $\begin{array}{l}\text {-Saúde e Qualidade de vida. } \\
\text {-Emocional, Inspiração, } \\
\text { Estético. } \\
\text {-Herança. } \\
\text {-Segurança. }\end{array}$ \\
\hline \multicolumn{4}{|c|}{ Percentual da apropriação qualitativa do PNB. } \\
\hline $62,7 \%$ & $24,8 \%$ & $5,9 \%$ & $6.5 \%$ \\
\hline
\end{tabular}

De acordo as respostas apresentadas no Quadro 4.4, a DAP encontrada está, maiormente relacionada ao valor de uso $(62,7 \%)$, o que torna o VET subdimensionado. Pode ser que se tenha ocorrência do viés parte-todo, posto que as pessoas pudessem ter dificuldades de separar seu valor de uso diante de um possível valor de existência.

Outro viés que pode ter interferido nas respostas é o Viés do entrevistador e do entrevistado, pelo fato de que o entrevistador é de outro país pode influenciar as respostas, já que então a pessoa que está sendo entrevistada pode sentir-se inibida a declarar um lance de baixo valor. A pesar de tentar minimizar este tipo de problema usando pesquisas adotando respostas já preparadas a serem escolhidas pelos entrevistados (escolha dicotômica).

Em relação ao veículo de pagamento, como não é fácil de burlar por está acompanhado com um serviço público, pode ser um fato para o protesto das pessoas e, portanto, afetar a magnitude dos valores respondidos.

Outro viés que pode ser percebido é o estratégico, onde é abordada a percepção dos entrevistados acerca da obrigação de pagamento e às suas perspectivas quanto à provisão do bem em questão. Se o entrevistado tem a sensação de que realmente pagará o 
valor citado, responderá valores abaixo de suas verdadeiras preferências. Além disso, como o usufruto dos bens ambientais, na maioria dos casos, não está vinculado ao pagamento e partindo do pressuposto que outros estarão dispostos a pagar o suficiente para garantir a provisão do bem, tendem a ter um comportamento de carona.

Tais preferências de comportamento das pessoas que não estiveram dispostos a pagar poderiam ser explicadas com o conceito de "free riders", ou seja, pessoas que se beneficiam do bem sem contribuir para a seu financiamento, devido às características dos bens públicos, os indivíduos preferem não contribuir com nenhuma quantia para a provisão desses bens, atuando, assim, como "caronas". Pode estar ligado ao conceito de viés estratégico, ao invés de ser um viés ligado apenas ao caráter hipotético. Este comportamento provoca subestimação dos benefícios para mensurar o valor do bem público a partir dos consumidores. Poderia desaparecer essa deficiência do mercado se financiassem o bem em questão via impostos, assim seria financiado por todos. Cabe ao Governo assumir tal papel, tornando-se uma questão de política pública, porque com aqueles indivíduos caronas, o Governo não possui uma relação dos benefícios que a oferta de determinado bem público geraria para uma sociedade.

Outra forma de evitar o comportamento de carona pode ser por meio de uma garantia de satisfação para aumentar a confiança dos entrevistados, caso não atinja o nível proposto.

Neste estudo foi obtido um valor significativo, que demonstra de maneira geral, a população de interesse, revelando uma contribuição significativa para o bem estar humano e reconhecendo o PNB como um patrimônio natural importante para a riqueza nacional. A maioria dos habitantes (56\%) demanda a preservação desse ativo ambiental, mesmo que fosse necessário abrir mão de recursos financeiros próprios para dar suporte ao programa ambiental. A disposição a pagar de um indivíduo por um bem público é também um reflexo de uma postura política pelas vias propostas pelo projeto.

Nesse sentido, o Governo deve elaborar projetos e políticas públicas voltadas para a preservação e utilização sustentável do bem. Para que essas ações sejam eficientes é necessário obter estimativas dos benefícios sociais gerados, cujos valores possam ser comparados com os custos de tais ações. 


\section{CONCLUSÕES}

Há uma disponibilidade a pagar pela conservação, preservação e a manutenção do Parque Nacional de Brasília, quantificou-se que 56.4\% dos entrevistados pagariam, isso revelou uma contribuição significativa do Parque para o bem estar humano o que poderia ser interpretado como uma iniciativa conservacionista e um comportamento de auto prevenção no intuito de não sentir-se afetados por problemas ambientais, assumindo o gasto para manter a qualidade e quantidade dos bens e serviços proporcionados pelo PNB.

Ainda que o Parque seja um bem público, a disposição a pagar média por mês é de $\mathrm{R} \$ 9,31$, estando em consonância com resultados de estudos no Brasil, o que poderia sinalizar um mercado com relação ao uso deste ativo ambiental. Com isso, é possível verificar a consciência social de que melhorias ou danos no PNB possam refletir em acréscimos ou decréscimos no seu bem-estar. Mas considerando a alta renda domiciliar per capita do distrito federal é a mais alta, conclui se que existe uma baixa disposição a pagar.

O Governo deve elaborar projetos e políticas públicas voltadas para a preservação e utilização sustentável do bem. Para que essas ações sejam eficientes é necessário obter estimativas dos benefícios sociais gerados, cujos valores possam ser comparados com os custos de tais ações. O valor do PNB se compõe de $62,7 \%$ de valor de uso direto, $24,8 \%$ indireto, 5,9\% valor de opção e $6.5 \%$ de valor de existência, os valores ficam disponíveis para a realização de análises econômicas de viabilidade para a tomada de decisão no intuito de auxiliar na visualização das opções mais eficientes.

Como o envolvimento da comunidade na conservação do parque é fundamental, conclui-se que conhecer a elasticidade das variáveis que influenciaram a DAP (a idade, a renda mensal, a ocupação e o conhecer o Parque), permite saber como as pessoas percebem as áreas verdes e assim os criadores de politicas ambientais, incorporando esses valores aos programas ambientais e assim terão mais eficiência em prol da melhoria do PNB. 


\section{RECOMENDAÇÕES}

Um viés levantado na pesquisa foi o desconhecimento do cenário. Há quem confunde o PNB com o Parque da Cidade. Conhecer o Parque é uma variável que influencia a DAP, recomenda-se promover o nível de conhecimento público das características naturais da área e compreensão de sua importância e funções, realizando atividades de formação e divulgação do Parque.

Para a parcela de entrevistados que não estiveram dispostos a abrir mão para apoiar o projeto proposto, uma possível explicação pode ser: a questão avaliada na enquete estaria muito distante da experiência cotidiana e a dificuldade de atribuir um valor monetário dos entrevistados, uma solução poderia ser utilizar a técnica Dephi, que consiste no envio de questionários a especialistas que possuam amplo conhecimento sobre assuntos ambientais para estabelecer incentivos financeiros apropriados.

Para futuros estudos recomendam-se apoiar com métodos alternativos/complementares ao MVC, como o Método Multicritério, Métodos Deliberativos ou neura economia que fornecem uma visão mais ampla sobre métodos de preferências declaradas, ao mesmo tempo em que apresentam diferentes soluções para alguns pontos problemáticos no MVC. 


\section{REFERÊNCIAS BIBLIOGRÁFICAS}

ABNT. NBR 14653-6: 2008. avaliação de recursos naturais e ambiental. Associação Brasileira de Normas Técnicas, ABNT, 2008.

ADAMS, C. et al. The use of contingent valuation for evaluating protected areas in the developing world: Economic valuation of Morro do Diabo State Park, Atlantic Rainforest, São Paulo State (Brazil). Ecological Economics 66 (2008) 359 - 370. Elsevier B.V. 2007.

ALMEIDA, A.N., DE OLIVEIRA, V. R., SOARES,R. C., ANGELO, H. DISPOSIÇÃO A PAGAR PELA PRESERVAÇÃO E MELHORIA DO PARQUE OLHOS DÁGUA - DF. IBEAS - Instituto Brasileiro de Estudos Ambientais. V Congresso Brasileiro de Gestão Ambiental Belo Horizonte/MG - 24 a 27/11/2014

ARAÚJO, M. A. R. Unidades de conservação no Brasil: da República à gestão de classe mundial. Belo Horizonte: Segrac, 2007.

ARAUJO, H. R. de. Valoração dos serviços ambientais da gruta do Salitre, Diamantina, Minas Gerais, Brasil. 2014. 72f. Dissertação (Mestrado em Sustentabilidade) Universidade Federal de Ouro Preto, Ouro Preto, 2014.

ARAUJO, ROMANA COELHO DE. Valoração econômica do dano ambiental em inquerito civil público. Escola Superior do Ministério Público da União, Brasília: 200 p. 2011. (http://www.esmpu.gov.br/linha-editorial/publicacoes) Acessado Outubro 2014.

ARROW, K., SOLOW, R., PORTNEY, P. R., LEAMER, E.E. RADNER, R., AND SCHUMAN, H. "Report of the NOAA Panel on Contingent Valuation." National Oceanic and Atmospheric Administration (U.S. Department of Commerce). 1993.

ARROW, K.J.; FISHER, A.C. Environmental Preservation, Uncertainty, and Irreversibility. The Quarterly Journal of Economics Vol. 88, No. 2. 1974.

AVILÉS, P. G., LEONARDO HUATO S. L., TROYO, D. E., MURILLO, . B., GARCÍA, H. J., BELTRÁN, M. L.. Valoración económica del servicio hidrológico del acuífero de La Paz, b.c.s.: Una valoración contingente del uso de agua municipal. Red de revistas científicas de América Latina y el Caribe, España y Portugal sistema de información científica, 2010.

AZQUETA, D. Valoración económica de la calidad ambiental. Editorial McGrawHill/Interamericana de España, S.A.U. 1999.

BARROS, A.L. F., Valoração econômica dos recursos naturais e ambientais: um estudo de caso do Parque das Dunas, Natal/RN. Tese de Mestrado Interinstitucional em Economia) Instituto Federal de Educação, Ciência e Tecnologia do Rio Grande do Norte/ Universidade Federal da Paraíba, 2013. 
BATEMAN, I. J.; TURNER, R. K. Valuation of the environment methods and techniques: the contingent valuation method. Capitulo 5. Sustainable environmental economics and management principles and practices. Londres: Belhaven Press. 1992

BATEMAN, I.J.; LANGFORD, I.H.; WILLIS, K.G.; TURNER, R.K.; GARROD, G.D. The Impacts of changing willingness to pay. Question format in contingent valuation studies: An analysis of open-ended, iterative bidding and dichotomous choice formats. CSERGE Working Paper GEC 93-05, 1-53. 1993

BATEMAN, J. I.; AND WILLIS G., Valuing Environmental Preferences: Theory and Practice of the Contingent Valuation Method in the US, EU, and developing Countries. Oxford University Press. 2001.

BENTES, E. dos S, SANTANA, A. C. de, HOMMA, A. K. O., GOMES, S. de C. Valoração econômica da jusante da barragem de Tucuruí. Revista de Política Agrícola, v. 23, n. 4, p. 102-110, out./dez. 2014.

BHANDARI, A., \& HESHMATI, A. Willingness to pay for biodiversity conservation. Journal of Travel \& Tourism Marketing, 27(6), 612-623. 2010.

BISHOP, R.C., CHAMP, A. Y MULlARKEY, D.J. "Contingent Valuation" en D.W. Bromley. The Handbook of Environmetal Economics, Blackwell, Cambridge, Ma. 1995.

BOYLE, K.L, WELSH, M.P. and BISHOP, R.C. Validation of emperical measures of welfare change. Land Economics, 1988.

BRUGNARO, C. Valuing riparian forests restoration: a CVM application in Corumbatai river basin. Revista de Economia e Sociologia Rural, RESR, v.48, n.3, p.507-520, 2010.

CARSON, R. T., MITCHELL, R. C., HANEMANN, W. M., KOPP, R. J., Presser S., Rudd P. A. A CONTINGENT VALUATION STUDY OF LOST PASSIVE USE VALUES RESULTING FROM THE EXXON VALDEZ OIL SPILL, A Report to the Attorney General of the State of Alaska. 1992.

CARSON, RICHARD; FLORES, N.; MEADE, N. Contingent Valuation: Controversies and Evidence. Environmental \& Resource Economics, v. 19, n. 2, p. 173-210, 2001.

CARSON, RICHARD; GROVES, T. Incentive and informational properties of preference questions. Environmental \& Resource Economics, v. 37, n. 1, p. 181-210, 2007.

CAVALCANTI, M. M.. Aplicação de métodos geoelétricos no delineamento da pluma de contaminação nos limites do aterro controlado do Jokey Clube de BRASílIA. 2013. 111 f., il. Dissertação (Mestrado em Geociências Aplicadas)—Universidade de Brasília, Brasília, 2013.

CENARGEN - CENTRO NACIONAL DE PESQUISA DE RECURSOS GENÉTICOS / EMBRAPA - EMPRESA BRASILEIRA DE PESQUISA AGROPECUÁRIA,. Avaliação Sócio-Econômica do Parque Nacional de Brasília. CENARGEN/EMBRAPA, Brasília, 130p. 1999. 
CEPAL, Comision Economica Para America Latina y el Caribe. Beneficios de las áreas protegidas. Una guía rápida. Valorando la Naturaleza. (http://www.cepal.org/es/search?as_q=beneficios\%20areas\%20protegidas). $\quad$ Acessado Dezembro 2014.

CHO, S.-H; CLARK, D.C; PARK, M.W.; KIM, S.G. Spatial and Temporal Variation in the housing market of lot size and open space. Land Economics. 85 (1), 51-73. 2009

CIRIACY-WANTRUP, S. Capital returns from soil conservation practices. Journal of Farm Economics, No. 29,. 1947.

CIRINO, J. F.; LIMA, J. E. Valoração contingente da Área de Proteção Ambiental (APA) São José - MG: um estudo de caso. Revista de Economia e Sociologia Rural, v.46, n.3, p.647-672, 2008.

CODEPLAN, Companhia de Planejamento do Distrito Federal. Pesquisa Distrital por amostra de domicílios, PDAD. (http://www.codeplan.df.gov.br/) acessado em 25 de janeiro de 2015).

COOK, M. J. VALUING PROTECTED AREAS THROUGH CONTINGENT VALUATION: A CASE STUDY OF CHITWAN NATIONAL PARK, NEPAL. RYERSON UNIVERSITY, 2011.

CORREIO BRAZILIENSE. Um Problema Estrutural. Especial Estrutural. 2014. (http://www.correiobraziliense.com.br/especiais/lixao-da-estrutural/) acessado em 25 de Abril de 2014).

COSTANZA, R. et al. The value of the world's ecosystem services and natural capital. Nature 387. 1997.

COTTA SILVEIRA VANESSA, CIRINO FERNANDES JADER E PRADO FILHO JOSÉ FRANCISCO. Valoração Econômica da Área de Proteção Ambiental Estadual da Cachoeira das Andorinhas - MG. Revista Árvore, Viçosa-MG, v.37, n.2, p.257-266, 2013

COTTRELL, S. Influence of socio demographics and environmental attitudes on general responsible environmental behaviour among recreational boaters. Environmental Behaviour, 35(3), 347-375. 2003.

DA SILVA, S. C., USO DO SOLO NO ENTORNO DO PARQUE NACIONAL DE BRASÍLIA: UMA ANÁLISE MULTITEMPORAL. Revista Brasileira de Cartografia No 58/02, (ISSN 1808-0936) Agosto, 2006.

DAVIS, R. K. «The Value of Outdoor Recreation: An Economic Study of the Maine Woods» Ph. D. dissertation, Harvard University. 1963.

DODDS, R., GRACI, S. \& HOLMES, M. Does the tourist care? A comparison of tourists in Koh Phi Phi, Thailand and Gili Trawangan, Indonesia. Journal of Sustainable Tourism, 18(2), 207-222. 2010.

DZIEGIELEWSKA, D.; MENDELSOHN, R. Does "No" mean "No"? A protest methodology. Environmental \& Resource Economics, v. 38, n. 1, p. 71-87, 2007. 
FENKER, E. A. A Valoração Econômica Dos Recursos Naturais na criação de Unidades de Conservação Federais (UCF) No Brasil: Um estudo empírico no Estado de Universidade do Vale do Itajaí. Santa Catarina, Biguaçu 2013.

GOMES DA SILVA, R. Valoração do Parque ambiental "Chico Mendes", Rio Branco AC: Uma aplicação probabilística do método referendum com bidding games Tese de Mestrado. Universidade Federal de Viçosa, Economia Aplicada. VIÇOSA MINAS GERAIS - BRASIL 2003.

GUJARATI D. N., and PORTER D. C., ECONOMETRÍA, Quinta edición. McGRAWHILL/INTERAMERICANA EDITORES, S.A. 2010.

HACKETT, S. C. Environmental andnatural resourses economics: Theory, policy, and the sustainable society. M.E. Sharpe, Inc. 2009.

HANEMANN, W. M.: «Welfare Evaluation in Contingent Valuation Experiments with Discrete Response», American Journal of Agricultural Economics, n. ${ }^{\circ}$ 66: pp. 332-341. 1984

HANEMANN, W. M. "Welfare Evaluation in Contingent Valuation Experiments with Discrete Response Data: Reply", American Journal of Agricultural Economics, Vol. 71, No. 41989.

HANEMANN, W. MICHAEL, JOHN LOOMIS AND BARBARA KANNINEN. "Statistical Efficiency of Double-Bounded Dichotomous Choice Contingent Valuation, " American Journal of Agricultural Economics, vol. 73, pp. 1255-1263, 1991.

HANLEY, N., Clive L. SPASH. Cost-Benefit Analysis and the Environment. Hants, Inglaterra: Edward Elgar, 1993.

HANLEY, N.; SHOGREN, J.; WHITE, B. Introduction to Environmental Economics. Second Edition. Oxford University Press, Oxford. 2013

HOROWITZ, C., OLIVEIRA, A., DA SILVA1 V., PACHECO, G., IRIS SOBRINHO, R. Manejo da Flora Exótica Invasora no Parque Nacional de Brasília: Contexto Histórico e Atual. Número Temático: Diagnóstico e Controle de Espécies Exóticas Invasoras em Áreas Protegidas. Biodiversidade Brasileira, 3(2): 217-236, 2013

HORTON, B., COLARUllO, G., BATEMAN, I., \& PERES, C. Evaluating non-user willingness to pay for a large-scale conservation programme in Amazonia: A UK/Italian contingent valuation study. Environmental Conservation, 30(2), 139-146. (2003).

HOSKING, S. G., PREEZ, M. D. Application of the Contingent Valuation Method to estimate a recreational value for the freshwater inflows into the Kowie and the Kromme Estuaries. NELSON MANDELA METROPOLITAN UNIVERSITY, 2009.

HOYOS, D., MARIEL, P. CONTINGENT VALUATION: PAST, PRESENT AND FUTURE. Prague Economic Papers, 4, 2010.

HUFSCHMIDT, M. et al. Environment, Natural Systens, anDevelopment. An Economic Valuation Guide. The Johns Hopkins Universitypress. Baltimore and London, 1983. 
IBAMA / FUNATURA. Plano de Manejo - Parque Nacional de Brasília (Revisão). IBAMA

http://www.icmbio.gov.br/portal/images/stories/imgsunidadeconservacao/PARNA\%20Bra silia.pdf (acessado em 3 de Abril de 2014).

IBGE, Instituto Brasileiro de Geografia e Estatística. 2010 (http://www.ibge.gov.br/estadosat/perfil.php?sigla=df) acessado 29 septiembre 2014.

IGLESIAS, C. T. Métodos de Bondad de Ajuste en Regresión Logística. Master Oficial en Estadística Aplicada. Universidad de Granada. 2013.

IUCN. Áreas protegidas - ¿Qué son y para qué sirven?. (https://www.iucn.org/es/sobre/trabajo/programas/areas_protegidas_copy_of_aires_proteg ees_quest_ce_que_cest quelle_est_leur_utilite_13012012_1127/) acessado 5 janeiro 2015.

IUCN. Categorías de gestión de áreas protegidas. (http://www.iucn.org/es/sobre/trabajo/programas/areas_protegidas/copy_of_categories_w cpa_french_13012012_1128/). acessado 11 janeiro 2015.

KAHNEMAN, D., AND KNETSCH, J. L. "Valuing Public Goods: The Purchase of Moral Satisfaction” Department of Psychology, University of California, 1990.

KLING, C. L., Phaneuf, D. J., Zhao, J. From Exxon to BP: Has Some Number Become Better than No Number? Journal of Economic Perspectives-Volume 26, Number 4-Fall 2012.

KOLSTAD,C. D. Environmental Economics. OXFORD UNIVERSITY PRESS, New York. 2009

KRUTILLA, J. Conservation reconsidered. En: American Economic Review, No 56, 1967.

MAIA, A.G. Valoração de recursos ambientais. Dissertação de Mestrado. Instituto de Economia UNICAMP, Campinas. 2002.

MALTA, R.R.; COSTA, N.M.C. da; COSTA, V. C. Valoração Econômica dos Serviços Recreativos e Ecoturísticos em uma Unidade de Conservação - O Caso do Parque Nacional da Tijuca (Rio de Janeiro - RJ) - Brasil. 2012.

MARTINS, C. R., DU VALL HAY, J., MACHADO, T. B., BARNES, C. E., VIVALDI L. J. Impacto da invasão e do manejo do capim-gordura (Melinis minutiflora) sobre a riqueza e biomassa da flora nativa do Cerrado sentido restrito. Revista Brasil. Bot., V.34, n.1, p.73-90, jan.-mar. 2011

MAYOR, K.; LYONS, S.; DUFFY, D.; TOL, R.S.J. A Hedonic Analysis of the Values of Parks and Green Spaces in the Dublin Area. ESRI Papers 331. ESRI, Dublin. 2009

MCVITTIE A., HUSSAIN S. S. The Economics of Ecosystems and Biodiversity Valuation Database Manual 2013. 
MEDEIROS, R. \& YOUNG; C.E.F.. Contribuição das unidades de conservação brasileiras para a economia nacional: Relatório Final. Brasília: UNEP-WCMC, 120p. 2011.

MITCHELL, R. C., CARSON, R. T., Using surveys to value public goods, The contingent valuation method. Resources for the future Press, Washington. 1989.

MMA, Ministério do Meio Ambiente. Areas Protegidas. Sistema Nacional de Unidades Conservação - SNUC. (http://www.mma.gov.br/areas-protegidas/sistema-nacional-de-ucssnuc). acessado em 21 de janeiro de 2015.

MORRISON, M. Aggregation Biases in Stated Preference Studies. Australian Economic Papers, v. 39, n. 2, p. 215-30, 2000.

MOTA, José Aroudo. Valoração de Ativos Ambientais como Subsídio à Decisão Pública. Tese de doutorado. Universidade de Brasília. Centro de Desenvolvimento Sustentável. Brasília, 262 p. 2000.

MUELLER, Charles C. Os economistas e as relações entre o sistema econômico e o meio ambiente. $1^{\text {a }}$ Edição. Ed. Universidade de Brasília, FINATEC, 2007.

NEXUCS ORG. Unidades de conservação no Brasil: o caminho da gestão para resultados/ organizado por Organização NEXUCS - São Carlos: RiMa Editora, 2012.

NOAA, Natural resource damage assessment under the Oil Pollution Act of 1990, Federal Register, 58(10): 4601-4614, 1993.

NOVOA G. Z. Valoración Económica del Patrimonio Natural: Las Áreas Naturales Protegidas. ESPACIO Y DESARROLLO N²3, 2011

NOGUEIRA, J.M.; MEDEIROS, M.A.A. de; ARRUDA, F.S.T. de. Valoração econômica do meio ambiente: ciência ou empirismo. Caderno Ciência e Tecnologia. v. 17 (2), p. 81115, maio/agosto, Brasília, 2000.

NPS, NATIONAL PARK SERVICE. Yellowstone National Park. Disponível em: <http://www.nps.gov/yell/espanol/index.htm > Acesso em: 03/02/2015.

OSORIO, J. D. Y CORREA, F., Un Análisis de la Aplicación Empírica Del Método de Valoración Contingente. En: Semestre Económico, No. 12, Julio-Diciembre. Medellín, Colombia. 2009.

PADILLA, R. E., ROCABERT, J. P. La agregación de costes y beneficios en la evaluación de proyectos intergeneracionales: El valor actual neto multigeneracional Hacienda Pública Española. Instituto de Estudios Fiscales / Revista de Economía Pública, 163-(4/2002): 934. 2002.

PEARCE, D. Economic values and the natural world. Londres: Earthscan Publications, 1993.

PEARCE, D. Environmental economics. Longman. Londres. 1976. 
PEARCE, D.; ATKINSON, G.; MOURATO, S. Cost-benefit analysis and the environment. Recent developments. OECD, Paris. 2006

PHILLIPS, A. A modern paradigm. World Conservation, n, 2. 2003

PIMENTEL, D.; WILSON, C.; MCCOLLUM, C.; HUANG, R.; DWEN, P.; FLACK, J.; TRAN, Q.; SALTMAN, T.; CLIFF, B. Economic and environmental benefits of biodiversity. BioScience, v. 47, p. 747-757, 1997.

POE, G.; CLARK, J.; RONDEAU, D.; SCHULZE, W. Provision Point Mechanisms and Field Validity Tests of Contingent Valuation. Environmental \& Resource Economics, v. 23, n. 1, p. 105-131, 2002.

PUGAS, M. A. R. Valoração Contingente de Unidades de Conservação: Avaliando a DAP Espontânea e Induzida da população de Rondonópolis (MT) pelo Horto Florestal. Dissertação (Mestrado em Gestão Econômica do Meio Ambiente). Centro de Estudos em Economia, Meio Ambiente e Agricultura - CEEMA, Departamento de Economia, da Faculdade de Economia, Administração, Contabilidade e Ciência da Informação e Documentação - FACE, da Universidade de Brasília - UnB. Brasília - DF, 2006. 129f.

RANGEL C. R. ET AL. Valoración Económico-Ambiental de Recursos Naturales seleccionados en la Cuenca del Río Guanabo, LA HABANA, CUBA. REVISTA IBEROAMERICANA DE ECONOMÍA ECOLÓGICA, 2013.

RODRIGUES, W., NOGUEIRA,M. J., CARVALHO, E. DE. Mensuração dos Impactos Ambientais de Empreendimentos Hidroelétricos: $O$ uso do Método de Valoração Contingente. RBRH - Revista Brasileira de Recursos Hídricos Volume 14 n.2 Abr/Jun, 39-45. 2009.

SAMDIN, Z. . Willingness to pay in Taman Negara: A contingent valuation method. International Journal of Economics and Management. 2008

SAMPAIO, C. Uso do solo no entorno do parque nacional de Brasília: uma análise multitemporal. Universidade de Brasília - UnB.Departamento de Geografia. Revista Brasileira de Cartografia No 58/02, Agosto, 2006.

SCHMIDT K. A., BOCATO, F. C., Avaliação Contingente da demanda turística do Parque do Ingá, Maringá - PR. IX EPCT - Encontro de Produção Científica e Tecnológica Campo Mourão, 27 a 31 de Outubro de 2014

SEROA DA MOTTA, R. Manual para Valoração Econômica de Recursos Ambientais. IPEA/MMA/PNUD/CNPq, Rio de Janeiro, Setembro de 1998, 242 páginas.(http://www.em.ufop.br/ceamb/petamb/cariboostfiles/manual20serroa20motta.pdf) - acessado em 25 de janeiro de 2014.

SILVA, R.G. Valoração do Parque Ambiental "Chico Mendes", Rio Branco - AC: uma aplicação probabilística do método referendum com bidding games. 2003. Dissertação (Mestrado em Economia Aplicada) - Universidade Federal de Viçosa, 2003.

TEEB - The Economics of Ecosystems and Biodiversity The Ecological and Economic Foundations. Earthscan, London. 2010. 
TEEB - Guidance Manual for TEEB Country Studies. (http://www.teebweb.org/wpcontent/uploads/2013/06/TEEB_GuidanceManual_2013_1.0.pdf ). 2013

TÔSTO, G. S. Sustentabilidade e Valoração de Serviços ecossistêmicos no Espaço Rural do Município de Araras, SP. UNIVERSIDADE ESTADUAL DE CAMPINAS. INSTITUTO DE ECONOMIA, 2010

TURNER, R. K; JONES, S. M,; FISHER, B. Ecosystem valuation: a sequential decision support system and quality assessment issues. Annals of the New York Academy of Sciences. Ecological Economics Reviews, 1185, pp. 79-101, 2010.

VASCONCELLOS, Pedro Gasparinetti. Método de valoração contigente: sobre a validade de preferências, cenários e agregação. Dissertação (Mestrado em Gestão Econômica e Meio Ambiente)—Universidade de Brasília, Brasília. 2012

VILLALBA, M. G. Valor econômico da visitação do parque Phillipe Westin Cabral de Vaconcellos. 2004. 62p. (dissertação Mestrado em Economia Aplicada), univeridade de Sao Paulo, Piracicaba. 2004. 


\section{ANEXO 01 - DO QUESTIONÁRIO}

Antes de ser aplicado em campo, foi elaborado um questionário piloto e aplicado em campo na forma de entrevista a 30 habitantes escolhidos ao acaso, este pré-teste do material (survey piloto) serviu para aplicar os cartões de pagamento e obter os valores de referência a serem utilizados no survey definitivo, identificar as falhas do questionário, além de perceber as dificuldades do entrevistado para entender a informação dada, permitiu reduzir as falhas de conteúdo e comportamento e produzir qualidade e confiabilidade ao instrumento.

O questionário final foi estruturado em três partes, teve 19 perguntas e aproximadamente 18 minutos para obter as respostas. Na primeira parte, perguntas sobre as características socioeconômicas do entrevistado; na segunda composta por questões sobre o conhecimento do Parque Nacional Brasília e a outra procurou captar a percepção ambiental do entrevistado. Na terceira parte, um modelo de perguntas de disposição a pagar baseado no método de valoração contingente chamado jogos de leilão (técnica em que se cria uma situação-problema, são apresentados um conjunto de valores ao entrevistado, a partir de um valor médio, o indivíduo escolherá o valor (lance) da sua disposição a pagar, frente às múltiplas alternativas. Caso o indivíduo aceitasse o valor inicial, lhe era oferecido outro lance superior, caso contrário, lhe era oferecido valores inferiores. sendo este um modelo ideal de perguntas para ter chances de medir todo o excedente do consumidor).

Entre os entrevistados não dispostos a pagar pelo programa, incluiu-se uma questão para objetivar e compreender os motivos para tal escolha, gerando razões para explicar DAP zero, sendo que um voto "não" é socialmente aceitável, os entrevistados foram convidados a escolher três razões entre a justificativa para votar contra o programa (viés de protesto).

As respostas identificadas como comuns e justificativas contidas no questionário foram: 1) Eu não posso permitir isso; 2) Eu não me importo com a melhoria da qualidade ambiental; 3) Em proteger o parque não merece gastar dinheiro; 4) É de responsabilidade da indústria; 5) Já paga suficientes impostos; 6) Estou satisfeito coma situação existente; 7) Isso não ajudaria a proteger mais e 8) É de responsabilidade do governo.

Foi divido em duas classes a informação utilizada para responder à pergunta da DAP: informação exógena que antes de iniciar o questionário, entregaram-se ao entrevistado cartões contendo uma breve descrição PNB, também fora apresentado 
material visual (mapas e fotografias), para um melhor reconhecimento e percepção do cenário e do bem. E uma informação endógena: que tem relação com a familiaridade, reação afetiva, sentimentos ou experiência passada do entrevistado com o parque em questão. A literatura sugere que a familiaridade com o objeto de mensuração apresenta resultados mais razoáveis. (PEARCE, 1993), (DODDS et al 2010)

Para a criação do cenário hipotético utilizou-se as informações apresentadas na seleção da área de estudo.

Os entrevistados questionaram sobre a restrição de sua renda para que seja declarado um valor relacionado a sua verdadeira disposição a pagar.

\section{Determinação dos valores dos lances da oferta}

Para determinar os valores a serem ofertados no questionário, baseou-se em um pré-teste (survey piloto) segundo Boyle et al, (1988); Mitchell e Carson (1989), utilizando o método de cartões de pagamento com diferentes valores, solicitando o indivíduo em escolher apenas um, aquele que representa sua disposição máxima a pagar. A interpretação dos resultados é, portanto, a mesma para o caso dos jogos de leilão (bidding game).

No cálculo dessa amostra segue o mesmo princípio que foi utilizado nesta pesquisa. Utilizou-se este procedimento para determinar quais valores de referência apresentados finalmente nos questionários definitivos.

\section{Veículo de pagamento}

Procurou-se um veículo com credibilidade, aceitabilidade, boa cobertura e que seja respeitado (CARSON e GROVES, 2007), pelo tanto o instrumento de pagamento escolhido foi uma taxa mensal, (é o período de leitura da distribuidora) cobrada na fatura da conta de energia elétrica do entrevistado durante cinco anos, já que a luz é cobrada no Distrito Federal. Cobrou-se mensalmente para que o cenário de avaliação seja mais realista e, assim, reduzir o viés de hipótese.

\section{Coleta dos dados}

Os dados para este trabalho foram procedentes de fonte primária, coletados por meio de entrevistas pessoais. Empregou-se um questionário estruturado, que foi aplicado durante os meses de fevereiro, março e abril do ano 2014, (Vide questionário nos ANEXOS 2, 3, 4 e 5) em três pontos de fluxo de pessoas na cidade de Brasília: a Rodoviária localizada na esplanada dos ministérios, o parque da Água Mineral e na Universidade de Brasília (Campus Darcy Ribeiro). Seguindo os critérios de adoção de uma 
amostra aleatória proporcional (MITCHELL E CARSON 1989), sem considerar a distribuição espacial dos pontos de amostragem. Estes locais foram selecionados para obter informações para pessoas de várias partes do DF.

As entrevistas foram feitas pelo pesquisador para ter um maior controle sobre a forma de conduzi-las. A única exigência foi ter idade mínima de 18 anos para os entrevistados.

O questionário utilizado tinha três seções da seguinte forma: Seção 1. Esta seção foi destinada a obter informações sobre dados demográficos dos entrevistados, sexo, idade, local de residência, escolaridade e renda; essas variáveis descrevem o perfil dos entrevistados. Seção 2. Incluíram-se questões sobre conhecimento ecológico do parque e responsabilidade ambiental. Seção 3 inclui a DAP do entrevistado sobre a abordagem das situações de mercado estruturadas de forma ao contingente, onde foram utilizadas as técnicas de referendo e a técnicas de leilão até capturar a máxima disposição a pagar para a situação em questão. O processo começou com a pregunta referéndum - Estaria disposto a contribuir por ano com uma quantia em dinheiro para ajudar na conservação $e$ manutenção do PNB? (seria cobrada junto com a conta de Luz), onde o indivíduo pode responder "sim" ou "não", dada uma função de utilidade indireta, consideraram-se as respostas afirmativas iguais a 1 . Nos casos em que o indivíduo respondesse NÃO, considerou-se a resposta negativa igual a 0 . Com os indivíduos que responderam SIM começou o processo de leilão com um lance médio de $\mathrm{R} \$ 10,00$ mensais, se a resposta foi "sim" para o primeiro lance, o valor foi aumentado para ver se o entrevistado estava disposto a contribuir com uma maior quantidade de dinheiro, o leilão continuou até que o entrevistado disse que não está disposto a pagar mais, sendo a última resposta positiva a máxima disposição a pagar. Se a resposta à primeira oferta é negativa é oferecido um valor menor ate responder "sim" a um dos lances oferecidos.

Iniciou-se ou processo de negociação sempre com uma oferta meia de R \$ 10,00 As Instruções para uma resposta "sim" para o primeiro valor de R $\$ 10,00$ é de repetir a pergunta aumentando em $\mathrm{R} \$ 5,00$ e continuar até obter um "não" como resposta, que se torna "sim" quando este valor é reduzido em $\mathrm{R} \$ 5,00$.

A instrução para uma resposta negativa ao primer lance de $\mathrm{R} \$ 10,00$ foi repetir a pergunta reduzindo o valor em $\mathrm{R} \$ 2,00$ e continuar até obter uma resposta "sim", que se torna em um "não" quando o valor sobe em $\mathrm{R} \$ 2,00$, de acordo com o apresentado no 
seguinte quadro de valores de referência (em $\mathrm{R} \$$ ) criados pelos ajustes das médias obtidas nos surveys pilotos leiloados para obter a DAP Máxima.

\begin{tabular}{|c|c|c|}
\hline Lance Inicial R\$ 10,00 & Sim Aceita o Lance Inicial & Não Aceita o Lance Inicial \\
\hline Lance 1 & $\mathrm{R} \$ 12,00$ & $\mathrm{R} \$ 7,00$ \\
\hline Lance 2 & $\mathrm{R} \$ 15,00$ & $\mathrm{R} \$ 5,00$ \\
\hline Lance 3 & $\mathrm{R} \$ 20,00$ & $\mathrm{R} \$ 3,00$ \\
\hline Lance 4 & $\mathrm{R} \$ 25,00$ & $\mathrm{R} \$ 1,00$ \\
\hline Lance 5 & $\mathrm{R} \$ 30,00$ & $\mathrm{R} \$ 0$ \\
\hline
\end{tabular}




\section{ANEXO 2 - Modelo de estimativa da DAP}

1. Estaria disposto a contribuir por mês com uma quantia de $\mathbf{R} \$ \mathbf{1 0 , 0 0}$ para ajudar na conservação e manutenção do PNB? (seria cobrada junto com a conta de Luz)
a) ( ) Sim pagaria
b) ( ) Não Pagaria

2. (SE A RESPOSTA É POSITIVA) Você estaria disposto a pagar:
a) ( ) A quantia for de $\mathrm{R} \$ 12$
c) ( ) A quantia for de $\mathrm{R} \$ 20$
e) ( ) Mais de R $\$ 30$
b) ( ) A quantia for de $\mathrm{R} \$ 15$
d) ( ) A quantia for de $\mathrm{R} \$ 25$

3. (SE A RESPOSTA É NEGATIVA)
a) ( ) A quantia for de $R \$ 7$
c) ( ) A quantia for de $R \$ 3$
e) ( ) $R \$ 0$
b) ( ) A quantia for de $R \$ 5$
d) ( ) A quantia for de $R \$ 1$ 
ANEXO 3 - Votos de protesto

\section{Selecione 3 opções das categorias de razões por que não contribuir.}

1 Eu não posso permitir isso

$1^{\mathrm{a}} \quad 2^{\mathrm{a}} \quad 3^{\mathrm{a}}$

2 Não me importo muito com a melhoria da qualidade ambiental

( ) ( )

( )

$3 \mathrm{Em}$ proteger o parque não merece gastar dinheiro

( )

( )

4 É de responsabilidade da indústria

( )

5 Já paga suficientes impostos

( )

6 Estou satisfeito coma situação existente

7 Isso não ajudaria a proteger mais.

( )

( )

( )

8 É de responsabilidade do governo 


\section{ANEXO 4 - Informações Socioeconômicas}
5. Sexo: a) ( ) Masculino
b) ( ) Feminino
6. Sua idade corresponde a que faixa etária:
a) ( ) $18-24$
c) ( ) $35-44$
e) ( ) $55-64$
b) ( ) $25-34$
d) ( ) $45-54$
f) ( ) Mais de 65 .

7. Local de residência.
a) ( ) Plano Piloto $12 \mathrm{~km}$
b) ( ) Candangolândia $16 \mathrm{~km}$
h) ( ) Brasilândia 48 km
i) ( ) Ceilândia $27 \mathrm{~km}$
c) ( ) Cruzeiro $\quad 10 \mathrm{~km}$
j) ( ) Riacho Fundo $25 \mathrm{~km}$
d) ( ) Núcleo Bandeirante $19 \mathrm{~km}$
k) ( ) Lago Norte $13 \mathrm{~km}$
e) ( ) Paranoá. $\quad 25 \mathrm{~km}$
1) ( ) Samambaia. $29 \mathrm{~km}$
o) ( ) Guará $\quad 17$ km
p) ( ) Planaltina. $\quad 37 \mathrm{~km}$
q) ( ) Gama $\quad 40 \mathrm{~km}$
r) ( ) Santa Maria $53 \mathrm{~km}$
s) ( ) Outra

f) ( ) Recanto das E. $36 \mathrm{~km}$

m) ( ) Taguatinga $23 \mathrm{~km}$

g) ( ) Sobradinho $17 \mathrm{~km}$

n) ( ) São Sebastião $47 \mathrm{~km}$

8. Grau de instrução acadêmica.
( ) Sem instrução.
( ) Primeiro grau completo
( ) Segundo grau incompleto
( ) Segundo grau completo
) Nível superior incompleto
( ) Pós-graduação

9. Ocupação laboral

( ) Primeiro grau incompleto
( ) Nível superior completo
( )Técnico

( ) Empregado/Assalariado

( ) Professional independente

( ) Empresário/Empregador

( ) Aposentado/pensionista

( ) Estudante

( ) Outros (dona de casa)

10. Renda mensal
( ) $\mathrm{R} \$ 000$ a 900
( ) $\mathrm{R} \$ 2701$ a 3600
( ) $\mathrm{R} \$ 3601$ a 4500
( ) $\mathrm{R} \$ 4501$ a 5400
( ) $\mathrm{R} \$ 901$ a 1800
( ) $\mathrm{R} \$ 1801$ a 2700

( ) $R \$ 5401$ a 6300
( ) $R \$ 6301$ a 7200
Mais de $R \$ 7.201$ 


\section{ANEXO 5 - Variáveis ecológicas e ambientais}

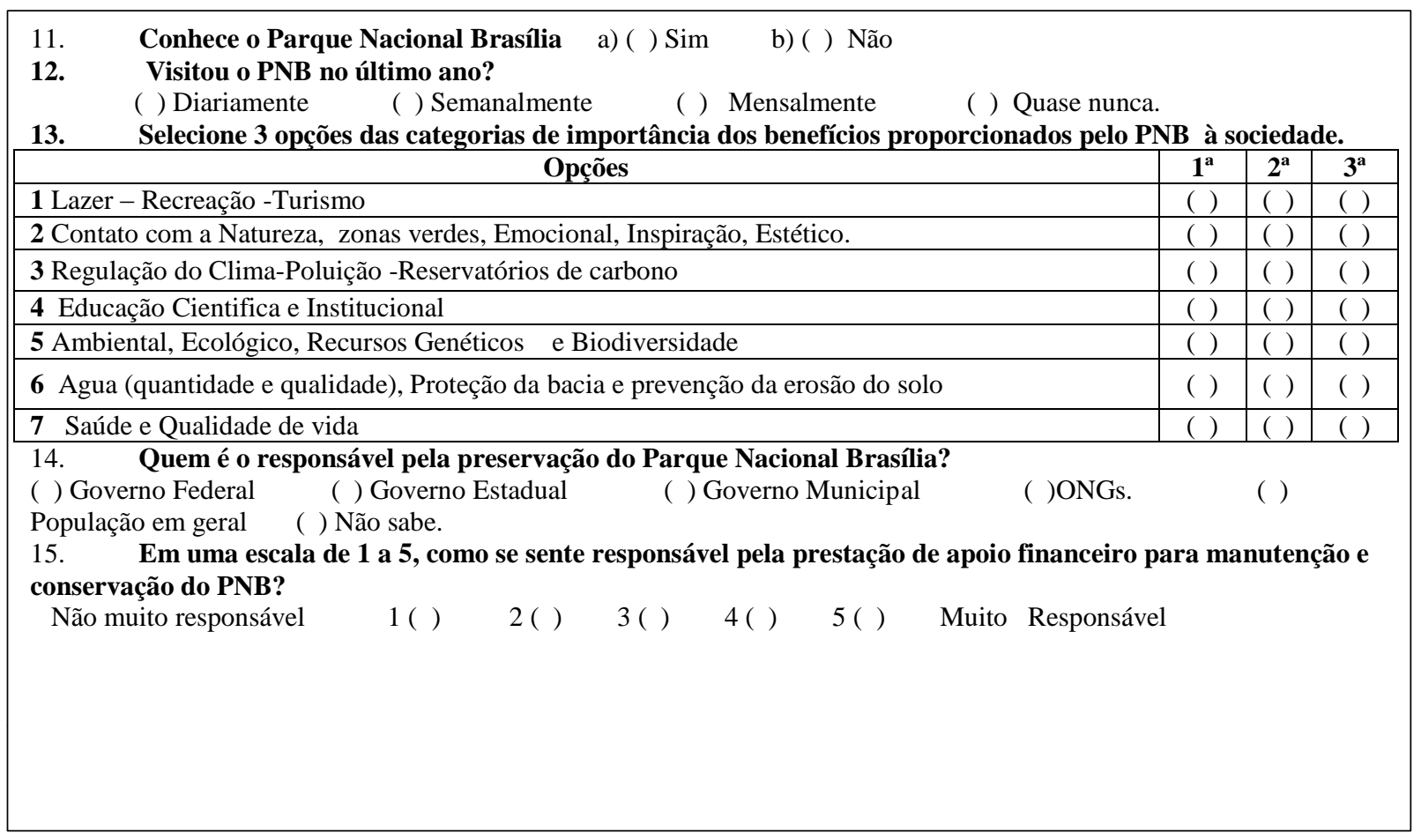


ANEXO 6 - $\mathbf{R}^{2}$ de Nagelkerke

Resumen del modelo

\begin{tabular}{|l|r|r|r|}
\hline Paso & $\begin{array}{c}-2 \text { log de la } \\
\text { verosimilitud }\end{array}$ & $\begin{array}{c}\text { R cuadrado } \\
\text { de Cox y } \\
\text { Snell }\end{array}$ & $\begin{array}{c}\text { R cuadrado } \\
\text { de } \\
\text { Nagelkerke }\end{array}$ \\
\hline 1 & $445,922^{\mathrm{a}}$ &, 192 &, 257 \\
\hline
\end{tabular}

a. La estimación ha finalizado en el número de iteración 4 porque las estimaciones de los parámetros han cambiado en menos de ,001. 
ANEXO 7 Teste de Stukel

Stukel's test of the logistic link

data: modelo

both $=4.3447$, df $=2$, p-value $=0.1139$

alternative hypothesis: both 


\section{ANEXO 8 - Teste de Hosmer- Lemeshow C e H. Teste le Cessie-van}

\section{Houwelingen}

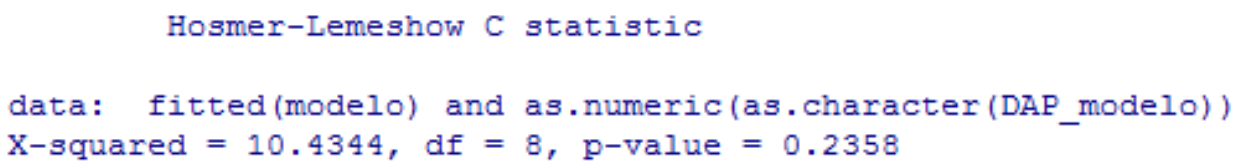

Tabla de clasificación ${ }^{\mathrm{a}}$

\begin{tabular}{|c|c|c|c|c|}
\hline & \multirow[t]{3}{*}{ Observado } & \multicolumn{3}{|c|}{ Pronosticado } \\
\hline & & \multicolumn{2}{|c|}{ DAP_modelo } & \multirow[t]{2}{*}{ Porcentaje correcto } \\
\hline & & 00 & 1,00 & \\
\hline \multirow{3}{*}{ Paso 1} & DAP_model, 00 & 97 & 72 & 57,4 \\
\hline & $\mathrm{o}$ & 48 & 168 & 77,8 \\
\hline & Porcentaje global & & & 68,8 \\
\hline
\end{tabular}

a. El valor de corte es ,500

A tabela acima mostra o percentual de classificação correta $(68,8 \%)$, que é um bom resultado, onde a categoria com mais alta classificação é $\mathrm{Y}=1$. 


\section{ANEXO 9 - ANÁLISE DE MULTICOLINEARIDADE}

Para esta análise foi realizado o teste do qui-quadrado para testar a independência entre as variáveis categóricas consideradas como variáveis explicativas. O teste contrasta as seguintes hipóteses: $\mathrm{H}_{0}$ : As variáveis são independentes, $\mathrm{H}_{1}$ : As variáveis não são independentes.

\section{Pruebas de chi-cuadrado}

\begin{tabular}{|l|r|r|r|}
\hline & \multicolumn{1}{|c|}{ Valor } & gl & $\begin{array}{c}\text { Sig. asintótica } \\
\text { (bilateral) }\end{array}$ \\
\hline Chi-cuadrado de Pearson & $59,930^{\mathrm{a}}$ & 40 &, 022 \\
Razón de verosimilitudes & 60,017 & 40 &, 022 \\
Asociación lineal por & 1,978 & 1 &, 160 \\
lineal & 385 & & \\
$\mathrm{~N}$ de casos válidos & & \\
\hline
\end{tabular}

a. 15 casillas $(27,8 \%)$ tienen una frecuencia esperada inferior a 5 . La frecuencia mínima esperada es 2,03.

Pruebas de chi-cuadrado

\begin{tabular}{|l|r|r|r|}
\hline & Valor & gl & $\begin{array}{c}\text { Sig. asintótica } \\
\text { (bilateral) }\end{array}$ \\
\hline Chi-cuadrado de Pearson & $5,986^{\mathrm{a}}$ & 5 &, 308 \\
Razón de verosimilitudes & 6,157 & 5 &, 291 \\
Asociación lineal por &, 409 & 1 &, 522 \\
lineal & 385 & & \\
N de casos válidos & & \\
\hline
\end{tabular}

a. 0 casillas $(0,0 \%)$ tienen una frecuencia esperada inferior a 5. La frecuencia mínima esperada es 9,02.

Pruebas de chi-cuadrado

\begin{tabular}{|l|r|r|r|}
\hline & Valor & gl & $\begin{array}{c}\text { Sig. asintótica } \\
\text { (bilateral) }\end{array}$ \\
\hline Chi-cuadrado de Pearson & $62,762^{\mathrm{a}}$ & 5 &, 000 \\
Razón de verosimilitudes & 70,173 & 5 &, 000 \\
Asociación lineal por & 5,282 & 1 &, 022 \\
lineal & 385 & & \\
$\mathrm{~N}$ de casos válidos & & & \\
\hline
\end{tabular}

a. 0 casillas $(0,0 \%)$ tienen una frecuencia esperada inferior a 5 . La frecuencia mínima esperada es 12,76 . 
Pruebas de chi-cuadrado

\begin{tabular}{|l|r|r|r|}
\hline & \multicolumn{1}{|c|}{ Valor } & gl & $\begin{array}{c}\text { Sig. asintótica } \\
\text { (bilateral) }\end{array}$ \\
\hline Chi-cuadrado de Pearson & $63,386^{\mathrm{a}}$ & 8 &, 000 \\
Razón de verosimilitudes & 78,724 & 8 &, 000 \\
Asociación lineal por & 57,121 & 1 &, 000 \\
lineal & 385 & & \\
N de casos válidos & & & \\
\hline
\end{tabular}

a. 1 casillas $(5,6 \%)$ tienen una frecuencia esperada inferior a 5. La frecuencia mínima esperada es 4,62.

Pruebas de chi-cuadrado

\begin{tabular}{|c|c|c|c|}
\hline & Valor & gl & $\begin{array}{l}\text { Sig. asintótica } \\
\text { (bilateral) }\end{array}$ \\
\hline Chi-cuadrado de Pearson & $41,274^{\mathrm{a}}$ & 8 & ,000 \\
\hline Razón de verosimilitudes & 43,523 & 8 & ,000 \\
\hline $\begin{array}{l}\text { Asociación lineal por } \\
\text { lineal }\end{array}$ & 16,417 & 1 & ,000 \\
\hline $\mathrm{N}$ de casos válidos & 385 & & \\
\hline
\end{tabular}

a. 0 casillas $(0,0 \%)$ tienen una frecuencia esperada inferior a $5 . \mathrm{La}$ frecuencia mínima esperada es 6,55 .

\begin{tabular}{|c|c|c|c|c|c|}
\hline \multicolumn{6}{|c|}{ Pruebas de chi-cuadrado } \\
\hline & Valor & gl & $\begin{array}{l}\text { Sig. asintótica } \\
\text { (bilateral) }\end{array}$ & $\begin{array}{l}\text { Sig. exacta } \\
\text { (bilateral) }\end{array}$ & $\begin{array}{l}\text { Sig. exacta } \\
\text { (unilateral) }\end{array}$ \\
\hline Chi-cuadrado de Pearson & $11,439^{\mathrm{a}}$ & 1 & ,001 & & \\
\hline $\begin{array}{l}\text { Corrección por } \\
\text { continuidad }^{\text {b }}\end{array}$ & 10,584 & 1 &, 001 & & \\
\hline Razón de verosimilitudes & 12,361 & 1 & ,000 & & \\
\hline $\begin{array}{l}\text { Estadístico exacto de } \\
\text { Fisher }\end{array}$ & & & & ,001 & ,000 \\
\hline $\begin{array}{l}\text { Asociación lineal por } \\
\text { lineal }\end{array}$ & 11,409 & 1 &, 001 & & \\
\hline $\mathrm{N}$ de casos válidos & 385 & & & & \\
\hline
\end{tabular}

a. 0 casillas $(0,0 \%)$ tienen una frecuencia esperada inferior a 5. La frecuencia mínima esperada es 29,13 .

b. Calculado sólo para una tabla de 2x2. 